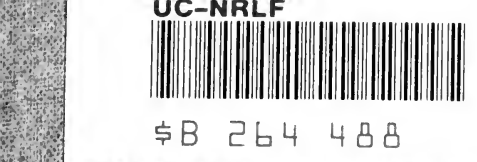

\title{
HEALTH IN THE SCHOOL
}

J.S. G. RLKINGTON M. D. 


\section{LIBRARY \\ OF THE \\ UNIVERSITY OF CALIFORNIA.}

Class 



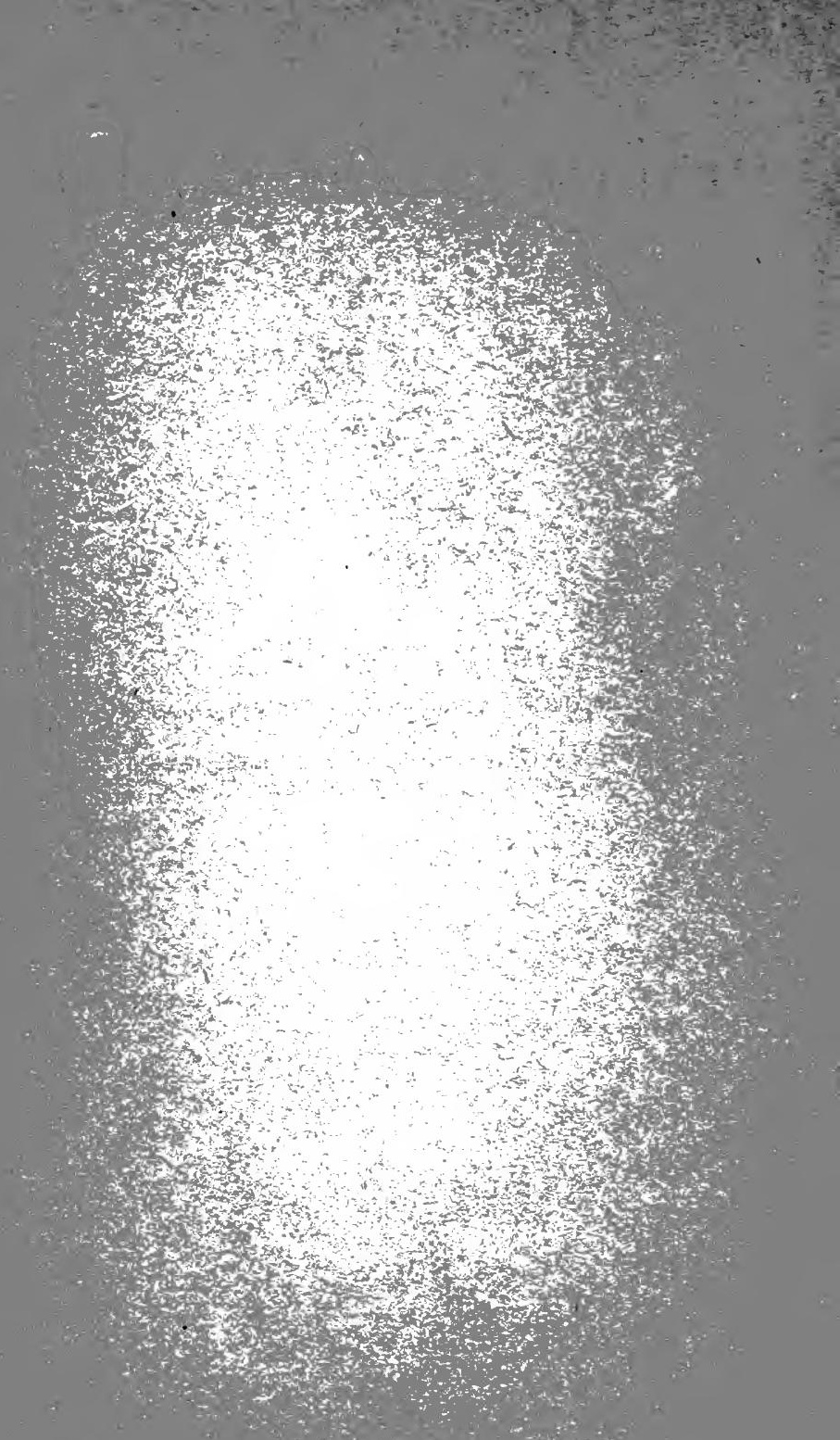




\section{BLACKIE'S LIBRARY OF PEDAGOGICS}

\section{Health in the School. By J. S. C. Elking-}

Ton, M.D., D.P.H., Head of the Department of Public Health in Tasmania. 2s. net.

Health in the School treats in a practical manner of the effects of the study of Hygiene on the teacher's work. It shows the intimate relations of the child's bodily health to its educational progress, and offers the teacher much sound advice as to the way in which he may further both. It is full of useful hints as to how the best may be made of buildings and furniture far from ideally perfect.

The Teaching of Latin. By W. H. S. Jones, M.A., the Perse Grammar School, Cambridge; author of Greek Morality. I $s$. net.

Contains an outline of a three-years' course of Latin on the new method, showing what a classical course can do for a boy, even if the time devoted to it is very limited.

The Teaching of Modern Languages. By Cloudes-

LEY BRereton, M.A., L.-Ès-L., Occasional Inspector to the Board of Education. Is. net.

An informing discussion of old and new ways of teaching modern languages, and plans for organizing language teaching in large towns.

\section{The Teaching of Grammar. English And Ele-} mentary Latin. By L. W. Wilsden, M.A. is, net.

A method of teaching, in the least possible time, the minimum of English grammar that will enable a boy to profit by his Latin lessons. The book takes the form of lessons addressed to a class. 
The School and the Child. Selections from the educational essays of Prof. JoHN DEwEY of New York. Edited by Prof. J. J. FindLAY, M.A., Manchester. Is. net.

These papers will be welcomed by all who know of the important work of Professor Dewey and his experimental school.

\section{The Education of Girls in Switzerland and Bavaria.}

By ISABEL L. RHYS, Head-mistress of Liverpool High School. I $s$. net.

The Swiss are thought by some to occupy the first place among educationalists. Miss Rhys's account of their methods deserves to be read by earnest teachers.

\section{The Teacher's Rabelais. Prepared by Geraldine} HodGson, Mistress of Method at Univerșity College, Bristol. I $s$. net.

A translation of the chapters dealing with the education of Gargantua, with an introduction on Rabelais' life and times, and his ideas on education.

\section{Natural Elocution in Speech and Song. By}

M'HARDY Flint, Professor of Elocution, Maynooth College, \&c.; Examiner, Royal Irish Academy of Music. Is. net.

The author of this little manual speaks out of a wide experience, and inculcates an elocution which is at once natural and effective.

\section{Reynolds's Discourses on Art. A Selection, edited} by Professor J. J. Findlay, M.A., Manchester. With Frontispiece. 2s. net.

These famous discourses reveal Reynolds the teacher. They throw light on the nature and function of Art, and on the mode by which the mind makes progress in the realm of Art.

\section{LONDON}

BLACKIE \& SON, Limited, 50 OLD BAILEY, E.C. GLASGOW DUBLIN BOMBAY 


\section{HEALTH IN THE SCHOOL}

OR

\section{HYGIENE FOR TEACHERS}

BY

\section{J. S. C. ELKINGTON, M.D., D.P.H.}

Chief Health Officer and Permanent Head of the Department of Public Health of Tasmania :

Lecturer on School Hygiene to the Teachers' Training College; Author of "Health Reader" \&c.

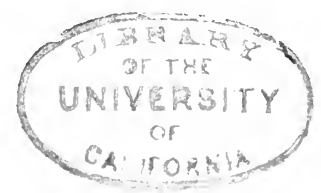

LONDON

BLACKIE \& SON, LIMITED, 50 OLD BAILEY, E.C. GLASGOW, DUBLIN, BOMBAY 


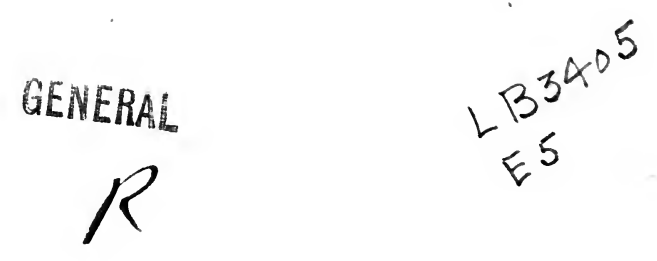




\section{PREFACE}

The official responsibilities of teachers increase with every new advance of that latter-day education movement which is effecting so notable a change in school methods and in school results. A certain degree of responsibility for the physical safety of the children in their charge has for long been incumbent on them. This little book is not put forward with the idea of adding new terrors to the pursuit of pedagogic success; but rather as an attempt to indicate phases of the subject, attention to which will materially assist the school work, whilst enabling the teacher to manfully meet this last-recognized responsibility. There is already a liberal supply of excellent special works on school health, containing a wealth of technical detail. Nevertheless, many teachers seem to find a difficulty in realizing that School Hygiene is not wholly a question of architecture, engineering, or medicine; or that it is possible to obtain excellent results by simple and inexpensive means. $\mathrm{A}$ rural teacher who suspects the water-supply, but contents himself with predictions of the evils that will result because a proper filter is not immediately forthcoming, has not learned this lesson. He who forthwith proceeds to sterilize the daily supply by boiling, and utilizes the opportunity for a timely demonstration to the children, will not only clear himself of responsibility for a typhoid outbreak, 
but will inculcate a lesson which may one day save many lives.

Looked at from the point of view of self-interest, teachers have every motive for preventing whatever may interfere with the children's work. There is nothing more brain-dulling than impure air, and the purblindness which arises from defective light management and improper working position. "School-stress" translated into plain language means, in the vast majority of cases, ignorant school management. It is of little use to study new educational methods unless the material on which they are to be tried is brought into a reasonable condition of physiological receptivity.

Slow as the public has been to recognize that primary education extends far beyond the historic "three R's", it is beginning to awake to the fact that even these modest requirements cannot be effectively met in semi-darkness, or in foul rooms.

To several writers in the technical journalsnotably to Professor Kenwood, to Professor Findlay, to Miss Alice Ravenhill, and to the accomplished author of the special articles in the British Medical Journal of 1904 and 1905-I am indebted for valuable information which has proved of much service in Tasmanian school practice, and in the writing of this book.

\section{J. S. C. ELKINGTON.}

Hobart, Tasmania,

February 14, 1907. 



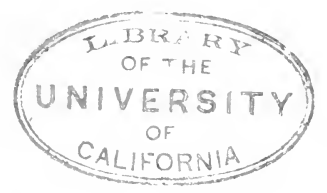

\title{
HEALTH IN THE SCHOOL
}

\author{
CHAPTER I \\ WHAT SCHOOL HYGIENE MEANS
}

The skilled educationist has long recognized that his work and that of the sanitarian are complementary, and that the neglect of hygienic requirements in school life absolutely renders it impossible for the most skilful and accomplished teaching to obtain the best mental reaction. Professor Nicholas Murray Butler has stated the case with characteristic terseness and accuracy: "It is not too much to say that health, its provision and protection, is all-controlling in present-day educational theory, although it is unfortunately far from being so in practice. The chief reason for this discrepancy between the ideal and the real is simple ignorance." Such ignorance displays itself in a variety of forms. There is the ignorance of the conscientious teacher, who despairs of satisfactory results because the school windows are too small, or because the lighting is bad, and who never realizes that the school-room and school building are pieces of teaching apparatus just as much as a book or a black-board are, and like these must be used to the best advantage, even if they are not what according to the best accepted principles they ought to be. There is 
the wilful ignorance of the resolutely unseeing person, who declares that it is all nonsense, and that he and the children in his charge never suffered any harm when this hygiene business hadn't been heard of. There is the ignorance of the timid brother, or sister, who foresees an invasion by doctors, followed by an epoch of inattention, and of indignant parental letters.

To the professors and followers of these and many other forms of ignorance there is an obvious answer. The object of School Hygiene in all its bearings is to increase educational efficiency and therefore to raise the physical and mental standard of the race. To this object it must be severely subordinated by the study of pedagogic requirements, and by due practical appreciation of the numerous difficulties, structural, administrative, and financial, which stand in the way of an ideal system. It must be admitted that much nonsense has been written and talked by sanitary enthusiasts who have not studied the problem from the teacher's stand-point; but it must also be remembered that floods of equally pernicious nonsense have been uttered by people who have never understood the sanitarian's method of looking at the subject.

Fundamentally, of course, all modern methods of education are unnatural, because they require much work to be done at a time when nature has not made adequate provision for its performance. Nevertheless, the work must be done. Experience has shown that the child suffers far more from the ignorance resulting from neglect than it does from the needful constraint and effort to acquire, and that the nation suffers with him. It therefore behoves the teacher to get the work done as completely and as rapidly as possible, exposing the children 
at the same time to the minimum risk from performing it. Biologically speaking, Education implies a process wherein certain growing discrete organisms are being fitted to their environment. That environment has a physical as well as a spiritual side, and nine-tenths of the children who undergo the fitting process will depend for their success and happiness in life almost wholly upon the physical side-in other words, upon the integrity of their bodies rather than upon the degree of culture of their minds. Some two-thirds of them, moreover, will be the parents of the next generation, and in the nature of things the stamina and aquanimitas of that generation will largely depend upon the healthy or unhealthy condition of the bodies of the children now in our schools.

It is a simple truism to those who are familiar with modern educational aims that school is not merely a preparation for life, but an important period of life itself, during which body and mind alike are plastic and capable of almost infinite development for good or ill. Nevertheless, the greatest of the faults committed in the past in the name of Education has been the non-recognition of the physical side of the child-environment, whether as an all-controlling factor in the development of the spiritual side, or as an all-important influence upon the child's future. This is not fair to the child. It interferes with his mental equipment for the struggle of modern competition, and possibly-frequently, perhaps-saddles him with a lasting physical defect. It is not fair to the teacher, since it interferes with the educational result, whilst it reacts injuriously upon the teacher's physical condition. It is not fair to the parent, since it prevents his children from getting twenty shillings- 
worth of useful training for each pound of taxes or fees spent on their education; and because, in addition, it involves him in further taxation for the care and relief of preventable disease occurring at all ages, but largely avoidable by sensible care and instruction at school. In fact, it is neither reasonable nor fair to anybody concerned, to continue attempting to force impressions through eyes which are prevented from seeing and ears which cannot properly hear; to seek, at a hurtful expenditure of time and energy, to reach brains somnolent and unresponsive from carbonic acid poisoning. Put in a nut-shell, it is a common-sense business proposition after all. The fitter the children the better the results obtainable from them, both at school and in after-life.

The arguments and aims of School Hygiene are based on the common sense of everyday medical practice and the elementary laws of physiological science. It is no new or untried branch of knowledge, and the proof of its accepted economic value is to be gathered from the strenuous attempts made in almost all civilized countries to improve the hygienic conditions of their schools. In London, great efforts are being put forth to better the physical and moral status of the County Council school population, and the results amply justify the cost. Throughout the British Isles the work is going on apace. Germany has for years past appreciated its value, with the result that the proverbially bespectacled student of a generation ago is becoming rarer with each new generation of scholars. Switzerland-ever leading in matters educational-has a widely organized system of examination and inspection by specially trained medical men. The Hungarian school is practically dominated 
by the school medical officer, who is a sort of hygienic autocrat. Many of the American States place the hygiene of their schools directly under the State Health Authority; and Japan has an exhaustive system of medical inspection and supervision by some 8424 specially appointed doctors - a system which follows the budding leader of civilization into the minutest circumstances of his daily life. Enlightened countries do not pay for this sort of thing unless it is of practical value, and those who scoff at School Hygiene as "another medical fad" stand self-confessed as incompetent critics. So much does America-that nation of utilitarians-value Hygiene that it is the only compulsory subject in the school curriculum of a number of the States.

Let us consider what School Hygiene implies. In the first place it does not stop short at school buildings. Important as these are, they do not as a rule concern the teacher, except in so far as he treats them as teaching apparatus already provided and to a large extent unalterable. It is nevertheless advisable for a teacher to become acquainted with the main principles that should govern those responsible in selecting a site for a school, in deciding on the structure, orientation, planning, lighting, and air-supply; but from a practical point of view, these are of less importance than the knowledge of how to utilize to the best advantage what is provided. He must accept the materials provided, but he should learn to make the best of them. For those who can afford to erect a private school building on correct lines, there is a large available literature in several European languages, and even in Japanese. In passing it may be 
mentioned, that when money is to be spent on school buildings and equipment it is as a rule better to expend it on the inside than on the outside. If it comes to a question between a bell-tower and mechanical ventilation or adjustable desks, the latter form the better investments from the educational point of view.

School Hygiene does not necessarily imply large or even increased expenditure; nor can a system of School Hygiene suitable for all latitudes and all classes of school be laid down. Like Opie's colours, systems of School Hygiene need to be mixed with brains. The teachings of Hygiene are available for the smallest of back-block schools in Canada, South Africa, or Australia, and are equally essential for the largest of the great establishments of London or New York. The genial climate and easy social conditions of some localities render unnecessary certain features, which become of great importance in the presence of cold winters and grinding poverty. Some measures of perfect sanitation are often out of reach, through the absence of systems of sewage removal, of power supply, of adequate financial support, or of effective sanitary supervision. Almost every school has some special hygienic drawback of its own, be it great or small, and a conscientious teacher will strive to discover the special difficulty and overcome it. In nine cases out of ten, and particularly under colonial conditions, the teacher who tries to do so will succeed.

School Hygiene is not intended solely for the child's benefit. The teacher is the mainspring of the school, and causes which operate adversely upon his or her physical condition interfere with the educational result. The teacher suffers from unhealthy school conditions, not 
perhaps to such a marked extent as the children do, but to a sufficient extent to interfere markedly with the attainment of the best mental reactions, and to inflict upon him serious bodily damage, especially if his health has been already weakened by any cause. It is obvious that association for several hours daily with a number of individuals drawn from a large variety of houses, must increase the risk of contracting communicable disease, particularly when the harassing character of the work involved in skilful and thorough teaching is taken into account. The bad effects of insanitary school conditions upon the teachers forms by itself a very important question in School Hygiene, and one which should appeal strongly to the influential and numerous class it affects. Certain teachers of long experience may be inclined to belittle its importance, but I would ask these to recall the number of their early contemporaries who have "broken down", and would, moreover, remind them that even if they themselves have survived risks without apparent damage, this fact does not protect their juniors and their pupils.

School Hygiene is not a question for state educational systems alone. Its importance is as great in private as in public schools, and its economic results are equally striking in both. There is no fundamental physiological difference between the state pupil and the private pupil, and there is no special moral or legal privilege vested in the private teacher which entitles him to risk or ruin the health and eyesight of children.

School Hygiene does not necessarily involve either Physical Culture or Medical Inspection. Both are desirable, both are necessary for the highest and best development of sanitary work, but excellent results may 
be obtained even if both are absent. As a rule, Physical Culture should be regulated by a medical man. It should never be forgotten that serious damage may be done to individual weakly children by physical overstrain. In the absence of a trained instructor (who may, of course, be one of the regular staff) it should never be undertaken. Ordinary healthy children derive more benefit from a noisy scamper round the playground than they will get from a half-hour's ordeal of club-waving, or toe-touching, mechanically directed by an uninterested and unskilled teacher. It should be remembered that no amount of Physical Culture can overcome the effect of bad school conditions, any more than it can cultivate the body in spite of existing organic defects.

The case for Medical Inspection has been excellently put by Dr. Mackenzie. "Education presupposes health," says he; "they are parts of one problem. Health is essential to education in any sense, physical or mental. And if it be the case that the conditions of health fitting a child for school life and school education cannot be ascertained without medical inspection, then medical inspection must become a part of school training. It is simply an additional method of securing that as far as possible the child shall be put into the state suitable for his training." 1

School Hygiene has yet another aspect. In these days of ever-increasing complexity of social life, of ever-increasing strain, and of ever-increasing artificiality, the child must be taught how to live. As Froebel pointed out, the child is not playing, it is primitive man trying to educate himself. As a pedagogic subject Elementary

${ }^{1}$ The Medical Inspection of School Children, 1904, p. 25. 
Hygiene needs no apology. It teaches the child to see, to reason, and to remember. It deals with a subject highly interesting to the child and supremely important. It lends itself both to training and instruction, and it possesses high ethical value. In conjunction with its allies, Domestic Economy and Civics, it practically conforms to that science of Eugenics-the coping stone of modern education-towards which the most advanced educational thinkers are striving. Such teaching must of necessity be simple, direct, and rationally adapted by local illustrations to local requirements. It is, for instance, of little use to attempt to fill the heads of children in an agricultural district with the principles of modern sewerage; but it is always necessary to explain and illustrate the need for and advantages of baths, tooth-brushes, fresh air, and properly cooked food. A few simple rules for the care of the baby, if taught in schools to the elder girls, may conceivably save hundreds of infant lives now sacrificed by impure milk, by "patent foods", and by the free advice of the ancient dame who knows all about it because she has buried sixteen.

The principal object of this book is to assist those teachers who work under rural and colonial conditions to put into practice the rules which must be observed in the care of the bodies of children entrusted to them. At the same time an endeavour has been made to indicate certain rational lines upon which Elementary Hygiene may be taught as a living subject, likely to interest and attract the child mind, and hence to be of practical benefit to the pupil in later life. 


\section{CHAPTER II \\ VENTILATION AND AIR-SUPPLY}

In theory, most people know well the value of fresh air; but few who have not specially studied the subject realize how absolutely necessary fresh air is, particularly for growing children. Educationally speaking, fresh air is essential if good mental reactions are desired. The brain depends for its powers of reaction chiefly on the purity of the blood-supply; the blood-supply depends for its purity principally on the lungs; therefore, if the lungs do not receive an adequate supply of really fresh pure air, the brain cannot do good work. Unlike food or drink, air must be taken as we find it, whether it be good or bad, at least 17 times a minute, or over 26,000 times a day.

The principal object of ventilation is to protect persons in the ventilated area from breathing air containing the body-sewage of themselves and others. Ventilation, therefore, implies the constant and adequate supply of pure air, and the constant and adequate removal of used air. Every time an average human being breathes, about three-quarters of a pint of air is taken into the lungs, held there for a little while, and then sent out again. Whilst in the lungs the air undergoes a profound change in its composition. It loses oxygen, which is absorbed by the blood, and it gains a large quantity of carbonic acid, some organic matter, and a good deal of moisture. Also it is warmed to about the body temperature. In 
the course of a day some $34 \mathrm{lb}$. of air is breathed, containing some $7 \mathrm{lb}$. of oxygen, and hence, measured merely by the weight consumed, the air-need of a human being is far greater than all the other bodily requirements put together. Pure air is thus the greatest of all essentials for good health.

Now, carbonic acid is an injurious and poisonous gas when breathed in any considerable amount, and although a small proportion exists normally in the air-about $3 \frac{1}{2}$ parts per 10,000-it is capable of doing much damage when the proportion exceeds 8 or ro parts per ro,ooo. The carbonic acid produced by respiration is particularly injurious, probably by reason of its association with the refuse organic matter from the body. This refuse matter is constantly being cast off by the lungs and skin. It is this foul body-refuse which causes a badly-ventilated room to smell "stuffy", and most teachers must have recognized the frequency of the connection between "stuffiness" and inattention, yawning, mental obscurity, and ill-temper. Weight for weight, children throw off nearly twice as much carbonic acid as adults.

In addition to respiration other agencies exist to render the air of inhabited rooms impure. Lighting is one of the greatest of these, and has to be allowed for. To get a 16 -candle-power light for one hour from tallow candles involves the production of as much carbonic as twelve adults would produce; from a kerosene lamp the same amount of light leads to the production of an amount of carbonic acid equivalent to the quantity produced by the respiration of seven adults; from coal-gas in an ordinary bat's-wing burner the amount produced is equal to that produced by the breathing of five adults, and in a ( в 775) 
Welsbach burner to that of three adults. An electric light does not vitiate the air at all. Fires produce much carbonic acid, and require a plentiful air-supply. Every pound of average coal when burnt produces from $2 \mathrm{x} / 2$ to 3 pounds of carbonic acid. It is therefore very necessary to provide proper means for removing from the area the products of combustion from lighting and warming.

Other sources of air-contamination are to be found in gas-escapes, foul gases from drains and rubbish heaps, and the rising of the ground-air into rooms when fires are lit in cold weather. The accumulation of dust in a building is also a dangerous source of contamination if the dust is allowed to rise and float about. The dust of inhabited rooms is very often the means by which disease is spread. The battle against consumption, which is being waged in many countries with such excellent results, is largely a battle against house dust. For this reason, all school sweeping and cleansing operations should be carried out at the end of the day's work, and not at the beginning, so as to give the dust time to settle before the room is used. The use of damp cleaning and of damp sawdust for sweeping is also an important precaution. When children are being marched into or out of a school-room, all unnecessary stamping-as, for instance, "marking time"-should be avoided. The reasons for these rules must be perfectly apparent.

If respiratory carbonic acid and its accompanying body-refuse are allowed to accumulate in a limited space, the death of those occupying it may rapidly result. The Black Hole of Calcutta was a notable example of the effect on people of the accumulation of carbonic acid and body-refuse-146 people were shut up for a night in 
a room measuring some 18 feet each way, with only two small windows on one side. Next morning 123 were dead and several others died shortly afterwards. These people were not merely suffocated in the popular sense of the word-they were poisoned by the organic refuse of the bodies of themselves and their companions. The definite toxic effect is shown by the fact that in this and somewhat similar instances many of the survivors have suffered for a long time from a form of blood-poisoning.

Long before the air-sewage reaches a proportion capable of producing such appalling results as this, it can seriously interfere with the health and working powers of those who are compelled to breathe the contaminated air. It should never be forgotten that this air-sewage is composed of much the same materials as other kinds of sewage to which far more popular attention is usually given, and is even more injurious in its possible effects. Yawning, languor, weakening of the powers of application and of memory, irritability and ill-humour are amongst its earlier effects alike on teacher and on pupils. An open window or two may make all the difference between an exhausting experience during which a harassed teacher struggles with a demoralized class, trying to control a generally rising temper in the midst of exasperating stupidity and scarcely veiled insubordination, and a wellinstilled and well-retained lesson, satisfactory to teacher and pupils alike. Constantly endured poisoning by airsewage generally produces weakness, pallor, indigestion, and a general lowering of the bodily tone. Many cases of anæmia in women teachers are due to neglect of classroom ventilation. This lowering of the bodily tone may lead to very serious results by preparing a suitable soil 
and so enabling disease to obtain a foothold. The absence of fresh air weakens the natural powers of resistance of the body to disease; and, at the same time, it enables infective material to increase and to become more virulent. It is futile to expect the best work from a teacher and a class half poisoned by the sewage from their own bodies. Once the carbonic acid in the room air rises above a certain point-about 12 parts per 10,000-it does not much matter whether the teaching system is the new education or the old. The results of both are swamped by the brain-clogging impure air. Many a teacher negatives much pedagogic study by neglecting the ventilation.

The evil effects produced by breathing impure air cannot be removed by subsequently breathing pure air, any more than the effects of bad water can be removed by subsequently drinking good water. Impure bedroom air is especially injurious, because most persons spend on an average one-third of their lives in their bedrooms. That is to say, a person of thirty years of age has spent at least ten years in bed, even if he has never had a day's sickness. Children, it must be borne in mind, require much more sleep than adults, hence they spend more than one-third of their lives in their bedrooms. Bad school-room air is scarcely less dangerous for teacher and pupils than bad bedroom air. It is no doubt very difficult to secure perfect ventilation in an ordinary school-room; but every effort should be made to obtain it. It is of supreme importance. Draughts must be avoided if possible; but it should always be remembered that infinitely more people are injured or even killed by defective ventilation than are harmed at all by 
draughts. The "open air" treatment of consumption is an object-lesson on the draught question, and is producing an excellent effect on public health and happiness, quite apart from its primary object of preventing and curing consumption. Children, however, teachers must remember, take chills easily; and no desire for free ventilation will justify the spectacle of a row of halffrozen infants listening to a teacher expatiating upon the benefits of fresh air from the warm security of the fireplace. It is far more needful, though, to remember that no desire to avoid chills will justify a foul school-room with stuffed ventilators and closed windows. The teacher is responsible for a common-sense use of the facilities provided; that is, he ought to make the best of them. Teachers will find it greatly to their personal advantage to set the children the example in their own daily life of the beneficial effects of fresh air.

Never take ventilators for granted. If there is something which is alleged to be a "Tobin's tube", or other supposed specific for getting rid of foul air, do not imagine that it can ventilate a school-room merely because it is called-usually quite incorrectly-by a learned-looking name. Where does it come from? Is its interior clean or dirty? What is the size of its narrowest part? Does it really bring air in? These are amongst the questions which have to be answered when inlet ventilators are being examined. It may come from under the floor, or from over a drain, and hence may bring in foul air. If its interior is of rough brick or wood it soon becomes coated with dust, and dirties the air passing through it, in addition to markedly lessening the supply. There is no reason to be less particular in 
avoiding air which is brought by a sewage-fouled channel than in avoiding food or water which is presented in a sewage-fouled plate or cup.

The total area of inlet channels is usually too smallthere should be at the very least a total of three square inches in the narrowest parts for each eight square feet of the floor space to be supplied. Even this is only sufficient to let a comparative trickle of air into a crowded room. Every right angle in a ventilating channel decreases its value fifty per cent. A wooden valve or lid is often fitted in these tubes, and it obviously must be open before the ventilator can do any good. Try the current of air coming up by means of a smoking piece of brown paper held over the top, and see where the smoke goes. That is where the air goes to under that particular set of conditions. The laws governing real ventilation are well known and have survived the test of frequent and varied application. Air is a physical thing, and is governed by simple physical laws.

There must be two sets of ventilators in every roomone for inlet, the other for outlet. Both kinds should be as short and straight as possible, and should be frequently and carefully cleaned. Air will no more go two ways at once, in a pipe or channel or other opening, than water will. If there is no inlet at all, we cannot expect foul air to be extracted. If there is no outlet we cannot expect fresh air to enter. There is only one kind of fresh air; that is, air coming directly from the outside. There is only one place where foul air can be properly disposed of; that is, the outside. When air is breathed it becomes warmer, and warm air rises. Hence we must put the outlets for foul air near to the ceiling, if we 
depend on natural ventilation, and must carry them through any roof space by means of smooth straight metal channels. The part to which we particularly wish to supply fresh air is the "breathing line", or level at which the children breathe; therefore inlets are placed lower. They cannot be placed below five or six feet from the floor because of the draughts they would cause if the entering air played directly on the children; they are sloped upwards, in order that the entering cold air may come in contact with the warm air in the upper part of the room, and thus fall evenly all over the breathing line, after being somewhat warmed. The air in a well-ventilated room is constantly tending to rise and to be renewed from below, but room air will not circulate in this way to a height greater than $\mathbf{I} 3$ feet, because at that height it becomes cooled and sinks again. Space over 13 feet from the floor is therefore useless as ventilation space, and the cubic space per child cannot be taken as including any vertical measurement over 13 feet unless mechanical ventilation is provided.

One principal outlet does not open near the ceilingthis is the fireplace. An opening into the chimney breast near the ceiling, fitted with a flap to prevent smoke from coming back, is very useful in extracting foul air from a room. The fireplace should never be stopped with a chimney-board, especially in school-rooms or bedrooms, because even when the fire is not lit, a draught is generally passing up the chimney and extracting air from the room. A piece of smoking brown paper will prove this.

When fresh air is supplied for diluting and removing foul air, without causing draughts, the process is called 
Ventilation. When the foul air is blown rapidly out of a room irrespective of draught, the process is called Perflation. Both are necessary in all ordinary schoolrooms, and both are intended to replace foul air by pure; not merely to churn up the room air. Ventilation is effected by admitting air through proper inlet channels

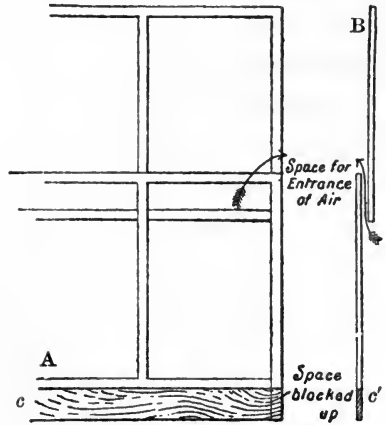

How to Ventilate a Room.

A, Front view of window; $B$, Side view ; $c, c^{\prime}$, Ventilating board. including the windows, and extracting it, after use, by proper outlet channels including the chimney. A certain amount of air also gets into a room by cracks and crevices, and through the walls; but the air so introduced cannot be depended on either for amount or purity. An ordinary sash window may be used as an inlet ventilator in cold weather, by putting a board on its edge under the lower sash so as to close the whole width of the window frame. A better method, suggested by Professor Glaister, is to let into the lower rail a sliding bar adjustable by set-screws. The air then gets in between the two sash rails above, and is directed up into the room, to fall evenly after it has been somewhat warmed. Side-pivoted or hinged casement windows are inconvenient for use as ventilators in cold weather. It is much better to pivot them at the bottom, and to have a triangular board at each side so as to make the window into a big hopper when it is opened at the top. The side boards are to prevent 
down-draught from the cold air tumbling into the room. The pivot should be so made as to allow the window to slip up a few inches for perflation. Several good patent windows are on the market, the "Magic" being one of the best.

In an ordinary school-room, however, an adequate air-

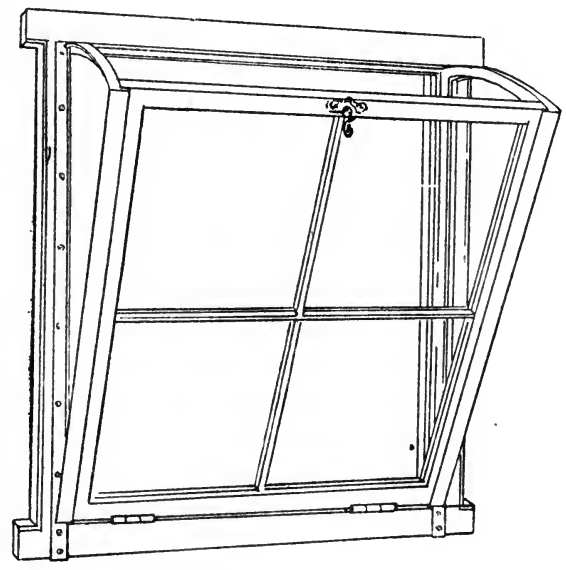

Hopper Casement.

supply cannot be obtained without discomfort in winter by any means of ventilation which does not also warm the entering air. Hence perflation of the room at regular intervals becomes necessary. This is done by opening the windows and doors, and flushing the whole room out with fresh air. It should be done during the interval, and at changes of class. A very few minutes is sufficient if the room has openings in opposite sides, and there is any breeze. By perflating a school-room once an hour, and attending to the ventilation in between, the educa- 
tional results obtained will be greatly improved. This has been tested by actual experiment, and is no mere hypothesis.

So far we have only considered those means of airsupply in which the air is made to enter and leave the room without the help of machinery and is not artificially warmed. These simple agencies-as opposed to mechanical systems of air-supply, where the air is artificially forced into and drawn out of a room at a regular rate after previous warming or cooling-are, however, the only ones available in the great majority of rural and colonial schools. They cannot be expected to do more than to keep the air sewage from accumulating to a hurtful extent, and arrangements depending solely on them are liable to be upset at times by changes of wind, by a still atmosphere, and by other causes. Nevertheless, with intelligent attention and management, they are capable of being made to yield good results even in a crowded school-room. Without common-sense management the most carefully planned arrangements may be rendered useless and even harmful.

For reasons which will be readily understood the whole question of ventilation is closely associated with that of heating, and certain ventilating stoves and other simple devices for the supply of warmed air in winter will be referred to later [Appendix I]. The great fault of natural ventilation by unwarmed air lies in the fact that if we. change the air of a room more than three times per hour in cold weather, unpleasant draughts are produced. If the children have only 100 or 120 cubic feet of space per head (as in most standard schools in English countries), it is obvious that to give each 2500 cubic feet of air per 
hour, a figure which represents the supply necessary to keep down the air sewage to an absolutely safe limit, the room air must be changed more than 20 times in each hour. This is impossible in cold weather. A simple calculation shows that the air of a room with I 20 cubic feet of space per head, and for which no ventilation is provided, will become foul in about $2 \mathrm{I} / 2$ minutes after it is occupied. In 5 minutes the air of such a room will become so vitiated as to interfere seriously with mental reactions. By constant natural ventilation we can dilute and convey away the poisonous material, and by securing perflation as frequently as possible at changes of class, and other intervals, we can make repeatedly a fresh start with pure air, but we are always running the risk of a foul room, and must inevitably exceed the limit of safety once an hour at least. Mechanical ventilation is therefore much superior to natural ventilation in cold climates, since it gets rid of the cubic space difficulty by enabling the entering air to be warmed. It is, besides, independent of weather conditions, and the supply can be regulated. The great drawback to mechanical ventilation is, that it is expensive to install and requires skilful attention. For large schools it is well worth what it costs, owing to the increased educational efficiency obtained. In Dundee the installation of mechanical ventilation in three schools raised the grant earned in them from 19s. $6 d$. to $21 s$. $8 d$. per head. This, however, represents only the immediate and visible effects of mechanical ventilation, and not the actual, which are immeasurably more important.

Children should be taught the necessity and value of fresh air, and the practical methods by which a room may be thoroughly ventilated. By appointing in turn 
one child as sanitary officer for the class-room, and charging him with the duties of attending to the ventilation and perflation amongst other matters, and of reporting anything wrong in this respect, much practical hygienic knowledge may be imparted. It should be impressed upon children that pure air is necessary at home as well as at school. The value of an open bedroom window and an open bedroom fireplace should be steadily insisted on.

To sum up, the following points should be remembered as showing the necessity for fresh air from an educational stand-point:-(I) Satisfactory mental results cannot be obtained or expected from children who are half-poisoned by their own body sewage. (2) The air of an ordinary school-room becomes so foul as to interfere with educational work in less than five minutes after occupation of the room has begun, unless a proper air-supply is provided and intelligently used. (3) No ordinary schoolroom can be safely occupied for more than one hour with natural ventilation only. The room at the end of the hour must be thoroughly perflated. (4) Perflating the room never wastes educational time; neglect to perflate it does; and no modern teacher can afford to waste school time. (5) For ventilation there are required an Inlet, an Outlet, and a Pure Air-Supply. (6) If there is down-draught from outlets, increase the inlets. If from inlets, try to deflect instead of stopping the entering fresh air. (7) A piece of smoking brown paper will always indicate the direction of an air current. (8) The ventilation of a room furnished with the most inadequate means may be greatly improved by intelligent management; the best provisions for ventilation may be rendered use- 
less or even harmful by careless or ignorant management. A teacher who will not endeavour by all reasonable means to avoid foul air in the class-room is unfit to have the charge of children.

\section{CHAPTER III}

\section{LIGHTING AND ITS MANAGEMENT}

Next to ventilation, the most important questions in School Hygiene are those dealing with the proper management of School Lighting and the avoidance of unnecessary eye-strain. Imperfect eyesight is a great disadvantage to anyone; and even where it is discovered early and corrected by glasses, it may affect harmfully a human life from babyhood. In early childhood it interferes with those strenuous play-lessons by which primitive man trains himself, improves his physique, and acquires control over his muscles. In later school years it presents endless difficulties to the pursuit of knowledge. Finally, it may-and often does-form an insuperable bar to a career which the pupil may desire to follow, and to the preparation for which he may have devoted much energy and time. In the examinations for the Indian Civil Service, for which a long and arduous course of preparation is required, more than to per cent of candidates have at times been rejected on account of defective eyesight alone, although they have satisfied the examiners in all other requirements, physical and mental. Most Government services require good eyesight in applicants 
for positions, and for obvious reasons the navy, the army, the mercantile marine, railway work, and several other good professions and occupations, are closed to those with defective sight, no matter how excellent are their mental attainments or their physical qualifications in other respects.

All this casts a great responsibility upon teachers, since they are to a considerable extent able to avert the most serious consequences from those children who come under their hands already suffering from eye defects, and since they may exercise valuable influence in preventing these defects. An alert and skilful teacher may prevent bad school conditions from producing or intensifying many of the worst effects of a badly-lit school; but a teacher who is ignorant or careless of the important principles involved may negative the best efforts of the school designer and may seriously interfere with the education of the children.

The great majority of young children have "visual" memories - that is, they depend on a host of eye-photographs which are continually being stored up in the brain -and the hearing memory is not developed until later. If the eye-photograph of any particular thing is blurred or indistinct the young child is heavily handicapped, because he depends almost wholly upon it for his memory of that thing. Every teacher knows that the senses must be trained before the mind; and, educationally speaking, the eye is the most important of all the senses. Later on, when the memory is being developed, the eye still remains one of the great portals to the soul, and unless it is capable of being properly used, ordinary educational methods are largely wasted. In the last 
stage of true education, the development of the judgment, the eye is also essential for good results from ordinary school methods. A vast amount of time, energy, and money has been wasted in devising complicated educational systems for showing pictures to artificially blind children; and a vast amount of misery must have been caused to all engaged in the work in consequence of those children being unable to see the pictures as the teacher or the educational authority believed they should be seen. Of course, seeing is one thing and understanding what is seen is another and quite separate affair; but unless we are sure in the first place that the child can really see, it is unnecessary to enlarge upon defects of perception. Later on we will have occasion to notice the differences between vision and perception, but for the present it will suffice to say that very serious results may arise from deficiency or bad management of light in a school-room, from carelessness on the part of the teacher in permitting bad habits of sitting or working, and from ignorance of the principles involved. Teachers know that the instruction of the blind is a very special and difficult branch of their art; but they are apt to forget that a great deal of unnecessary evil and unhappiness arises from attempting to teach the partially blind by methods for whose success good eyesight is essential.

A certain proportion of children come to school with originally defective eyes, but most cases of bad sight found in young adults and children arise during school life and are principally due to improper school conditions. It is obvious that both the original and the manufactured defects will tend to be made worse by unnecessary eye- 
strain of any kind. Such school conditions do not mean only those arising from defects of buildings and equipment, such as incorrect situation and placing, insufficient window space, ill-fitting desks, and other mistakes and deficiencies which the teacher is usually powerless to directly remedy. They include such questions as the enforcement of proper positions in reading and writing, the placing of desks relatively to the light, and a keen systematic watch for signs of defective or overstrained eyes. It is useless for a teacher to plead defective buildings or furniture as an excuse for bad lighting until it can be shown that every reasonable effort has been made to utilize to the very best advantage what light there is.

The methods by which light is obtained in schoolrooms may be conveniently subdivided as (a) Natural, from direct daylight entering by windows; (b) Artificial, from gas, kerosene, electricity, or other artificial illuminant, or from reflectors, prisms, \&c., which form the main instruments for transmitting daylight indirectly; and $(c)$ Combined, in cases where direct daylight forms the main source of the illumination, but not being sufficient is supplemented from an artificial source. Whichever of these means of lighting is used-and for present purposes only natural lighting need be fully considered-two main principles must be closely observed. These are:

r. Amount. There must be sufficient light.

2. Direction. The light must come from the proper direction relatively to the children as they work.

In considering the amount of light required, it is necessary to ascertain in the first place how much is 
required, and in the next, how that amount may be obtained.

\footnotetext{
Generally speaking, it may be sajd that every child sitting in its usual place should be able to read at a distance of $\mathbf{1 6}$ inches that kind of small type which printers call "Diamond". If this small type cannot be read at 12 inches under such conditions, there is a serious defect either of lighting or of vision, and it is generally easy to detect which of the two is at fault. This paragraph is printed in

"Diamond" type, and may be used as a test for the purpose.
}

For children who cannot read, other tests are available, a good one being the ability to distinguish as separate dots, at a distance of ro feet, a line of square dots each I millimetre ( $\frac{1}{25}$ th of an inch) square and one millimetre apart. Another test is to show a line of E's and reversed E's in diamond type, thus:

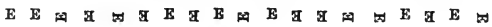

and to ask the child which is the open side of the letters.

In using these type tests the distance may be readily got by using a ruler or stick of the requisite length (r6 inches) with one end resting on the book and the other touching the child's forehead just above the root of the nose. Each eye should be tested separately, the other being obscured with the hand or a piece of cardboard held an inch or two away.

This simple test furnishes a fairly accurate indication of the sufficiency of light in a room or in any particular part of it.

The methods of obtaining such sufficiency are largely architectural, and although few teachers can alter original defects of placing, \&c., it is advisable to understand the main principles involved. The first point-and it is a very important one-is that the main light should be secured from the best-lit part of the sky in all temperate 
and even in most subtropical latitudes. It is an easy matter to cut off excess of light when not needed, but it is usually very difficult, often, indeed, impossible, to increase sufficiently the light from a structurally deficient light source. Further, the neat alignment of a school building on a site is of much less importance than the defective lighting which it may perhaps necessitate; and if the two clash the alignment should go.

The area of window-space in all temperate and most subtropical latitudes should never be less than one-fifth of the floor space, and that one-fifth should be of real glass, and not partly of wood in the shape of frames, rebates, or sashes. The best light comes from the top of the window, and most of that from the bottom panes is wasted on the floor. Hence windows should have square tops and should reach to within six inches or so of the ceiling. This arrangement of the windows is of use also in securing ventilation and perflation. The windows should be as wide as possible so as to avoid unnecessary shadows from the wall between, and the panes should be large. Bevelling of the frames and angles of the piers greatly increases the area of sky available. Frosted glass should never be used. In all cases every child in the room should be able, by turning in his usual seat, to see a piece of the sky. School-lighting has an extensive literature of its own, and the few principles here stated comprise but a brief outline of the recognized requirements.

Having arranged for getting sufficient light into a room, its direction as regards the children's work should be carefully considered. It is clear that with righthanded folk the main light should, wherever possible, 
come from the left side, in order to avoid hand shadow from the hand engaged on the work. This left lighting is very important indeed, and should never be neglected. It can generally be obtained by the exercise of a little common sense, and perhaps in cold weather some personal sacrifice on the part of the teacher, who may be compelled to work away from the fireplace. Given these conditions, rearrangement of the desking will often be possible with excellent results. The direction in which the light falls is a matter in which the teacher is largely concerned.

There are, however, certain conditions which may prevent the use of left light alone. In deep rooms the innermost desks may be insufficiently illuminated from a unilateral light source, and generally speaking, no room which is more than 24 feet wide can be properly lit by windows in one side only. Hence windows in other directions may be required, and these should be at the right of, or behind the children. In no case should they ever be in front. It is positively criminal to submit children to a strong light shining directly into their eyes for hours together. With strong back-lighting the teacher has to bear front light whilst at work, but the effect on an adult is much less injurious than on a child. The teacher, moreover, can move about; the child cannot. Light from above is not desirable for school-rooms, but may be used for assembly halls, drawing-class rooms, and other rooms where fine work is not done.

Main left lighting with subsidiary right lighting is the most desirable alternative to left lighting alone, because the windows on opposite sides assist in ventilation and perflation, and any unnecessary strain upon the teacher's 
eyes is avoided. The right light, however, should not be allowed to preponderate. If this arrangement is impossible, main left lighting with subsidiary back lighting is next best.

When the light comes from the back only, serious effects may be produced upon scholar and teacher alike. The heavy shadow falling in most parts of the room from the body and head upon the work causes the child, particularly when writing, to twist round in his seat, lifting the left shoulder and lowering the right, and causes him at the same time to drop his head and screw his eyes sideways along the lines. The attitude so produced is most unnatural and fatiguing; it completely interferes with the correct handling of pen or pencil; and by twisting the spine and straining the eyes may-and doesproduce serious results, particularly in weakly children. Herein, as in most other hygienic defects of schools, it is the strenuous, hard-working child that is liable to suffer most. The effect upon the teacher working in a back-lit room is often to produce eye-strain, with consequent headache and irritability. Unfortunately these are frequently overcome by drawing the blinds and thereby further limiting in its most useful portion a usually inadequate light-supply. For the sake of teacher and scholar alike every endeavour should be made by rearrangement of desks to convert a back-lit room into a left-lit one. Care must be taken when making such rearrangement that no part of the room is overcrowded, as such overcrowding would spoil the ventilation.

A great deal of light may be absorbed by dark colouring of walls and furniture and so lost. All school interiors, therefore, should be painted in light colours to diffuse 
light and to prevent dazzling (see "Interiors"). A white ceiling acts usefully as a reflector of light.

The teacher may sometimes be able to do a great deal to improve lighting, in addition to securing proper direction of it. "Frosting" should be cleaned off windows with a solution of caustic soda applied by a rag-pad fastened to a stick. A quarter of an hour after its application the glass should be washed clean with water. The effect of ordinary frosting is to stop some seven-tenths of the light. Dirt and dust on the panes also stop out much light. In city and town schools adjacent walls may interfere with light, but if these can be whitewashed much improvement will result. In country schools trees may obstruct light and should be removed or lopped. Shades and blinds should be adjusted or refitted (see "Interiors") where necessary.

It may be necessary to improvise a "daylight reflector" with a piece of white enamelled tin or wood (a box lid will serve) hinged or hung inside or outside the window in order to light up a dark corner or space. By the use of such patented devices as "prismatic panes", ribbed or "factory" glass, obstructed lighting may be greatly improved.

During repainting all dark colours in the interior should be replaced by grey, light green, or light blue, with the surfaces "flatted" to avoid glare. The blackboards should be carefully attended to, both to preserve a dull black surface and to prevent them from "shining". Sometimes a small curtain may have to be rigged up on one side, where wall boards are not provided, but alteration of position will generally suffice.

Rearrangement of rooms may be made to utilize the 
light to the best advantage, finer work being done in the best-lit rooms or best-lit portions of a large room, and the worse-lit parts employed for work requiring less strain, such as black-board work, oral lessons, brush drawing, and so on. These matters of structure and management have been alluded to in some detail, and are of much importance; but one great responsibility of teachers still remains to be mentioned, namely, the prevention of improper working positions on the part of the children, and of the injury that is caused by such positions to the children's eyesight (see Chapter VIII, p. 102).

For reasons which will be explained later children of school age should never be allowed to develop the habit of working at any less distance than 12 inches between eye and work, and every effort should be made by the teacher to overcome such habit if it is already formed. It is in the infant classes that this most dangerous and pernicious habit must be attacked in the first place, but the battle requires to be fought every day, every term, every year, and the teacher must be unyielding. No degree of lighting, however effective and well directed, can wholly compensate for a bad working attitude, but on the other hand, the acquirement of a good working attitude may overcome many of the dangers arising from deficient or wrongly-directed light.

Where gas or other artificial illumination is employed similar principles must be observed if eye-strain is to be avoided-that is, the light must be adequate in amount, it must come from a proper direction, and a proper working position must be enforced. With the exception of the incandescent electric light, illuminants of this nature require to be considered in relation to ventilation. Gas 
jets and lamps should always be fitted with globes to minimize flickering and to equalize the light. The Holophane pattern of globe with a Welsbach or other good incandescent burner is the best for the purpose, but failing this, "ground glass" may be used if sufficient light is provided to overcome its lack of translucency. For table lamps a green shade is advisable, and if it is necessary to work at night with an unshaded light above the level of the eyes, a green-lined forehead shade should be used.

Children should be regularly instructed regarding the necessity for care of the eyesight, and cautioned in simple clear phraseology against the dangers of reading by firelight or any other uneven and flickering light source. For reasons which will be explained in Chapter VIII permanent short-sight (myopia) is very easily acquired at school age, and once developed it is a heavy handicap upon an individual's chances in life.

\section{CHAPTER IV}

\section{INTERIORS AND FURNITURE}

When one comes to think of it, the external appearance of a school as contrasted with its internal construction and arrangement is a comparatively unimportant affair The vast majority of children will never have a chance of arranging the exteriors of their homes when they come to possess them in after-life; and even if they have such a chance, any rational system of instruction in architectural 
æsthetics will inform them that outside style is-or should be-secondary to inside arrangements. In the case of a school a gorgeous bell-tower and fretted stone window mullions outside, and dirty dark rooms within, form a combination which may well be productive, even unconsciously, of evil effects upon the minds of children, and will certainly be so if by any chance they come to deliberately contrast the two. As a rule, when children get outside the school-room they are too much occupied in the real business of their lives to waste time in admiring architectural glories. That the countless eye-photographs which are unconsciously stored up in their minds during the hours of enforced school work should retain the image of an unclean and untidy school-room, is tantamount to a course of deliberate instruction in dirt and slatternliness for guidance in after-life.

School buildings are erected for the special purpose of containing for several hours daily a large number of beings who are particularly liable to suffer ill effects from house-dirt and its consequences, who are usually brought to school willy-nilly by the law, and whose habits render them important factors in that very accumulation of dirt which carries with it such dangerous possibilities to themselves. Ordinary structural methods are obviously unsuitable for such a building. The inmates are drawn from many houses, and every fresh source of attendance increases the risk of infectious material being brought into the school, whether as the spores of ringworm or other skin complaint, as coughs or colds, as the virus of one or other of the infectious fevers, or in other shapes and forms. They tramp in and out of the room several times daily, raising the floor dust and causing 
that from the walls and ceiling to settle down into the atmosphere to be rebreathed when they re-enter. Let infection be brought from one house to that room and it is carried far and wide on the clothes and in the bodies of the children when they disperse to their homes. The dust of occupied rooms is the most dangerous of all forms of dirt, and its constituents are often of a disgusting character. The interiors of school-rooms should therefore be designed as far as possible to prevent its accumulation, and to favour its detection and easy removal.

Anybody who has ever tried will know how much easier it is to clean a smooth surface than a rough one. Moreover the smooth surface does not collect so much dust as the rough one, and does not require cleaning so frequently. Smooth impervious interiors are the most economic if the room is to be kept clean, and for the reasons already stated it is very important from the educational stand-point that it should be kept clean. Putting aside for the present the educational value of school example in developing cleanly interests in the coming generation, dirt means disease, disease means interference with school work, and interference with school work involves waste of money and effort. Dirty schools are unbusinesslike concerns, and the erection of school-rooms in such a fashion as will tend to promote the collection of dirt and will interfere with its easy removal is an unbusinesslike proceeding.

School interiors should therefore be so constructed and arranged as to-( $\mathrm{I}$ ) prevent as far as possible the accumulation of dust and dirt; (2) to facilitate its detection and removal as early as possible; (3) to assist in the lighting by preventing glare and dazzling, and by not 
absorbing light in any unnecessarily dark coloration; (4) to develop the æsthetic sense of the children by constant exemplification of cleanliness and of artistic and harmonious colouring and arrangement. These requirements sound somewhat serious and complex; but in reality it is almost as cheap and easy to build and equip a school in reasonable conformity with them, as it is to provide a dirt-collecting, insanitary barn, impossible to keep clean and chronically perverting the æsthetic sense of the inmates. All that is required is a little common sense, and a stern disregard for the ideals of the so-called "practical builder", whose misguided soul yearns for complicated dust-traps under the guise of what he believes to be ornamentation.

The walls should be smooth and unabsorbent. The best wall surfaces are made of hard cement painted with three coats of good oil paint in suitable colours and varnished. Plaster similarly painted after it has had time to dry thoroughly (but not before) is perhaps next best. It may, however, take several months to dry sufficiently for painting. In some American schools a prepared jute canvas called "Burlap" is used for wall surfaces over plaster, and is said to give excellent results when painted. Wood should not be used whenever it can be avoided, and it is never a good lining for a school-room even when painted. Bare brick, bare plaster, and distempered walls are absolutely bad. They collect and retain dust and never can be satisfactorily cleaned. Brick, plaster, and wood, if they must be used, should be painted over with three coats of good oil paint, dulled ("flatted" as painters call it) and varnished if possible.

The coloration is important, and good oil paint is 
perhaps the best means of securing it for walls. Light green, light blue, bright grey, and greenish-grey form the best tints. An excellent greenish-grey may be obtained by a mixture of Antwerp blue and raw sienna with white as a basis. Dadoes or wainscots should be olive-green or blue. Presses, mantel-pieces, and other fittings should be painted white or in soft colours, and the whole colour scheme made to harmonize as far as possible. The entire coloration should be restful to the eye, while diffusing light well and tending to educate the colour sense of the children. Whatever colours are used, shiny surfaces should be avoided by proper "flatting".

All unnecessary horizontal surfaces for the collection of dust, whether these be projecting door or window frames, cornices, or anything else which need not be there so far as the stability of the building is concerned, should be abolished. If they are there and cannot be got rid of, bars of wood of prismatic section should be screwed into the angles to enable dust to be easily seen and got at from below. Tops of book-cases, presses, and shelves should be sloped to the front for the same purpose. The angle between the floor and the wall should be filled up by a screwed prism-shaped bar of wood or metal to avoid the collection of dust in a part of the room which is otherwise very difficult to clean properly.

Every school-room should have a ceiling not more than 13 feet from the floor, rendered impervious to dust and dirt, and painted white for reflection of light. Steel ceilings are cheap and very efficient, but failing these galvanized iron makes a good school ceiling. The joints should be rendered dust-proof in order to prevent 
filtering down of dust from the roof space. Boarded ceilings should be abolished, and it is in fact better to have no ceiling at all than a boarded one, which generally serves merely as a sprinkler for the foul dust collecting in the roof space.

Floors are often mere dust-traps. A good deal may be done by planing a floor smooth and ironing hot paraffin wax into it with a tailor's goose. Old floors may be planed and painted if waxing is impossible. The use of oil to keep down dust from school floors has been very successful, but is apt to cause difficulty with womenteachers' dresses.

Blinds form an important feature in school interiors, and the best of all for school purposes are light springroller washing blinds, of green tints. These should be made double, one roller working up and the other down, and set in the middle of the window instead of at the top. Failing double rollers a single roller set at the bottom of the window, with a ring and wire at each side for the blind to slide on, gives good results. As has been already stated the best and most useful light comes from the top of a window. The old-fashioned top-set blind generally cuts off far more light than is necessary for the mere avoidance of glare or direct sunlight, and in doing so often causes eye-strain. The so-called venetian slat blinds are dirty and uneconomic affairs, and they should never be employed in schools. For use in summer a light canopy can often be rigged up on a couple of stays outside the window to temper the direct sunlight.

Turning now to school furniture we have to consider especially desks, seats, black-boards, and slates as being 
of particular interest to teachers in relation to School Hygiene.

Desks and seats may be taken together, and they are well worthy of the close attention of a conscientious teacher. There are two important facts which it is well that teachers should keep clearly in view. It is foolish to expect children to sit still for long periods even in the most correctly designed seat; to the child such procedure is impossible, it is so utterly unnatural. The most hygienically constructed seating accommodation does not succeed in maintaining the children's health unless the teacher enforces correct attitudes amongst those using it. Good desks and seats are not easy to devise, as they must conform both to pedagogic and hygienic needs, and must at the same time be convenient and cheap. The ordinary long desk and movable form are certainly cheap, but in every other respect they are utterly evil things. Their construction and use show an absolute disregard of the progress that has been made in the serious study of the whole matter of school furnishing and School Hygiene. There is only one position in which a child can sit at a desk without being twisted into an unnatural or injurious attitude, and it is obviously impossible to seat six or eight children of varying sizes on the same form at the same desk without risking damage to some of them.

There are excellent anatomical reasons for this statement. In sitting, the body rests upon two curved bones shaped something like the staves of a cask, and hence is in a position of unstable equilibrium. To keep it from tilting forwards it may be supported in front by the thighs-a position which may be called the "forward 
sitting" position; to keep it from tilting backwards there is the point of the sacrum (a broad wedge of bone which continues the spinal column down between the two sides of the pelvis) permitting of a "backward sitting" position. Above these supports is the body, packed full of complicated organs, the digestive organs below, the lungs, heart, and central circulatory mechanism above. The flexible spinal column runs up at the back of all, and terminates in the heavy and mobile head supported on the neck, through which run the great vessels supplying the brain. It is clear that in the forward sitting position the tendency is for the head to fall forward, then for the body to bend forwards, since the spinal column runs up the back of this irregularly-shaped flexible box of closely-packed organs and is necessarily subjected to considerable leverage by their weight. This tires the muscles, which pull on the spine from behind in the body and neck and tend to keep it erect.

The results are inevitable. The bending of the head, like a lily on its stalk, as the neck muscles grow fatigued, brings the eyes too near to the work and produces temporary short-sight, which may, by continuance, become permanent. At the same time it bends the great vessels in the neck and interferes with the blood-supply to the brain. Then the back bends and forces the chest into a contracted position by its attachment to the ribs, interfering with breathing and hampering somewhat the action of the heart. Further curving of the back jams the abdominal organs between the great muscular mass of the diaphragm and the bony pelvis, interfering with the digestive mechanism. By this time the child has generally got one elbow on the desk to support the back 


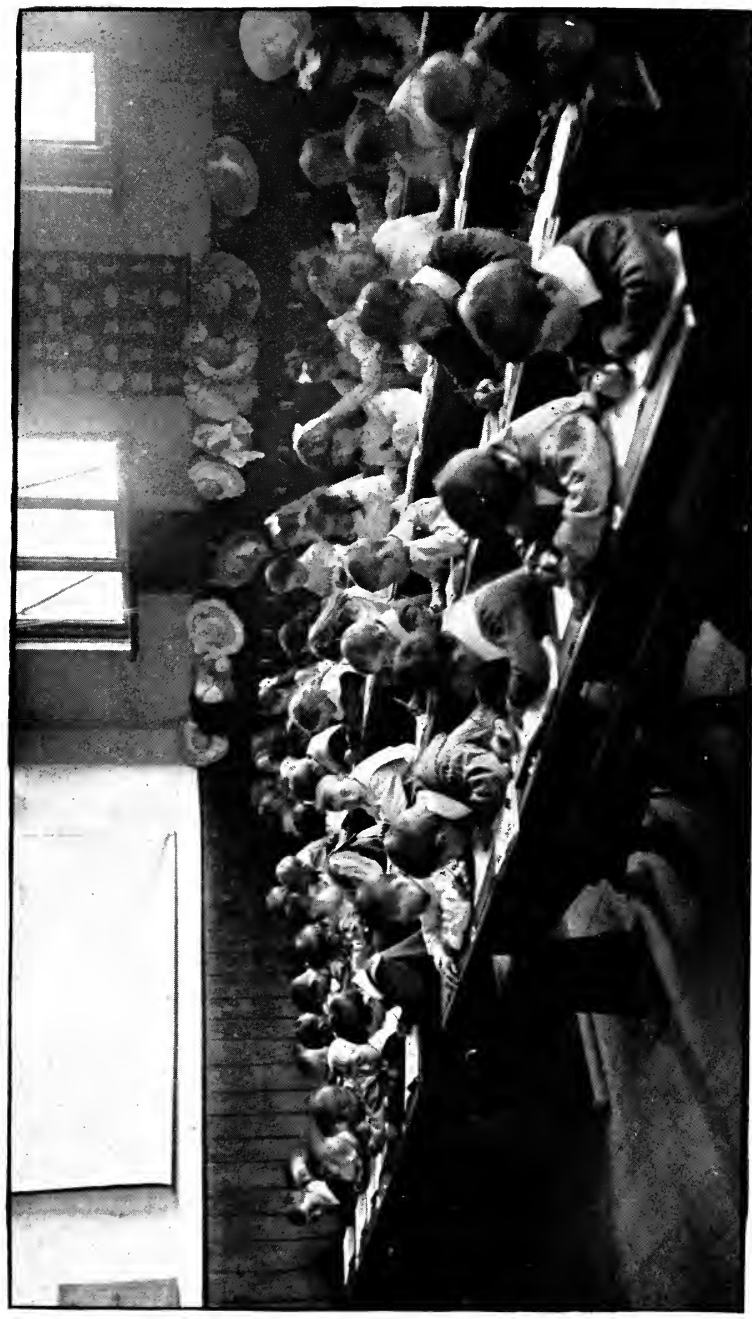

吾) 

muscles, and has thereby produced a lateral twist in its spine. Later, if the strain is allowed to continue, the muscles of the shoulder-blades become fatigued and the chest is leaned against the edge of the desk, thus still further interfering with respiration.

A great authority on School Hygiene (Dr. Combes) has put the whole matter neatly: "In short," he says, "the forward position, which is forcibly brought about whenever benches or seats without backs are provided, or [where they] are provided with backs that are vertical, causes an incurving or lateral deviation of the vertebral column; it causes also an abnormal and difficult action in respiration, circulation, and digestion; it provokes too great an approximation of the eyes; it ought therefore never to be tolerated in schools where it is possible to do otherwise". The forward position is the only one possible with the long unbacked form. Children spend a good deal of their time in schools, their framework and organs are far more plastic than is the case with adults, and it is futile to expect that evil results will not ensue in a certain proportion of them from the defects above outlined. There is no "doctor's fad" about this, or about any of the other elementary questions of care for the children's bodies at school. It is just plain common sense.

The backward sitting position, on the other hand, is the ideal one, the child sitting upright, being able to expand its chest and to keep a proper working distance. Unfortunately it also cannot be sustained for long without support. This support can be given readily only if the seat is supplied with a back. The back to supply the support effectively should slope slightly backwards. 
Given a properly fitting seat with a back permitting of an upright position, the establishment and enforcement of a proper working distance-which, as will be remembered, implies a separation from eye to work of at least I 2 inches, and preferably 15 inches-is purely a matter for the teacher. This proper working distance is, without exception, the most useful thing that can be taught to the children in any school. Without it eye-strain is inevitable, eye injury probable, and the formation of proper writing or reading habits impossible. If a teacher did nothing more for his or her pupils than to thoroughly train them to observe proper working distance and attitude the result would, from the point of view of real education, far outweigh the most laudatory inspectorial reports of progress in book knowledge.

The requirements for a good desk and a good seat should be considered together, for it is only when the two are properly combined that satisfactory results can be obtained. In considering school furniture the necessity for attending to teaching requirements and to questions of convenience in cleansing, and of cost, must always be taken into account along with the hygienic needs. Certain hygienic requirements relating to seating and desking should be clearly understood by teachers, since if they thoroughly understand these they may be able to mitigate at any rate a few of the evils attending the archaic long desks and forms, by sorting the children into sizes as nearly as possible fitted to the desks and forms, and by securing proper relative position of such desks and forms.

For practical purposes the following rules will be found helpful. The height of the seat from the floor 
should equal the vertical distance from the heel to the under surface of the knee when the foot is flat on the floor. The difference in height between the edge of the desk and seat should equal the vertical distance from the elbow when the arm is hanging loose, to the seat. This is about one-sixth of the child's height. The edge of the seat should at least touch a vertical line from the edge of the desk, and may with advantage be an inch farther forward than where such a vertical line meets the seat. This measurement is known as the "distance", and is of extreme importance in preserving a proper working distance and an upright position. It should never be to the rear of the desk line, as the vertical line from the edge of the desk to the seat is called. Every seat should have a back, slightly inclined backwards, about 4 inches wide, and reaching to about the lower angle of the shoulder-blades, but no higher. The "small" of the back is the part most needing support. The seat should be at least 8 inches deep from front to back, should have a rounded front edge, should be curved to fit the seat-bones, and should be slightly higher in front than behind. When the desk and seat are separate they must both be firmly fixed to the floor in proper relative positions. The desk (if not adjustable) should slope at an angle of about $15^{\circ}$ to the horizon, which is practically the mean between the best slope for reading and the best for writing.

Dual desks are now condemned by leading educational thinkers of all classes, because they allow the children to be too close to each other, and because, to prevent copying, the teachers are often obliged to make the occupants adopt injurious attitudes. 
Single adjustable desks are in all respects the best, as they allow good separation, are easy of access, and can be readily fitted to the children. They are, however, expensive, often difficult to clean, and take up a good deal of room. Amongst the best types are the American

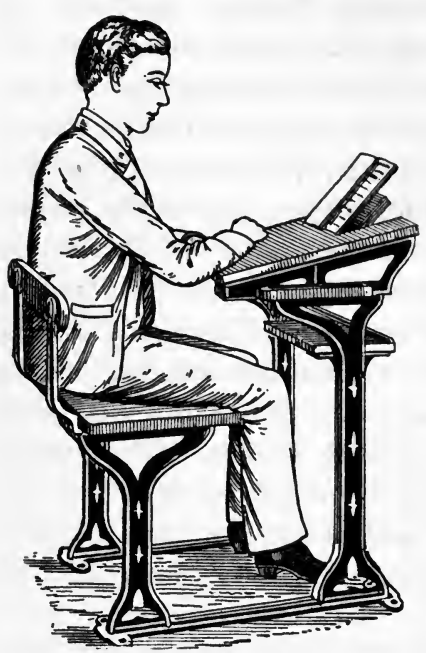

A good form of desk "Shaw Chandler" desk and the. "Heusinger" pattern.

The best available compromise between the old long desk and seat and the new single desk is provided by the so-called "Sheffield" method, where separate backed seats, each supported on a metal standard, are used with a long desk. These are easy to clean, easy to get into and out of, take up little room, separate the children well, and (especially) are cheap. They can often be fitted to the existing desks, and by a simple bolted collar can be made adjustable in height. Whilst endeavouring to obtain gradual reorganization of desking and seating arrangements in schools where the old-fashioned long, unbacked forms are still used, teachers should do their best to fit the children to the existing ones by commonsense utilization of the simple principles alluded to above. At least twenty per cent of the seats and desks in a 
school should be adjustable for height, owing to the great variations amongst children of the same age.

If adjustable desks and seats are provided, teachers require to take care that the adjustment remains correct. Great variations in height occur amongst children of the same age. Of nearly 25,000 children examined in Boston some years ago boys of six years were found to vary as much as $61 / 2$ inches, girls of the same age varying some $63 / 4$ inches. At eleven the figures were 8.03 inches for boys, and 8.63 inches for girls; at fifteen, I I.35 inches for boys, and 7.6I inches for girls. The sitting height of girls is greater than that of boys and requires to be allowed for. Children grow in a series of "jerks", with intervals of rest between (see Chapter XI), and the growing spells should be carefully watched for, as they may completely upset the fit of the seat and desk in the course of a month or two. Observation of the rate of growth and development is of use in other important respects, and should be made in any case as a routine practice in the interest of the children's health.

Of all classes of school children those under eight years of age are most dependent for protection from injury and strain upon proper desking and seating, and require the closest attention from the teacher. In schools where they still exist, galleries for infant classes should be got rid of as early as possible, and replaced by suitable desks or chairs arranged at the floor-level. Where it is not possible to reorganize the desking and seating throughout a school, the change should be initiated in the infant department and carried through by degrees from the lowest to the highest classes. The younger the child, 
the greater is the liability to severe and lasting injury from unhealthy school conditions.

Black-boards should be dull black and not shiny. Small dusters should be used instead of large ones, to prevent unnecessary dissemination of chalk dust into the air, and a small ledge at the bottom is useful for catching this dust. Good lighting of the board is of course necessary. In many American schools glass with a black backing is used, and dark green "boards" have also given good results. "Hyloplate" and certain similar materials yield excellent results and are cheap and easily fixed.

Slates.-The school slate must be unhesitatingly condemned. No amount of instruction or supervision will ever prevent the majority of children from privately regarding the saliva as the only natural and proper fluid for cleaning a slate, and the fingers or cuff as the orthodox medium by which it should be applied. Paper pads are far superior in every respect. The cost of the pad is undoubtedly greater; but there are several educational compensations. The slate has had its day, and although there once were certain advantages peculiar to its use their sacrifice is a trifle in comparison with the superior sanitary advantages and legibility secured by the use of paper. In Tasmania a suitable pad is supplied by the Education Department at a cost of a penny. 


\section{CHAPTER V}

\section{CLEANSING, DISINFECTION, AND WATER-SUPPLY}

The primary object of school cleansing is to prevent disease. Absence of cleansing means presence of dirt, and presence of dirt sooner or later means presence of disease. There is no such thing as "clean dirt" in occupied apartments. All room dirt is filthy, for it soon comes to consist in great part of decomposable organic refuse cast off from the bodies of the inmates, whether as tiny fragments of skin, as organic matter from the lungs, as bits of hair, or in other forms, such as the solid matter left behind when sweat dries, together with organically charged dust blown or carried in from streetgutters and yards. Few persons would care to deliberately eat food defiled with gutter-filth, horse-dung, and spittle, but this is no more unhealthy, and should be no more repugnant, than the breathing of air in which these substances are suspended in the form of dust.

Besides the sanitary aspect of clean schools, it is necessary to consider the effect of such as an educational example upon the occupants. Children are continually storing up brain photographs for use in after-life; and, if dirt and dust figure in these photographs as natural appurtenances of school life, dirt and dust will come to figure in a similar way in their own homes when they have them. They cannot be expected to have an inborn appreciation and understanding of cleanliness any more than they can be expected to instinctively understand arithmetic or reading. Hence, with that disconcerting 
directness of reasoning which most children display just when it is least required, they are apt, unless it is kept constantly before them by daily example and precept, to refuse to acknowledge cleanliness to be a necessary adjunct to proper living. A third reason for school cleanliness lies in the indisputable fact that it is necessary for the economic upkeep of the school buildings. Organized cleansing operations mean organized measures for the early detection of defects, and hence for remedying these defects before they assume extensive proportions.

Dirt accumulates with remarkable rapidity if allowed to do so, and there are certain parts of the building where it particularly tends to lodge. Being particulate it is of course acted upon by gravity, and hence all horizontal surfaces are especially liable to collect it. The floor is the greatest dirt-collector, as might be expected, and for this reason school floors should be unabsorbent and without cracks for the dirt to lodge in. Attention should always be given to preventing the accumulation of dirt on floors, and to destroying its more dangerous constituents, by daily damp sweeping or swabbing, and by regular scrubbing with soap and hot water with a good, real disinfectant in it. Practically speaking all horizontal surfaces should be similarly treated, and we have already considered the construction of school interiors with a view to their easy and thorough cleansing. If the walls are rough they are liable to collect dirt although they are vertical, and it cannot too often be pointed out that rough absorbent surfaces in a school-room increase enormously the difficulty of proper cleansing. The roof space is a great place for the accumulation of dust and dirt. 
It should be regularly cleaned out when the school is undergoing its periodical overhaul. The need for carrying exit ventilators through the roof space by means of metal shafts, and for rendering ceilings impervious, has been already alluded to. Furniture should of course be cleansed together with the interior, special attention being paid to horizontal (dirt-collecting) surfaces.

School-cleansing operations are divided into the regular routine measures carried out at short intervals, and the more extensive periodic cleansing and overhaul and scouring-out which every school should-and in certain countries and places does-receive once a year at least. The routine sweeping and dusting is, however, of more immediate interest to teachers, and here it is well to remember that there is a time for all things, even for cleansing operations. Cleansing should be carried out after the room is vacated for the day, and not before it is about to be occupied. One of the principal objects of the cleansing is to prevent the children from breathing dangerous dust, and hence all cleansing should be effected by damp methods. Dry dusting and dry sweeping should never be used for a school-room, and more especially they should never be employed in the morning before the room is about to be occupied. Damp cleansing should be the rule, and even damp cleansing should not take place shortly before the rooms are to be occupied. The advantages of damp cleaning over dry cleaning are manifold - it prevents the dust from rising into the air to be rebreathed by the sweeper and others; it collects the dust and allows of its easy removal from the room instead of leaving it to settle again in fresh places; and, if an efficient antiseptic or disinfectant is added to the water or other 
damping agent, it may deal to a considerable extent with infective material which may be-and usually is-present in the dust.

Wherever possible, therefore, a daily rough dampcleansing of school-rooms should be carried out somewhat as follows:-

A sufficient amount of saw-dust is placed in a tub or bucket and thoroughly saturated with an antiseptic solution. Such a one may be made by adding $x / 2$ pint of crude carbolic or two ounces of Cyllin (Disinfectant) to a bucket of soapy water and stirring it well in. It should remain soaking in this for a day. The last thing in the afternoon, the damp saw-dust is freely scattered over the floors, a broom is swirled out in some of the solution, and the floors thoroughly swept, the sawdust with its attached dust being afterwards collected and burnt. A cloth wrung out of the solution should be used to swab over the tops of desks, door-frames, and other wood-work and dust-collecting surfaces. The effect of this upon the sweetness and wholesomeness of the school-room is almost incredible to those who have not tried it. Where punishment detention is employed, organized "cleaning drill" of some such nature as this will be of far more permanent benefit to those unfortunates whose ways lie amongst the "kept in" than will any amount of extra eye-strain in the form of writing or reading.

Once a week, or oftener, all desks and seats should be gone over with a cloth wrung out of a mixture made by stirring $1 / 2$ pint of crude carbolic acid, or a few table-spoonfuls of "Cyllin" and $x / 2$ pint of kerosene, into a bucketful of hot soapy water. This will keep off and 
kill fleas and other insects which live and breed in the cracks. If effected overnight, and the windows left open, the smell will disappear before morning.

All ventilating channels and shafts-where such existshould be cleansed frequently with a mop if their structure permits. If it does not, they are constructed on a wrong principle unless they form part of a system of mechanical supply.

At least once a year every school should receive a thorough cleansing and overhaul. This requires to be effected on organized lines, and need not be further gone into here.

Disinfectants.-Mention has been made of disinfectants, and it will be of service to briefly consider the nature of real disinfectants. The qualification is employed as a protest against the ridiculous and misleading statements which are so often made under an authoritative guise about such substances. Disinfection is a process for killing the living organisms of disease. These organisms are often remarkably tough creatures, and it is by no means correct to conclude that, because a man is much bigger than a bacillus, a quantity of sulphur fumes, for instance, which will make that man exceedingly uncomfortable, or even kill him, will effectually settle the bacillus. There are real disinfectants and imaginary ones, and the imaginary are by far the more common, especially when used according to the directions on the tin or bottle. Some are "deodorants", that is they will destroy or weaken bad smells, but this does not by any means imply that they will kill or even cripple any disease germs which may be present. Others are "antiseptics", that is, they can prevent the growth and multiplication 
of germ-life if applied in sufficient strength for a sufficient time. Very few are "disinfectants", that is, substances capable of certainly killing disease germs when applied in sufficient strength for a sufficient time.

The "disinfecting powders", guaranteed to instantly slay any germ daring to intrude into an apartment in which they are placed, the evil-smelling fluids for use in saucers "to disinfect the air", and the "disinfectant candles" and their like, are each and all utterly useless as safe-guards against disease. Sometimes they replace one bad smell by another, but more often they do nothing at all. In any case they are a waste of money, and if depended upon are actually dangerous by reason of the sense of false security engendered by their use. Common soap, washing-soda, and plenty of hot water make a better disinfectant than four-fifths of the evilsmelling articles in tins and bottles concerning whose allegedly wonderful effects so much is advertised by the philanthropic persons who profit by their sale.

Real Disinfection is another affair altogether. The best of all disinfectants is Heat. Boiling for half an hour will kill any germ that ever existed. Boiling water is an excellent disinfectant. Articles of no value are best destroyed by fire, and all dirt and rubbish swept up in a house or school should be at once burned. A vegetable steamer affords a ready means of applying moist heat in domestic disinfection of small articles from a sick-room, if they cannot stand boiling. Some articles, such as boots, hats, and silks, must be disinfected by dry heat, and this can with care be applied under domestic conditions by putting them into an ordinary oven, heated to a temperature just short of browning cotton, and 
keeping them there for an hour, carefully watching them to avoid scorching, whilst maintaining a proper temperature.

Moist heat-steam or boiling water-is, however, a much more powerful disinfectant than any kind of dry heat, where it can be used without injury.

Next to heat in order of efficiency come Chemical Disinfectants, and they require to be carefully applied if they are to be of real service. One of the best-known chemicals is Carbolic Acid, but it is generally used in too weak a solution to produce much effect. The crude black or brown acid, at a few shillings or so a gallon, is actually better for disinfecting purposes than is the expensive pure article, because it contains certain cresols and other chemical impurities of high disinfectant value. For general cleansing and for drains it should be used in a strength of at least $I$ in 40 -that is, about a table-spoonful to the pint, or rather over $1 / 2$ pint to a 3-gallon bucket. For use after infectious disease, double this strength is necessary-two table-spoonfuls to the pint, or $\mathrm{I} / 4$ pint to the bucket. It should be mixed with hot soapy water-soft soap is the best for the purpose-and well stirred so as to form an emulsion. Articles to be disinfected should be soaked in the $\mathrm{r}$-in-20 solution for eight hours. If it is used hot, a shorter time-two hours-will be sufficient. It should not be put on the face, nor on the tender skins of children.

Chlorinated Lime is a strong disinfectant, but it has the disadvantage of corroding metals and rotting linen and other textile fabrics. It is, however, very useful for scrubbing floors and other wood-work. It should be 
fresh, with a perceptible but not overpowering sharp smell of chlorine gas. It must not be used for underground drains, as it is apt to deposit and block them.

Formalin is a good disinfectant when used in a strength of I part to 19 of water. It is, however, somewhat expensive, and has an irritating odour.

Perchloride of Mercury, or "corrosive sublimate" as it is usually called, is a powerful and cheap disinfectant for wood-work or clothing. It has several drawbacks, however. It is very poisonous, it corrodes metals, and unless made up with an acid it is apt to be rendered inert when mixed with discharges or other animal substances. Hence it has to be made up with an acid, and the general formula used is as follows, the strength being I in 1000:-An ounce of spirits of salt (hydrochloric acid) is mixed with $1 / 2$ pint of water; $1 / 2$ ounce of corrosive sublimate is stirred into this with a stick or glass rod. More water is gradually added until the whole of the corrosive sublimate is dissolved, and the whole mixture is then made up with water to 3 gallons. The mixing must not be done in a metal vessel or it will be corroded. Some aniline blue should be added to prevent accidents. This solution is useful in disinfection after infectious diseases, but is not a good routine school disinfectant for the reasons given. Textile articles to be disinfected should be soaked in the I-in-I000 solution for from six to eight hours, all stains and spots of discharges being previously rubbed over with soap.

When any textile fabric has been soaked in a disinfectant solution it should be well washed in cold water immediately after being taken out, to remove all traces 
of the chemical substance in which it has been soaked.

Many new chemical disinfectants are now on the market. Amongst the best of these are Cyllin, Izal, and Kerol. All of these are much stronger than carbolic acid, and may be confidently used in the manner prescribed in the directions. With the introduction of new and more certain methods of testing the real efficiency of disinfectants these substances have been shown to be relatively much cheaper than carbolic acid, owing to their greater strength.

All disinfectant solutions should be clearly labelled "Poison", and should be kept out of the reach of children.

Fumigation, as generally performed, is of no use whatever. To burn a handful of sulphur on a hot shovel or hot brick is mere waste of time and material if disinfection is aimed at. It is quite useless to attempt to disinfect even the air of a room by "fumigation" with any known chemical, unless every crack and crevice is carefully sealed up in order to retain the fumes for at least eight hours, and unless a sufficient amount of the chemical is employed in a proper manner. Drawers and cupboards must be opened, and bedding, clothes, \&c., hung over lines across the room. In any case far more reliance should be placed on soaking, swabbing, and scrubbing with a disinfectant solution made from one or other of the above substances than upon any so-called "fumigation", no matter what the advertisements say. Sulphur fumigation is practically useless as a disinfectant for ordinary infectious diseases.

Fumigation may, however, be useful in purifying the air and the surface of things in a room where infective 
particles may be suspended in the air, after certain infectious diseases such as scarlet fever, diphtheria, and small-pox. In these cases, however, it must always be followed by disinfection by means of chemical solutions for all surfaces and for furniture, and for textile fabrics where saturated steam is not available. Fumigation may also be required for such articles as books, which will not stand wetting. Books are very difficult to disinfect, and where possible should be burnt if exposed to infection. If this is not feasible they should be hung over lines so as to expose the pages freely, in a large box or cupboard made as air-tight as possible by paper and paste. An Alformant lamp, with twenty tablets of Paraform should be placed in the box or cupboard, and the gas allowed to act for eight hours. This should be repeated in the case of any particularly serious disease such as small-pox.

To disinfect a school-room after diphtheria or other infectious disease is not at all easy, but the following procedure should afford a good chance of success :-

I. Spray over the whole interior-walls, floors, desks, forms, cupboards, black-boards, window and door frames, \&c.-with I-in-2o solution of carbolic acid or formalin made up as above, or with $I$ in 100 of cyllin. If a sprayer of any kind is not obtainable, the solutions may be swabbed on with a mop. All collections of dust should be thoroughly wetted down and removed for burning.

2. Scrub all floors, and the wainscot, cupboards, \&c., to a height of 6 feet, with hot water and plenty of soap, the water containing $1 / 2$ pint of kerosene to the bucketful.

3. Scrub all kindergarten toys with carbolic solution; soak pens, pencils, slates, dusters, blinds, curtains, \&c., in the same for six hours. 
4. Clean out all ventilating channels with a mop soaked in the carbolic solution.

5. Burn all papers and books which can be destroyed. Disinfect other books by formalin as above described. Loose papers written in ink or pencil, or printed, may be disinfected by soaking for a quarter of an hour in a solution of corrosive sublimate in methylated spirit, of strength I in 500 or stronger. Copying ink or copying pencil will "run" under this treatment, but ordinary ink or pencil will not.

6. Leave all doors and windows open, to freely expose the room to the fresh air, for at least twelve hours before reoccupation. It should be remembered that infectious disease may recur in a room owing to the undetected presence of a mild case.

Water-Supply.-The presence of dangerous disease germs in water is not necessarily, or even usually, accompanied by any outward signs of smell or turbidity. There is no sign of danger in the taste or colour of the water. The most dangerous of waters may indeed be clear, sparkling, and palatable. So elusive are diseaseproducing agencies that one thousand gallons of ordinary sewage may be added to every million gallons of a watersupply without the most careful chemist being able to certify that the water is definitely sewage-polluted.

Water may be contaminated in many different ways both before and after it reaches the consumer's premises. If a tank is used for collecting the roof water, the dust and filth deposited during fine weather on the roof and in the gutters is liable to be washed into the tank with the first shower. This dust and filth may be of a dangerous as well as of a disgusting character. Several devices 
have been patented to get rid of the danger arising from this mode of securing a water-supply. For school purposes in the country an adjustable spout is very efficient, and is less likely to get out of order. It may be made by means of an elbow on the downspout, capable of being turned away from the tank opening, and only turned over it after the roof has been washed clean by a smart shower. A piece of canvas hose may be employed, but if used it should be carefully attended to in order to keep it clean. Boiling at intervals, after soaking out dirt in clean water, is the best method of cleansing the canvas hose. The metal elbow is preferable. Tanks should always be covered, and should be regularly cleaned out, as should also the roof gutters. Special attention should be devoted to these where the rain-water collected from the roof is the source of the water-supply.

Wells in inhabited localities are always liable to contamination, particularly by surface soakage, if they are not lined with water-tight material for 20 feet or so down. The drippings from the pump or bucket should never be allowed to flow back into a well or underground tank. Great care must be taken to keep the water in the wells or tanks perfectly pure. The water must never be drawn from either well or tank by dipping a vessel into it. Such a method is sure to foul the supply. Watersupplies brought in pipes are liable to be contaminated, not only at the gathering ground, or catchment area, but in the pipes themselves. Seldom or never, except in particularly well managed cities or towns, can they be taken for granted as being safe. If leaks or cracks in the pipes exist, foul matter may be sucked in from the ground when the pipe is running, or when a main is turned off 
below. It may also be sucked in through taps or fireplugs if these be improperly placed.

For these and other reasons drinking-water should always be either boiled, or filtered through a Real Filter. Real filters are rarer even than real disinfectants. The bogus varieties - which include all "dripstones", "charcoal filters", and their kind-are direct invitations to disease. Instead of excluding dangerous contaminatory matters, these bogus filters retain most of it and spread it out over a week's or a month's supply, whilst enabling its bacterial contents to grow and increase in virulency. It is preferable to have no filter at all rather than to depend on one of these dangerous frauds.

The surest method of rendering drinking-water safe is to boil it for a few minutes and to store it in a clean vessel which has been well scalded out and is protected from dust and flies. Distilled water similarly treated is of course equally safe. The flat taste may be remedied by shaking the boiled or distilled water vigorously with air in a large bottle or can. The palatability of distilled water may be greatly improved by adding for each gallon about 2 grains of bicarbonate of soda dissolved in a tea-spoonful of water containing two drops of pure hydrochloric acid. A day's supply can be boiled overnight and set aside in a well-scalded covered jug or can in a cool place.

A Pasteur-Chamberland filter forms the next best safeguard for ordinary use. The filtering material is a special kind of porcelain. These filters are worked most satisfactorily by pressure either from a pump or a piped supply. Another good and safe pressure filter is the Jeffery, made in Melbourne (Australia). Pasteur-Cham- 
berland and Jeffery filters can be obtained in "batteries" up to any required capacity, are cheap, and are strong and durable. As is the case with all filters, they require to be regularly cleaned and examined for cracks and faults in the "candle" (as the filtering medium is termed) or at its junction with the metal fittings. Nonpressure forms are on the market, but although effective they are slow in action. The Berkefeld filter has been widely advertised, but experience shows that these filters are fragile and require to be very carefully cleaned at least every second day. The cleaning rapidly destroys the filtering material.

After water is filtered it should be kept in clean vessels, protected by a cover from dust and flies, and drawn off as required by a tap or clean "oil pump".

Drinking-cups, if used in common, may spread diphtheria and other infectious diseases. If possible each child should be made to bring its own drinkingvessel to school. If a common vessel must be used, it should be well scalded out every day, but it is safer to avoid it altogether for school use.

\section{CHAPTER VI}

SANITARY ACCOMMODATION, DRAINAGE, AND REFUSE DISPOSAL

Wherever human beings are gathered together in any number, the safe and proper disposal of the decomposable refuse produced by them becomes an important question if their health is to be maintained. 
The frightful pestilences that ravaged mediæval Europe were almost wholly due to the failure of our ancestors to recognize this; and even at the present day, troublesome and fatal diseases are allowed to flourish in many parts of the world by reason of the ignorance of the people with regard to this subject, and of their indifference and laziness. It is not only the body refuse that has to be considered. The household refuse and other decomposable waste which civilized man produces in large quantities, through his methods of living, is also capable of causing great discomfort and annoyance, and even of becoming a danger. The body refuse is, however, the most important, and both for sanitary and æsthetic reasons it is worth while taking a good deal of trouble to dispose of it in a cleanly and satisfactory manner. Particularly is this the case in schools, where a large number of those who are most susceptible to filth diseases are not only compulsorily gathered together, but are there for the specific purpose of being instructed in the principles and practice of citizenship and of self-development. If sanitary matters are neglected at school, and the children have put before them an example of carelessness and neglect of this most important business, the immediate result is to send out future citizens with a school-taught standard of dirt and carelessness by which to regulate their after-life.

Too often has one heard teachers in country schools plaintively enquire: "What can I do? There are no drains." The answer to this is that the majority of such schools are better without underground drains, and that, in the absence of a well-designed and wellconstructed sewerage system, covered drains are often 
dangerous. "Out of sight, out of mind" is a proverb frequently illustrated in connection with drainage, and on investigation it is only too often found possible to add an unauthorized but very evident corollary, "but in the drinking-water and under the floor". Wherever sewage is diluted with water, and conveyed in pipes underground, the "striking distance" of any infection contained in it is very greatly increased if it escapes from the pipes. Hence all such systems require to be scientifically constructed in all parts, and looked after with very great care if they are to remain safe. It is not intended to here discuss in detail the requirements necessary for a safe and satisfactory water-carriage system for schools, and teachers desiring to go into the subject should procure one of the special works dealing with it.

Effective and wholesome sanitary accommodation is perfectly possible in the absence of deep drainage and water-closets, provided that common sense and ordinary care and precaution are exercised in its construction and management. Such accommodation should be adequate in amount-one closet seat for every twenty-five boys, and one for every fifteen girls is the usual standard. It should be erected well away - at least 30 feet-from the school building, and should be properly screened. It should not, however, be placed at an excessive distance from the building; as, for obvious reasons, this may lead, in wet weather, to damage to the health of the children. Closets for different sexes should be well apart, and their entrances widely separated by a fence. The height of the seat should never be greater than I 5 inches from the floor, and for young children this 
should be reduced to 12 inches by a broad step. This is important, as children are very apt to "rupture" themselves when using a closet seat which is too high. It should be remembered that such places may be the source of moral as well as physical contamination. They should be frequently inspected, and the necessity for decency and cleanliness in their use should be systematically inculcated, without false shame or concealment.

The most satisfactory kind of school closet for nonsewered localities is that generally known as the Dryearth Pan-Closet, where a metal receptacle is used to receive the excreta, and earth is regularly added to deodorize and humefy the contents. The construction of this form of closet is important, but, as this does not affect the ordinary teacher so much as the management does, it may be sufficient here if it be briefly summed up as follows:-

r. The space beneath the seat should be floored with some impervious and easily-cleaned material, such as faced and tarred concrete, or lead, turned up at the front and sides to prevent leakages from getting forward under the floor.

2. The pan should fit the space so that its outside and the floor of the space will not be soiled when the closet is in use. The top of the pan should not be more than I $1 / 2$ inch below the under surface of the seat, and should be large enough to project well in front of and behind the seat aperture. Wooden guides should be screwed to the under surface of the seat to ensure that it will be replaced in proper position.

3. The space under the seat should be ventilated, and 
there should be a door at the back or side for removing the pan.

4. A box and scoop should be provided for the earth.

With good management a closet so constructed may be made almost as safe and wholesome as the best of water-closets. Bad smells and danger to those using such closets are due to: fouling of the outside by leakage, overflow, bad placing of the pan, or neglect to use earth or other deodorant.

Good management implies:

I. Daily inspection to ensure that the supply of earth or other deodorant is properly maintained and used, and that fouling of the outside is not taking place.

2. Arrangements for frequent removal and proper disposal of the contents.

The best earth to use is garden mould, but any loamy surface-earth will give good results. Surface-earth is required because that taken from a greater depth does not contain the micro-organisms necessary for the work of deodorization and humefaction. For the sake of these micro-organisms the earth must never be baked or heated to dry it. A supply should be kept stored in a shed or covered box to protect it from the rain, and the closet earth-box filled from this as required. A metal scoop should be provided for its application. If the children cannot be depended upon for its proper use a daily covering of the pan contents should be effected at the close of the day by a teacher or other responsible person. Where suitable earth is not obtainable, sifted ashes or saw-dust may be made to serve.

The difficulty so often met with in earth-closets for girls may be got over by providing a saw-dust urinal fitted 
with seats. Even if a mistake is occasionally made in its use, it can be readily set right.

Regular removal is sometines difficult to secure, but every effort should be made to have the pan contents removed and properly disposed of at least once or twice a week. The inside of the pan should be washed before replacing, and if possible tarred. The tarring increases its working life, and removes odour. The bottom of the pan, and the sides for some 6 inches up, should also be tarred, once every three months-standing the pan in hot tar is the best method of doing this.

The contents should never be disposed of in any place where they can contaminate a water-supply, or otherwise give rise to danger. If buried they should be placed in a trench about 8 inches deep and covered with from 4 to 6 inches of clean earth. Contractors should not be allowed to bury the material just behind the closet, or in the playground, as is sometimes done in country places. Deep burial is not required. The nitrifying organisms of the earth live near the surface, and deep burial has been well described by Dr. G. V. Poore as "putting the dog's bone under the kennel instead of in it".

In hot climates a daily removal of the contents of the closet may be required. Under such conditions it may also be advisable to dispose of the material otherwise than by burial. If saw-dust is used in the pan, the contents may be mixed with kerosene or tar and burned. Where the removal is irregular, or uncertain, much nuisance and danger may often be avoided by using pans with removable lids which can be clamped down so as to hermetically seal the receptacle. These pans can be removed when full, and kept covered, a spare pan being 
put in the place of the removed one. Several patterns of covered pans have been patented, but where one of these cannot be obtained, any good tinsmith can contrive a suitable pan.

Cess-pools and Privy Vaults.-Generally speaking these receptacles for excretal matter are as dangerous as they are unæsthetic, and should be got rid of from schools wherever possible. Unless made water-tight they contaminate the ground water, and are therefore a serious source of danger to the neighbourhood as well as a bad example to the children. Where it is impossible to secure a pan service, however, and no water-carriage facilities exist, a cess-pool or privy vault may be the only feasible alternative. In all cases such a receptacle should be solidly constructed in brick or stone and thickly cemented on all interior surfaces, the corners being filled in to facilitate cleaning.

The cement lining should be given several coats of tar when dry, to render it water-tight. Endeavour should be made to keep out liquids as much as possible, by the use of a saw-dust urinal as hereafter described. A liberal supply of dry earth should be sprinkled over the surface of the contents at the close of each day, and it should be emptied at intervals of not more than three months. Where a cess-pool or privy vault is replaced by some more hygienic arrangement, it should be thoroughly cleaned out, the interior being liberally covered with chloride of lime, and then it should be filled up with clean earth. A new site should be chosen for the accommodation which is to replace it.

It should always be clearly remembered that all forms of closet other than water-closets are wholly dependent 
for satisfactory and safe results upon the dryness and regular humefaction of their contents. Deodorants and the so-called "disinfectants" should not be employed in connection with them, as these substances merely serve to conceal dangerous conditions. With good management deodorants should not be required.

Urinals.-In the absence of a constant water-supply, and a system of sewerage, urinals are apt to become a dangerous nuisance, especially in hot weather. Typhoid fever is exceedingly likely to be spread by defective urinal arrangements, as the specific bacteria are often present for many months in the urine of convalescents from this disease. If a channel is used it should be made of impervious and non-corrodible material, such as well-baked earthenware, and should have a special flush tank for cleaning it. Where these are not obtainable a saw-dust or dry-earth urinal will give excellent results if properly constructed and managed.

In its simplest form this consists of a wooden trough, triangular in section, about 18 inches deep and 20 inches wide at the top. The length depends on the number of boys using it-about I foot run should be allowed for every twelve boys, with a minimum of 4 feet. When set up it should be sloped to one end, a pipe leading from its bottom to a pit or short trench full of stones, to give drainage. The trough should then be filled with clean fresh saw-dust; but if saw-dust cannot be obtained, dry loamy surface earth may be used. It is essential to provide a roof to keep out the rain, as the urinal depends mainly upon evaporation for its results, and will not work if allowed to grow sodden. A movable cover of galvanized wire netting over the top of the trough is 
useful for preventing mischievous meddling with the saw-dust or earth. The trough may be made of any rough wood, and need not be closely jointed except at the bottom, where the sides meet. An improved form of trough consists of wooden frames panelled with perforated zinc to give it greater evaporating powers. For large schools this form of urinal may be made double the width mentioned above, with a well-painted matchboard partition run up in the centre to enable it to be used from both sides. A similar urinal, fitted with seats, will be found useful in girls' closets on the earth system.

The effluent from such a urinal is surprisingly small in amount and will not decompose when exposed to the air. Once a week the surface should be raked over to a depth of a few inches. One filling will last under ordinary conditions for over a year, and if removed at the commencement of the summer holidays, and spread out for a week or two in an open shed in order to thoroughly dry and air it, one filling may be made to serve for several years.

Pipes and drains from school lavatories may give rise to unpleasantness, and even become dangerous, owing to the mixture of soap and organic matter which adheres to the interior and there decomposes. These pipes should be frequently flushed down, especially in hot weather, with a bucketful of hot water in which has been dissolved a handful of washing-soda. Where the oldfashioned tipping basins are used, their metal receivers should be scrubbed with the same solution and some good antiseptic, and the basins cleaned with a disinfectant. Even a short length of piping may produce a serious nuisance if not regularly attended to. In private 
houses the kitchen-sink pipe is apt to be responsible for a most abominable odour, owing to the lining of soap and grease which it quickly acquires if not properly flushed. The mixture of soap-suds and urine which constitutes the ordinary domestic "slops" is particularly offensive when allowed to deposit in this way on the interior of an untrapped pipe, such as a sink-waste.

In country schools where a sufficient area of fairly porous ground is available, a filtration gutter may be used to dispose of waste water. Where the teacher resides at the school, this device may also prove useful for getting rid of the bath water, household slops, and kitchen liquids. It is constructed as follows:-A trench 18 inches deep and from 15 to 18 inches wide is dug in a suitable position at a sufficient distance from the buildings to be served. A length of 12 feet will usually serve for an ordinary house, or for the lavatory waste of the largest country school. The trench is filled in to about 2 inches from the top with some such material as broken stones, slag, broken bricks, or, if nothing better can be obtained, with broken bottles or tins which have been hammered down. Whatever is used must be non-decomposable and capable of allowing free percolation between the pieces. The filling must not of course be rammed. A piece of corrugated galvanized iron is perforated with numerous holes, punched in the bottoms of the corrugations, where it is to cover the trench, each hole being about $1 / 8$ inch in diameter. The iron should be sufficiently long and wide to cover the whole trench, and to rest on the ground for an inch or two on each side. Its purpose is to keep leaves and other solid substances out of the trench and to spread 
the liquids. A 6-inch weather-board should then be supported on edge with pegs along each side, and the earth heaped up against it on the outside.

The liquids to be disposed of are brought to the filtration gutter by an open channel made of earthenware halfpipes set in cement, or even of well-tarred wood if these or other suitable materials cannot be obtained. The channel should have a proper fall of at least $1 / 2$ inch to the foot in all parts of its course. If the kitchen-waste is to be here disposed of, a strainer made of half a kerosene tin or other metal receptacle, with holes punched in the bottom, and containing some straw, should be placed under the outlet of the sink-pipe in order to keep back pieces of fat, vegetable-parings, and other solid matters. The straw should be renewed every few days, and in hot weather daily, the old straw being burned or buried. If the sink-pipe is flushed with hot water or disinfectants, as above described, care should be taken to divert the flushings from the filtration gutter.

When properly constructed and managed such a filtration gutter will give excellent results in temperate and sub-tropical climates. Shrubs may with advantage be planted along the sides at a distance of a few feet, in order to conceal it and to assist in securing an open subsoil. The points to be remembered in construction are:-I. The ground must be fairly open; absorbent gravel or loose loam are the best soils for the purpose. 2. Solid substances must be carefully excluded. 3. The channel must be open and requires to be kept well scrubbed down with water-disinfectants must not be used. 4. It must not be placed so as to drain to a tank or well, or under a building, 
and should be at least 30 feet away from the house or school-room.

House refuse in the solid form is of two principal kinds-that which will rot, and that which will not. The first kind (decomposable refuse) is the more troublesome to dispose of, but may be utilized in several ways. In country schools fowls and pigs (if permitted to be kept) afford a profitable means of disposal for kitchen scraps and the school lunch-remnants. Pigs may be kept in perfectly cleanly fashion if the sties are well constructed and managed. Tea-leaves may be kept for use in sweeping the floors. All decomposable refuse which cannot be usefully disposed of should be burned or buried daily. An excellent way is to make a couple of circles of wire netting about 3 feet in diameter and the same in height, supported on stakes, and to throw into one all decomposable refuse, covering it at once with a sprinkling of clean earth. When full it should be allowed to sink and "ripen", and in a couple of months will be found to consist principally of garden mould. It should then be sieved and any remaining fragments burned or buried. The mould so obtained is excellent for potting plants. One circle should be filling whilst the other is ripening.

If none of these methods is possible, decomposable refuse should be regularly burned. That from the kitchen may be conveniently disposed of by a removable sheetiron box, placed in the stove-pipe or hung in the chimney. The contents are rapidly carbonized and rendered inoffensive by the heated air. The box should be perforated at the sides and open at the top.

Non-decomposable refuse should be burned wherever possible. Dry bones burn well, but are very durable if 
buried. Tins, if hammered down, make excellent foundations for a garden path, as does broken glass. Tins are useful in many other ways, however, and with holes punched in their bottoms form good pots for school plants.

Many of the suggestions given above were first made by the late Dr. G. V. Poore, and two excellent little works on domestic sanitation are amongst his many writings. Although the author cannot agree with many of Dr. Poore's views on the water-carriage removal of sewage, he can vouch for the great practical utility of the saw-dust urinal and filtration gutter.

\section{CHAPTER VII}

\section{DISEASES OF SCHOOL LIFE}

Certain diseases are of considerable importance in relation to school life, and amongst these the communicable diseases occupy a foremost place. This class includes those formerly termed "infectious" and "contagious", and comprises all diseases which can be communicated to others. Schools play an important part in spreading many of these diseases, particularly diphtheria, and it is therefore advisable that teachers should possess some accurate knowledge of what causes them, of the signs by which they may be detected, and of how they spread. Such knowledge does not imply the acquirement of a large amount of technical medical skill, verbal or uther, but rather the acquisition of such 
an amount of knowledge as shall enable the teacher to take proper precautions to prevent the school from becoming a centre for spreading the disease.

It is probable that all communicable diseases depend upon the introduction into the body, or into particular parts of the body, and the growth there, of certain minute forms of life, principally bacteria, but in some cases yeasts and moulds. Of many diseases, including tuberculosis, diphtheria, and typhoid fever, the actual germ is known, but in others, such as small-pox and scarlet fever, the germ or living cause has not yet been ascertained with certainty. It is important to recognize this germ origin of communicable diseases, because it at once indicates two important things: first, that dirt, darkness, and "stuffiness" encourage communicable disease because they encourage the growth of the tiny organisms which give rise to it; and, second, that only those agencies which will kill out these organisms will kill out the diseases to which they give rise. As has already been pointed out under disinfection, most of these little organisms are difficult to reach, and extremely tenacious of life when they are reached.

Improper construction and insufficient cleansing may therefore render a school a more or less constant centre for the spread of disease through a whole district. Even if the conditions as to structure and cleansing are all they should be, the risk does not disappear, although it will have been considerably diminished. One infectious child in a clean well-constructed school may infect many others by contact or propinquity, whether by its person or by its clothes. The teacher, therefore, requires to be constantly on the look-out for signs of communicable 
disease, and to this end a daily "head and hand drill" proves of great service. Such daily drill secures, in addition, the æsthetic and sanitary advantages of clean hands and faces and tidy clothing. Wherever possible a medical certificate should be obtained before a child is readmitted after suffering from any communicable disease, and the clothing of other children from the same house should be certified to as having undergone proper disinfection.

The evil springing from communicable diseases is not confined to the immediate risks to life, or to the upsetting of school work produced by an extensive outbreak. The after results of these diseases are often very serious, either by reason of the actual damage to the system caused by them, or from the condition of lowered powers of resistance to the assaults of disease-producing germs which enables some other serious disease to get a hold on the system. Scarlet fever often gives rise to persistent ear disease of a most dangerous character, and it may also cause serious kidney disease. Measles may work serious damage to the eyes or to the ears; and an attack of measles seems to have a special faculty for enabling tuberculosis to get a foothold afterwards, either as consumption of the lungs or as hip disease, or as spinal disease, which may deform and cripple the child for life. Whooping-cough throws a tremendous strain on the heart, and may permanently damage it. Diphtheria may leave permanent heart mischief behind it, or a serious form of paralysis. There is no necessity for any child to have these diseases, and the pernicious theory that they were bound to have them, and that "they had better get it over", is being knocked out of existence, to the great benefit of all concerned. 
When disease germs gain admission to the body they do not set up disease at once. In many-perhaps in most-cases they do not grow at all on their first introduction, but are killed off by the resisting tissues. If not so killed they take a certain time, more or less constant for each disease, to produce their effect. The process is very similar to that which occurs when bread is made with yeast, and this is not at all surprising, because yeasts are closely related to bacteria. The act of infection corresponds to putting in the yeast, the incubation period to the time elapsing before it works, the onset of the symptoms to the "working", and the natural cessation or decline of the disease at a particular time to the death of the yeast either from the products of its own action or from heat. Incubation periods are distinctly important in relation to school disease, and they may be briefly summarized as follows for the more important communicable diseases.

The table on p. 82 tells us that if a case of scarlet fever turns up in a school, the infection has probably been received from three to five days before, possibly at any period between one and eight days before, and that it will be at least six weeks before that particular child can be safely readmitted. Other children in the same house require to be excluded for ten days after last exposure to infection. If effective isolation at the home is impossible (as it usually is in working-class homes) they should be excluded for at least as long as the sick child, unless it is definitely known that they have had scarlet fever. If fresh cases are going to occur, they will probably show up within the next five days. If no cases occur for eight full days after the last attendance of the sick child, or of others from 


\section{INCUBATION AND QUARANTINE PERIODS}

\begin{tabular}{|c|c|c|c|}
\hline Disease & $\begin{array}{l}\text { Incubation } \\
\text { Period }\end{array}$ & $\begin{array}{l}\text { Quarantine } \\
\text { required after } \\
\text { last exposure }\end{array}$ & $\begin{array}{l}\text { Period after which sufferers } \\
\text { may be safely readmitted }\end{array}$ \\
\hline $\begin{array}{l}\text { Scarlet } \\
\text { Fever }\end{array}$ & $\begin{array}{l}\text { I to } 8 \text { days, } \\
\text { usually } 3 \text { to } \\
5\end{array}$ & Io days & $\begin{array}{l}\text { When all traces of peeling, } \\
\text { skin-cracks, discharge from } \\
\text { ears, nose, or eyes, have } \\
\text { disappeared, but never less } \\
\text { than } 6 \text { weeks. }\end{array}$ \\
\hline Diphtheria & $\begin{array}{l}2 \text { to ro days, } \\
\text { usually } 2 \text { to } \\
4\end{array}$ & I2 days & $\begin{array}{l}\text { Never less than } 6 \text { weeks; not } \\
\text { then if any discharge from } \\
\text { throat, ear, eyes, or nose, } \\
\text { or if child is not fully re- } \\
\text { covered or is pallid. Best } \\
\text { indication is by a negative } \\
\text { result in three consecutive } \\
\text { bacteriological examina- } \\
\text { tions of "swabs" from } \\
\text { throat. }\end{array}$ \\
\hline Measles & $\begin{array}{l}7 \text { to } 14 \text { days, } \\
\text { usually I2 } \\
\text { to } \mathrm{I}_{4}\end{array}$ & I6 days & $\begin{array}{l}\text { After all throat, ear, nose, } \\
\text { and eyedischarge has ceased } \\
\text { and skin is quite clear. Not } \\
\text { less than } 4 \text { weeks. }\end{array}$ \\
\hline $\begin{array}{l}\text { Typhoid } \\
\text { Fever }\end{array}$ & $\begin{array}{l}7 \text { to } 2 x \text { days, } \\
\text { usually ro } \\
\text { to } \mathrm{r}_{4}\end{array}$ & - & $\begin{array}{l}\text { At least } 4 \text { weeks, but varies } \\
\text { greatly. }\end{array}$ \\
\hline $\begin{array}{l}\text { Whooping- } \\
\text { cough }\end{array}$ & 7 to 14 days & 21 days & $\begin{array}{l}2 \text { weeks after termination of } \\
\text { "whooping". Not less } \\
\text { than } 5 \text { weeks from begin- } \\
\text { ning of "whooping". }\end{array}$ \\
\hline Mumps & ro to 22 days & 24 days & $\begin{array}{l}\text { I week after all pain and } \\
\text { swelling have disappeared. } \\
\text { Never less than } 3 \text { weeks. }\end{array}$ \\
\hline Ringworm & & & $\begin{array}{l}\text { After disappearance of all } \\
\text { "scurfiness" and broken- } \\
\text { off diseased hairs. }\end{array}$ \\
\hline Small-pox & $\begin{array}{c}6 \text { to } 19 \text { days, } \\
\text { usually } \mathbf{2}\end{array}$ & $\begin{array}{l}\text { 2I days. } \\
\text { Varies ac- } \\
\text { cording to } \\
\text { degree of } \\
\text { vaccinal } \\
\text { protection. }\end{array}$ & $\begin{array}{l}\text { When every scab and scale } \\
\text { has disappeared from skin, } \\
\text { scalp, under nails, soles, } \\
\text { palms, and elsewhere. }\end{array}$ \\
\hline
\end{tabular}


the same family, it may be reasonably concluded that scarlet fever from that particular source is not going to spread. Finally, it is advisable to keep a watchful eye on the school for eight days (and particularly on the third day) after the return of the sufferer or of other children from the same house. The necessary details for other communicable diseases may be easily worked out from the table. Exclusion of others from the same house is not usually required in the case of typhoid fever.

The absence in many colonial and rural localities of any effective arrangements for municipal disinfection after communicable disease renders the question of readmission a very difficult one. Teachers can often obtain useful assistance from a chat with a friendly doctor, especially if he happens to be the Medical Officer of Health for the district. In most places certain of the communicable diseases are recognized by the law, and teachers will find it useful to possess at least an elementary knowledge of the local health legislation regarding these diseases.

It should never be forgotten that any of the communicable diseases may assume a mild or a dangerous form, and that mild cases are capable of giving rise to severe ones.

Diphtheria is one of the most important of school diseases. It is caused by a particular kind of bacillus which gains access to the throat either by the air (wherein it is suspended in tiny drops coughed up by a sufferer, or attached to particles of dust), or from pencils, slates, drinking-mugs, or other articles on which it has been deposited. The disease is spread by bacilli coming from the throat, nose, or mouth of somebody else, either directly or indirectly, and the old loose method whereby 
the disease was ascribed of necessity to the nearest "drain", has now been replaced by a systematic search for children with "sore throats", and their exclusion when found. Drains should of course be overhauled on the appearance of diphtheria in a school; but far more success is to be expected from the exclusion of "sore throats", however slight; from the prevention of the use in common of slates and pencils, and drinking-mugs, and from the systematic cleansing and disinfection of the school-room, the furniture, and the offices whenever this disease is known to be in a locality. If not properly dealt with, the bacteria may remain virulent for many months in dust on books, clothing, or walls.

In an ordinary case diphtheria begins after an incubation period of two or three days, with shivering and sore throat. The child is tired and languid, and often complains of headache. On looking at the throat the entrance looks as if some dirty white paint had been smeared about its upper part. This is the stage at which the teacher will usually come across an average case. It is necessary to be careful in examining cases of sore throat in children, lest they cough or splutter in the examiner's face. This can usually be avoided by holding a handkerchief in the hand ready to stop any particles of saliva. The handkerchief should be boiled or soaked in a disinfectant immediately afterwards, together with any spoon or other article with which the tongue has been depressed, and the hands washed in a disinfectant. The slate, pencils, books, and other school outfit of the sufferer should at once be secured for disinfection.

Children with diphtheria should be excluded, together 
with all others from the same house, until a medical certificate of freedom from infection is brought. At least six weeks must elapse before the patient is allowed to return.

As with other diseases of this class, diphtheria may assume a very mild form, which is quite as dangerous to others as the most severe forms. These cases are highly dangerous in a school, and, together with those in which the bacillus is found without any appearance of disease, are often termed "carrier cases". There is no eruption in diphtheria.

Scarlet Fever is a highly communicable disease, and the infection from it is particularly difficult to kill out. Of recent years the type of this disease has become milder, but there is no guarantee that this mildness will continue, and an outbreak of malignant scarlet fever is a very serious affair indeed. In most parts of the world children of from five to six years of age are most liable to it, and the probability of infection lessens year by year after this age. It is usually spread by inhalation, but milk food-stuffs, toys, and milk may carry it. It is infectious from the very beginning of the symptoms and before the appearance of the rash. Mild cases often occur and may be so slight that the child attends school throughout, without even the peeling of the skin being recognized. This is a frequent cause of a widespread outbreak.

Scarlet fever generally begins suddenly, about three days after exposure to the infection. The three principal symptoms at first are sore throat, headache, and vomiting. The child is flushed and weary, the tongue is coated, and the breath bad. The eruption does 
not generally appear for about twenty-four hours after these symptoms begin, and the teacher will generally see only the foregoing manifestations. The characteristic peeling of the skin begins in about a week, and may last for many weeks, or even for months. Cracks in the skin behind the ears and about the mouth and nose often appear during the peeling. These cracks are very infective. Discharge from the nose of those who have had the fever often persists for long, and is also very infectious. When scarlet fever is about, a careful lookout should be kept for peeling on the hands, wrists, and feet, and for children returning to school after a short absence with any appearance of nose discharge, skin cracks, peeling of the wrists or neck, or pallor of the face. Kidney disease often follows scarlet fever, and is shown by the swelling of the face or feet.

In Measles the eruption does not come out for some four days after the symptoms begin and the infection has become pronounced. This renders measles a very difficult disease to deal with in schools, and especially in the infant division, where the likelihood of infection and the probability of serious consequences are greatest. The child is feverish, suffers from headache, and after the first day begins to sneeze and to develop the signs of a bad cold. These marked catarrhal signs about the eyes and nose are very significant when measles is about. After some four days of this the rash comes out, but by this time the child has generally been withdrawn from school.

When dealing with an outbreak of measles it is a good plan to keep on excluding sufferers and house-contacts until the attendance falls to $5^{\circ}$ per cent of the average. 
The school is then reopened on a contact basis, only the children from non-infected houses who have themselves not had measles being excluded. One attack is generally protective, so that children who are known to have already had measles need not be excluded at all. The progress of the infection in a new outbreak is generally so rapid that the above plan will be found to result in a minimum loss of attendance. The school should be well cleansed and aired before the non-immunes are readmitted.

It is particularly amongst the youngest children that measles is to be feared, and the occurrence of two or three cases in an infant class justifies the closing of this department of the school. In certain localities where measles has been introduced for the first time it has caused a frightful mortality. A recent outbreak in Fiji killed over 1800 persons, and a previous one killed many thousands, depopulating whole islands in the South Pacific. Measles seldom kills by itself amongst European people, but is especially prone to give rise to serious after-effects and complications, chief amongst which are bronchitis, pneumonia, and tuberculosis.

German Measles is a communicable disease which varies widely in severity. It begins like measles but with much less catarrh. An important sign in it is the enlargement and hardening of the glands behind and under the ear. It is not in itself very serious, but may be followed by tuberculous disease of the glands in the neck or elsewhere.

Whooping-cough is another disease of much importance amongst the younger children, and is insidious in its onset. In most temperate climates it causes more 
deaths amongst children than do the last four diseases put together. The child is feverish, and appears to have a "cold", with discharge from the nose, sneezing, watering of the eyes, and slight headache. These may persist for several weeks before the "whoop" begins, or the latter may not show up at all. As a rule, however, the characteristic crowing "back-draught" after a fit of expiratory coughing appears in a week or two. The child is infectious from the time the preliminary "cold" begins.

Typhoid fever (which is identical with Enteric Fever) is not often seen amongst school children except when the infection is conveyed by contaminated milk. Headache, feverishness, bleeding from the nose, and steadily increasing lassitude and heaviness are amongst the more usual symptoms. Typhoid fever is caused by the entry to the digestive system of the specific bacteria of the disease, cast off in the discharges of some previous sufferer. Water, milk, and food are the principal carriers, and, when the disease is about, special care should be taken to safeguard the school water-supply by filtration or boiling. Flies frequently carry infective material from closets on their feet and deposit it on food or in water or milk. This is no surmise, but a proved fact. The same thing occurs with cholera, dysentery, and infantile diarrhœa.

Mumps is a very actively communicable disease, and may lead to serious complications. The incubation period is strikingly long - up to at least twenty-two days. The child is feverish, and often suffers from headache and vomiting. In a few hours the jaw on one side becomes stiff and painful. Soon this part begins to swell, giving 
the face a curious lopsided appearance. Tenderness in the hollow beneath the ear is marked. The swelling may extend to the neck. Mild attacks are frequent, with little swelling or pain. They are quite as infectious as severe ones. Contacts need not be excluded.

Chicken-pox is very seldom at all serious amongst healthy children, but is of some importance because of its similarity to small-pox. It is sometimes a matter of very great difficulty for even an expert medical observer to distinguish between the eruptions of these two diseases, and when small-pox is about, teachers should draw attention in the proper quarter to any eruption of pimples or blisters in any child. Chicken-pox is extremely communicable, and disinfection, if undertaken for it, should be therefore of the most thorough description.

Small-pox rarely occurs amongst school children, but when it does, the consequences to the unvaccinated and incompletely vaccinated are of the most serious description. On October 27, 1904, a teacher in a school at Commonside, Ossett (England), noticed a girl aged I I with a suspicious rash on the hands and face. The Medical Officer of Health was called in and diagnosed small-pox. The child was removed to hospital; disinfection, vaccination of contacts, and all other precautionary measures were put in hand at once; but, as events showed, the infection had already been sown. In the infected child's class there were 27 children, from 9 to I3 years of age. 6 had been vaccinated and revaccinated before the infection, and I 3 had been vaccinated in infancy only. All these vaccinated children escaped. 8 were unvaccinated, and every one of them developed small-pox. In addition to these there were 42 
other children in the same large room, 8 of whom had been vaccinated and revaccinated, and 20 vaccinated only in infancy. All the revaccinated escaped; of those vaccinated only in infancy 5 took the disease and all were over I I years of age. I 4 were unvaccinated and of them no less than 12 went down with small-pox, only 2 escaping. In another room there were 74 children, $3 \mathrm{I}$ vaccinated and 43 unvaccinated. None of the vaccinated suffered, but I 3 of the unvaccinated took the disease. In a third room were 26 children from 6 to 9 years of age, whose chances of mixing with the scholars of the first room was very small. I4 were vaccinated and I 2 unvaccinated. All the vaccinated escaped, but 4 of the unvaccinated took small-pox.

This is no isolated instance of the protective effects of vaccination, and other equally striking examples could be cited. In Germany and some other European countries small-pox has been wiped out of existence by vaccination in infancy and revaccination at the age of twelve to fourteen. To such an extent is this the case that when the doctors in Germany wish to study small-pox they have to come to England, where people are still at liberty to perpetuate the disease in themselves and their innocent children by pleading a "conscientious objection" to vaccination. It will serve to show, however, that vaccination does protect against small-pox when properly done, and that revaccination is necessary for complete protection of children over ten. The subsequent history of the cases in the outbreak in question once more proved the well-known fact, that even where the protective effect has worn away through the lapse of time, the seriousness of the disease is for long periods very much lessened. 
Teachers will do well to take no notice in their official capacities of the arguments of those who set themselves up to resist vaccination, but to use every endeavour to promote vaccination and revaccination amongst the children under their charge, particularly if small-pox is known or suspected to be in the locality. Whatever contrary views they may choose to hold privately the responsibility is too great for these to be practically applied, excepting to themselves and their own families.

Sometimes the preliminary fever and other symptoms of small-pox are very slight, even in cases which afterwards prove severe, and when the disease is known to be about the teacher should every day carefully examine the faces and wrists of children. If any pimples are found on the face or wrists (and particularly, hard little shotty ones on the forehead) the child should be promptly reported for medical examination, and enquiry meanwhile made for contacts. At such times all children returning to school, after any considerable absence on account of illness, should be carefully inspected for small dark scabs under the skin of the palms and under the nails. The scalp should also be looked at for scabs or crusts. All these are very significant of small-pox and are evidences of virulent infectivity if the child has been suffering from it.

Pediculosis (Lousiness) arises from the presence of small insects, which live in the hair or clothes and suck blood through the skin. Three kinds exist, the head, body, and pubic lice. The head louse is often found in the long hair of girls, and may be detected by its eggs ("nits"), which resemble tiny white figs, each firmly attached to a hair. Unlike "scurf" they cannot be brushed 
off. The body louse produces considerable irritation and leaves red marks where it bites. These are brighter coloured than flea-bites and have not the central puncture. The insect can generally be found on investigation in the breast or neckband of the underclothing. It is white, but often has a central dark spot due to the blood in its stomach. Pubic lice ("crabs") are seldom found in school children, for obvious reasons.

For head lice the hair should be well combed with a fine-tooth comb dipped in vinegar to kill the "nits". The head should then be well washed and dried, and a mixture of olive-oil and kerosene rubbed well in to the roots of the hair and left for several hours. The hair should then be washed again. This procedure should be repeated every alternate day for a week. The cap or hat should be boiled or burned, and the coat collar ironed with a hot iron.

For body lice the child should receive a hot bath with carbolic soap, and the underclothing should be boiled. The remaining clothing should be ironed or boiled.

The presence of lousy children in a school cannot be accepted with equanimity by any self-respecting teacher. Their cleansing is often a matter of great difficulty, requiring much tact in managing parents, but it should always be attempted and never neglected. A daily inspection of heads at morning assembly is a useful procedure in this connection.

Ringworm may interfere seriously with school management, and is very "catching" if a case is introduced. It is due to a tiny fungus which attacks the skin or hair, or both, generally on the scalp, face, or neck, but sometimes in other parts. It begins as a small red patch, 
which spreads in circular shape. On the bare skin it causes ring-like patches with slightly raised margins, the ring gradually widening out unless treated. Several rings may coalesce and form irregular patches. Amongst the hair it causes semi-bald areas, the affected hairs if looked at closely being seen to be broken off and stumpy. So long as a ringworm patch remains "scurfy" it can convey infection, and this may last for many months in untreated cases. The parents should be warned of the danger of its spread to others of the family unless treated. It is very liable to be spread by towels and brushes, and, if an outbreak occurs, the lavatories should be locked and only allowed to be used at regular hours, when a teacher is in attendance to exclude suspicious cases. Known or suspected sufferers should be excluded from school.

Scabies or "Itch" is due to a minute insect, rather like a cheese-mite, which burrows in the skin, particularly between the fingers and in the bend of the wrists and elbows. The burrows appear as faint dark lines, and are exceedingly itchy. It is very catching, and the clothes may retain the insects for a long time unless baked, boiled, steamed, or well fumigated with sulphur in a closed box or cupboard. Sufferers should be excluded. Sulphur ointment and baths will usually cure the disease.

"Blight" or contagious ophthalmia is a very serious eye disease of a most "catching" nature, which is common in many warm localities and in not a few cold ones. Very serious results-even partial or complete blindness -are often due to it. It is conveyed particularly by dirty hands, by flies and dust, and by towels. Any cases of acute or chronic inflammation of the eyelids, with redness and discharge, should be carefully watched, and prompt 
precautions taken against spread through the lavatory, by interchange of slates, books, \&c. The attention of the parents should be drawn to the probable danger to sight, and a visit to the doctor advised.

Tuberculosis is a communicable disease of appalling importance to civilized mankind. It assumes several forms. Consumption is the principal one, but in addition to the lungs the bacilli of tuberculosis may attack almost any other part of the body, and in children have a great partiality for bones and joints. Hip disease, spinal disease, and lupus of the face are evidences of this. Tubercular inflammation of the brain-membranes (tubercular meningitis) is another fatal form of the same disease. The great means by which all tubercular diseases are spread is the filthy habit of spitting. A consumptive person brings up literally billions of virulent tubercle bacilli every day from the diseased lungs. Unless proper precautions are taken, by thoroughly disinfecting all coughed-up material and all articles contaminated with it, the infective matter will dry and be diffused abroad as fine dust. This fine infective dust may gain entrance to the bodies of children and adults in various ways, but more particularly by the breath. If the bacilli in it obtain a foothold the disease begins either in the lungs or in other parts to which they may be carried in the lymph stream. No child is too young to be instructed in the danger to the public of spitting about, and due emphasis should be given to the instruction by the enforcement of strict rules against spitting on school premises, whether in the playground, in the building, on slates, or elsewhere.

Open windows and regular damp-cleansing are the principal domestic foes of tuberculosis. Consumption is 
not hereditary, but unless the room in which a consumptive person lives or sleeps is thoroughly disinfected, and kept free from dust, the infection may remain in it for years. Children suffer from consumption as well as adults, and attention should be paid to any child who is noticed to be suffering from chronic slight cough with loss of flesh and flushed appearance over the cheek bones. If consumption is suspected, the child should be at once excluded from the school and kept out till a medical certificate is obtained.

Chorea, or "St. Vitus' Dance" as it is popularly called, is not a communicable disease, but is of somewhat frequent occurrence amongst strenuous overwrought children. The symptoms are unmistakable in advanced cases; they develop gradually, and are marked by their perversion of muscular purpose, as shown by curious twitchings and contractions particularly, at first, about the muscles of the face and eyes. For its own welfare a child with chorea should be immediately removed from school and placed under treatment. If the child cannot be so removed the teacher should deal carefully with him, or particularly her, assigning work so that the child may feel that it is recognized as a member of the class, but not criticizing or pointedly correcting errors due to the disease. No home lessons should be required, and the child should be protected in playtime from teasing and annoyance. Chorea occurs more frequently in girls than in boys, and particularly in anæmic girls. It is very liable to be followed by heart-disease.

Whitlows are caused by inflammation of the pulp of the finger or of the tendon sheath, and if untreated may lead to crippling of a finger or of a hand, or even to loss 
of the hand or arm, or death from septic poisoning. Medical advice should be sought by the parents.

Malaria is of some school importance in certain colonial localities. It is conveyed by a certain species of mosquito, the Anopheles, of which a number of varieties possess this power whilst others do not. There is no "theory" about this question of mosquito conveyanceit is an established scientific fact. The principal preventive measures are the eradication, as far as possible, by oiling and drainage of all breeding-places-pools, puddles, and other collections of water-in the vicinity of the school, the mosquito-proofing of the building or room if used after dusk, and the instruction of the children in the methods of avoiding being bitten by mosquitoes, and of exterminating them from the vicinity of houses. Details of the proper procedure necessary to avoid infection can generally be obtained locally from a doctor.

Diseases of the eyes, throat, and ear will be subsequently dealt with.

\section{CHAPTER VIII}

DEFECTS OF SPECIAL SENSES-TESTS OF VISION AND HEARING

It is too often forgotten that for all practical purposes the whole question of teaching ordinary children in ordinary schools depends on the condition of their eyes and ears. These are the two great portals to the child soul, as they are throughout life to the soul of the normally constituted human being. Ordinary educational method 
is almost wholly designed to work through these two senses, and if these fail to discharge their functions, that is, if they fail to convey the sense impressions to the brain, or if they convey them in a blurred or indistinct form, ordinary educational method becomes a mere waste of time and money. Besides, attempts to use ordinary educational method by means of defective eyes may convert a temporary defect into a permanent one, and hence may-with the very best pedagogic intentions-cripple the child for life. Professor Shaw, speaking from the responsible stand-point of a Professor of Pedagogy in a great University, has put the whole case in a nutshell. "School life", says he, "impairs more or less the eyesight of the greater number of those who pass through the grades. Our progressive civilization seems destined to tax the eyes to a still greater degree in the future than even at present, if we may judge from the growing demands of the past. The school is therefore culpable if it, through disregard, or even through neglect, fails to take every precaution against impairing the eyesight of pupils" (School Hygiene, p. I 70).

Certain questions of school lighting have already been dealt with in Chapter III, and from these may be inferred the fallacy and danger of the reasoning that leads too frequently to the usual procedure, wherein money and time are wasted in attempting to teach children by means of pictures which they cannot plainly see. By placing one's self in the mental attitude of an earnest and sensitive child hampered by an unsuspected defect of sight, it is possible for most teachers of experience to awaken in themselves uneasy memories of punishments inflicted for "inattention", "carelessness", and similar 
subjective misdemeanours. Let such a one picture himself-or herself-sitting well back in the class, endeavouring to copy down a sentence from the board. The letters look blurred and "wobble" somewhat if stared at; c's change mysteriously into e's, and e's appear now and then where there were c's; n's, m's, and u's transform themselves in a similar inconvenient fashion. The harder they are stared at the more exasperatingly do these annoying letters disguise themselves, and the i's show a tendency to disappear altogether. Upon inspection of the attempt to reproduce, the teacher perhaps prophesies certain unpleasant results that will follow a repetition of what that omniscient and omnipotent authority describes as "carelessness". Strenuous endeavour to avoid the promised consequence leads to an unpleasant feeling in the head, and to watering in the eyes, which does not diminish the antics the letters seem determined to play.

Finally arrives the order to stay in and copy out the lesson after school. The victim stays in, gets into the front seats, where the letters do not wobble, and earns an apparently deserved reputation for "inattention" when he hands in the correctly written copy. So the process goes on day after day, until he leaves school a welldeveloped and incurable case of myopia, case-hardened to fault-finding, which, do what he will, seems to be always his lot, an educational "bad bargain" and hampered for ever, physically and morally, in the race of life.

That teacher who chooses to remain ignorant of the methods in which such responsibilities should be met, will continue to punish the blind for not seeing, the deaf for not hearing, and to be responsible for the deformity of 
many human souls. The majority of children are irresponsible healthy young animals from whom school troubles slide off like water from a duck's back. From a moral stand-point it is the sensitive brooding minority who have to be specially considered, and these are specially frequent amongst the children in whom vision and hearing are defective.

In Chapter III it has been shown that adequate lighting of the school-room, important as it is, is by no means the sole essential for the protection of eyesight, but that the enforcement of a proper working position, from the first day on which the child attends school, forms one of the most serious responsibilities of any conscientious teacher. It has been further pointed out that certain serious defects of construction and arrangement may often be much improved by the exercise of a little judgment and common sense. It should be clearly understood that the tests hereafter to be described are of little or no use unless the teacher is prepared to act on the information so obtained, and has already taken all reasonable attainable precautions to avoid unnecessary strain on delicate sense-organs.

In its general mechanical principles the human eye somewhat resembles a photographic camera. There is a lens in front, fitted with an adjustable diaphragm (the iris) for cutting off unnecessary light rays ; there is a blacklined box for the rays to pass through from the lens without reflection from the sides; and there is a screen (the retina) at the back on which the lens focuses the rays which make up the picture. So far the simile holds, but in the eye the lens is fixed in one position, and its shape is altered when objects at different distances are focused 
for. In the eye, too, the image is focused particularly upon one little spot (the "yellow spot") and not upon the whole screen, which is curved instead of being flat, as in the camera. If this little spot is out of focus, we

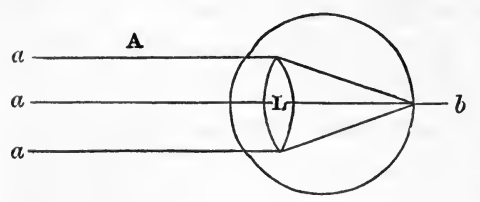

cannot get clear vision any more than we can get a clear sharp picture on a photographic plate which is out of focus in the camera, and just as spots or dirt on the camera lens will appear imaged on the screen or plate, so will any opacities in the lens or other parts directly in front of the eye interfere with the image on the sensitive spot in the retina.

Now it will be A, Ordinary Eye, rays of light $a a$ from a distance
coming through the lens $L$ to a point $b$ on the retina. $B$, Short-sighted Eye, rays from a distance coming to a point $b$ in front of the retina $b^{\prime}$. C, Long-sighted Eye, rays from a distance coming to a point $b$ behind the retina $b^{\prime}$. L is the lens in each case.

obvious that as the power of the lens to accurately alter its shape depends on a very small muscle which drags upon or relaxes the elastic capsule in which the lens is slung, any material modification of the length of the eyeball from the normal will cause the image to focus either in front of or behind the sensitive spot on the retina, according as the alteration of length is in the direction of increase or decrease when the little muscle is contracted or relaxed to its fullest capacity. It is 
further conceivable that, if the eyeball is irregular in shape, the rays of light will not fall accurately and fully on the sensitive spot, but may be reflected across it, with the effect of lengthening a dot into a blurred line. And again, if the little muscle gets out of control from any cause, it may simulate some of the conditions produced by alteration of the length of the eyeball from the normal. Upon these few simple principles depend all the chief errors of refraction, popularly known as short sight and long sight, together with that important but somewhat obscure defect to which oculists apply the name astigmatism.

The eyes of young children differ from those of adults in that they are normally somewhat long-sighted, the eye being relatively shorter from front to back. This means in practice that a child has to strain its eyes proportionately much more than a normal-sighted adult in order to clearly see any near object. As soon as the object is brought nearer than 12 inches from the eye, the strain increases very rapidly with every inch of nearness. The powerful muscles round the eye pull at the same time on the globes, so as to roll them inwards. The child's eye is not nearly so well supported and packed up with fat at the back of the socket as is that of an adult, and all this pulling and dragging is very likely to bulge the back wall of the eye backwards. Directly this occurs, the eye has become longer than it should be, the lens cannot focus clearly on the sensitive spot, the image falls short, and the condition called short sight, or myopia, is permanently produced. A difference in length equivalent to the thickness of a sheet of thin paper is sufficient to cause Myopia. The eye condition which predisposes to 
this defect disappears only very gradually, and is present in considerable degree up to ten and even twelve years of age.

It is hence of very great importance that children, and especially infants, should not be allowed to work at any nearer distance than $\mathrm{I}_{2}$ inches ( 15 inches is even better) between any object and the eye. The enforcement of this habit of proper working distance should be begun on the first day on which the child attends school, and should be insisted upon up to the day he leaves. Whether in kindergarten, in reading, in writing, in sewing, or in any other kind of school occupation, it is of the greatest importance to insist on this working distance being maintained both as an essential to the easy and effortless use of the eyes, and as a necessary safeguard against serious injury to these important and delicate organs. The teacher of an infant class is particularly concerned in this matter, for it is here and only here that the ingrained habit of proper working attitude can be really formed; and it is here that the eyes are most liable to damage. It is here, too, that objects are most likely to be brought close to the eyes.

Some children, of course, come to school with originally defective eyes, but most cases of short sight arise during school life, and are undoubtedly due principally to bad school conditions. I believe, after considerable enquiry into the subject, that it is due mainly to conditions of thoughtless and ignorant school management. Children's eyes are not intended by nature for fine work, and every effort must therefore be made to guard against unnecessary strain. The type and paper of books, colour and spacing of lines of copy-books, colour of sewing-thread and 
materials, size of writing on the black-board, degree of blackness of the board, fineness of maps, are all very important in relation to eye-strain. Teachers cannot alter some of these perhaps, in all cases, but they can generally so arrange the time and place as to get the best available light for lessons wherein these articles are used. One strong objection to the use of slates as compared to paper pads lies in their poor legibility, especially when greasy.

No type smaller or more closely set than that which printers call leaded Brevier should ever be used for schoolbooks.

No type smaller than Smallpica should ever be used for class or home work by children under twelve years of age.

And no type smaller than Pica should be employed in teaching children to read.

(The different kinds of type here referred to are used above.)

School-books should be printed on opaque paper, with a matt surface-not a glossy surface. So important are these requirements that, where selection is possible, the teacher will do well to reject any book not in accordance with them, even though it may fill pedagogic requirements better than one which is less liable to cause danger to eyesight. Book defects can be remedied afterwards, eye defects usually cannot.

Myopia, or short sight, is practically incurable, and the sufferer from it will be obliged to use glasses for 
many years, if not for his whole life, if he is to see clearly beyond a short distance. Further, he is debarred from certain important occupations and professions. Myopia is therefore the greatest and most important eyedefect of school life.

If, on the other hand, the eyeball is too short for the little ciliary muscle to sufficiently relax the elastic capsule of the lens, even when exerted to its utmost capacity, the image will fall behind the sensitive spot, and the condition called hypermetropia or long sight is set up. In children this is due to an exaggeration of the normal condition, but the hypermetropia of persons advanced in years is due to another cause-the diminished elasticity of the lens itself.

Sometimes the eyeball is irregularly shaped, so as to make a small dot appear blurred or drawn out in one direction. Severe eye-strain, with headache and nervous symptoms, may then be set up, with great difficulty in using the eyes. The condition is termed astigmatism. It is a complicated defect and requires very skilful treatment for its correction, by glasses. When a child under ten suffers habitually or frequently from headache, astigmatism is very often the cause. Astigmatism is the disease, par excellence, of the earnest student. It has recently been argued, with every show of probability, by highly skilled eye-surgeons, that the ill-health of Darwin, Wagner, Carlyle, and several other men of genius, who suffered from all manner of obscure and mentally-crippling symptoms for many years, was probably due to astigmatism.

The last of the principal internal eye conditions which can be here dealt with is that known as habit spasm, 
arising from overstrain of the little muscle of accommodation, which pulls on the capsule in order to slacken it, and to allow the lens to become more convex. The eye is quite normal in shape and structure, but overstrain has rendered the little ciliary muscle so irritable that, when the child desires to look at a distant object, the muscle contracts spasmodically and pulls the lens into near focus. The eye is out of control, and the child appears short-sighted because it is unconsciously and involuntarily focusing for near objects when distant ones have to be looked at. The teacher cannot positively distinguish between this condition and real short-sight, and it requires a medical specialist to do so with certainty. If allowed to continue, it may lead to real and permanent short-sight. These are the very cases which may be ruined for life at the hands of the socalled "certified optician", or the spectacle-merchant generally, whether he be the potentate who runs a "sight-testing establishment" or the chemist who "prescribes glasses". Nobody except a medical man should be allowed to prescribe glasses for a child.

The method of sight-testing which will now be described is no elementary or haphazard affair, and accurate and useful results may be obtained from it if properly carried out. The precise nature of any defect must however be determined, where necessary or feasible, by a medical man, and cannot be correctly ascertained without putting drugs into the eye in order to temporarily paralyse the accommodation. No nonmedical person is justified in putting drugs of this character into a child's eyes. Tests should be applied to every child before it is allowed to begin serious 
reading, writing, or other fine work, and repeated thereafter at the beginning of each school year. The results should be kept in a note-book (or in large schools in the form of a small card-index) together with other information concerning the physical condition of the child. A sample card plan will be found in the Appendix.

The simplest procedure in Eye-Testing is carried out as follows. A set of test letters mounted on a card is hung at about the level of the child's eyes in a good light. A distance of 20 feet is measured perpendicularly out from the wall on which the card hangs, and a line drawn, or a couple of brass-headed tacks put in, to mark the 2o-feet distance. Each child to be tested is made to stand with its toes to the mark, and is directed to read the letters row by row, beginning at the top, with each eye in turn. The eye which is not in use should be obscured with a piece of card, taking care that it does not touch the eyelids, lest disease be conveyed by it from one child to another. Each row of letters has a number marked under it-6o, 40, 30, 20, and so on. These figures represent in metres, or feet (I metre $=39^{\circ} 37$ inches), the distance at which the corresponding line should be easily read by the normal eye in a good light.

If the child reads all the letters down to the 20 -feet line (supposing the card to be marked in feet) correctly, with each eye in turn, from a distance of 20 feet, its vision is reasonably normal, so far as myopia, hypermetropia, and habit spasm are concerned. The card will not detect astigmatism.

The results are recorded in the form of a fraction, the numerator expressing the distance of the type card from 
the eye, the denominator the distance at which the normal eye should be able to read the lowest line read. The result should be recorded for each eye separately, in abbreviated terms for right and left vision respectively. Thus: Johnny Brown toes the line, the card is placed so as to obscure his left eye, and he reads off each line to 20 , or possibly beyond. $\mathrm{He}$ is marked R. V. $\frac{20}{20^{\circ}} \mathrm{He}$ changes the card to his right eye, and reads them off correctly with the left. $\mathrm{He}$ is entered L. V. $\frac{20}{20}$, and passed out. Tommy Jones arrives, perhaps after an embarrassing interview with his teacher concerning alleged "habitual inattention" in class, and ill-spelt copies as a consequence. He reads the 60 line with his right eye, and boggles badly over the next one. $\mathrm{He}$ is marked R. V. $\frac{20}{60^{\circ}}$. With the left eye he cannot manage the 30 line although reading the 60 and the 40 , after some trouble. $\mathrm{He}$ is marked L. V. $\frac{20}{40^{\circ}}$ A note should be sent to his parents advising them to take him to a medical oculist at the first opportunity, as he apparently has a serious defect of sight. It is probably either myopia or habit spasm, but for reasons already given the teacher cannot distinguish between them with certainty. Pending the visit to the oculist, his seat should be changed to the best-lit part of the class space, eye-strain avoided as far as possible, and judicious leniency shown to his mistakes.

In using test types certain errors must be guarded against. A child may be so long sighted that it cannot 
read the proper letters at 20 feet, although it may be found that they can be read at 25 or 30 feet without difficulty. Such children frequently have chronically red and watery eyes, and suffer from pain in them or from headache after reading or writing for any time. Another source of error lies in placing the types in any place where they are likely to be seen and read at ordinary times, and consciously or unconsciously committed to memory. The card should therefore be kept out of sight when not being used, and, whilst testing, other children should not be allowed to look on.

In certain cases the eyes may be perfectly normal but the capacity of intelligently appreciating and interpreting the things seen be defective or absent. This capacity is quite a different thing from vision, and is termed Perception. As a matter of fact vision does not take place in the eye at all, but the effect produced by the impact of the image on the retina is conveyed to the back of the brain by the optic nerves. There it is dealt with by a complicated arrangement of special nervous tissue, which breaks it up into understandable form and sets it before the thinking centres. To pursue the photographic simile, perception corresponds to the processes of development and printing, which must follow the correct exposure of a photographic plate before a picture can be obtained for ordinary use.

These known as Snellen's Types are amongst the best of these testing devices, but others are obtainable at a small cost, capable of yielding accurate results. The device known as Landolt's "broken ring" optotype is particularly useful for children who cannot read.

With a little more apparatus the test may be rendered 
much fuller, and the dependency of headaches on eyestrain ascertained with considerable accuracy. The apparatus required consists of a set of test types, a round white card with four moderately thick black parallel lines running across it, a "trial frame" for glasses, and two curved lenses of the kind known by ophthalmologists as $+\mathrm{ID}$, and $+\cdot{ }^{5} \mathrm{D}$ respectively。

The child is placed at the fixed distance from the test types, and the vision for each eye noted separately. If any abnormality is found, or if the child is known to suffer from headache or nervous symptoms, the $+\mathrm{ID}$ glass is placed in front of each eye separately and the child asked whether it can now see better, the same, or worse.

If he sees better, or the same, he is hypermetropic.

If he sees worse, try the $+\cdot 5 \mathrm{D}$.

If this still renders the vision worse than without it he is either myopic or astigmatic or emmetropic (i.e. correctsighted).

To exclude astigmatism, the card with the horizontal black lines is then shown to each eye in turn, at the same distance, and rotated slowly round. If the lines tend to run together in any direction he is astigmatic; if he sees them clearly in all directions he is not.

If he is simply myopic (short-sighted), or is emmetropic (correct-sighted, though perhaps with temporary habit spasm), the headaches are not due to errors of refraction. If he is hypermetropic or astigmatic they most probably are. Strained-looking inflamed watery eyes are frequent accompaniments of these conditions.

Hearing is almost equally as important as eyesight in relation to school work, but luckily this sense cannot be 
so easily damaged or affected by defective school conditions. The normal ear works by transmitting the atmospheric waves of sound to a small sac set deep in the bones of the head. This little sac is lined with very delicate nerves, and is filled with fluid in which exist certain tiny particles of sandy material. The transmission is affected by a chain of three small bones pivoted to each other, of which the outer one is attached to a thin membrane stretching across the passage from the outside, and the inner one fitted into the end of a coiled space in the bone containing the little bag of fluid and sand. The membrane, or "ear-drum", closes the whole of the channel from the external ear, and it is therefore necessary that the air pressure on each side should be even, in order to prevent the membrane from being stretched or burst inwards or outwards by alterations in the pressure of the air. This is effected by a little tube passing up from the throat cavity, known as the Eustachian tube.

Ear defects are frequent in children, and are of two chief classes: first, those arising from disease of the drum and deep parts, and second, those from wax or other obstructions in the outer channel, and from blocking of the Eustachian tube. Disease of the deep parts is difficult or impossible to cure, although it can be much alleviated. The second group of causes of deafness is as a rule very curable, and generally depends on post-nasal growths, or adenoid growths as they are usually termed by doctors.

Post-nasal Growths are extremely important agencies in the school life of many countries, particularly in cold and temperate climates. They arise from the 


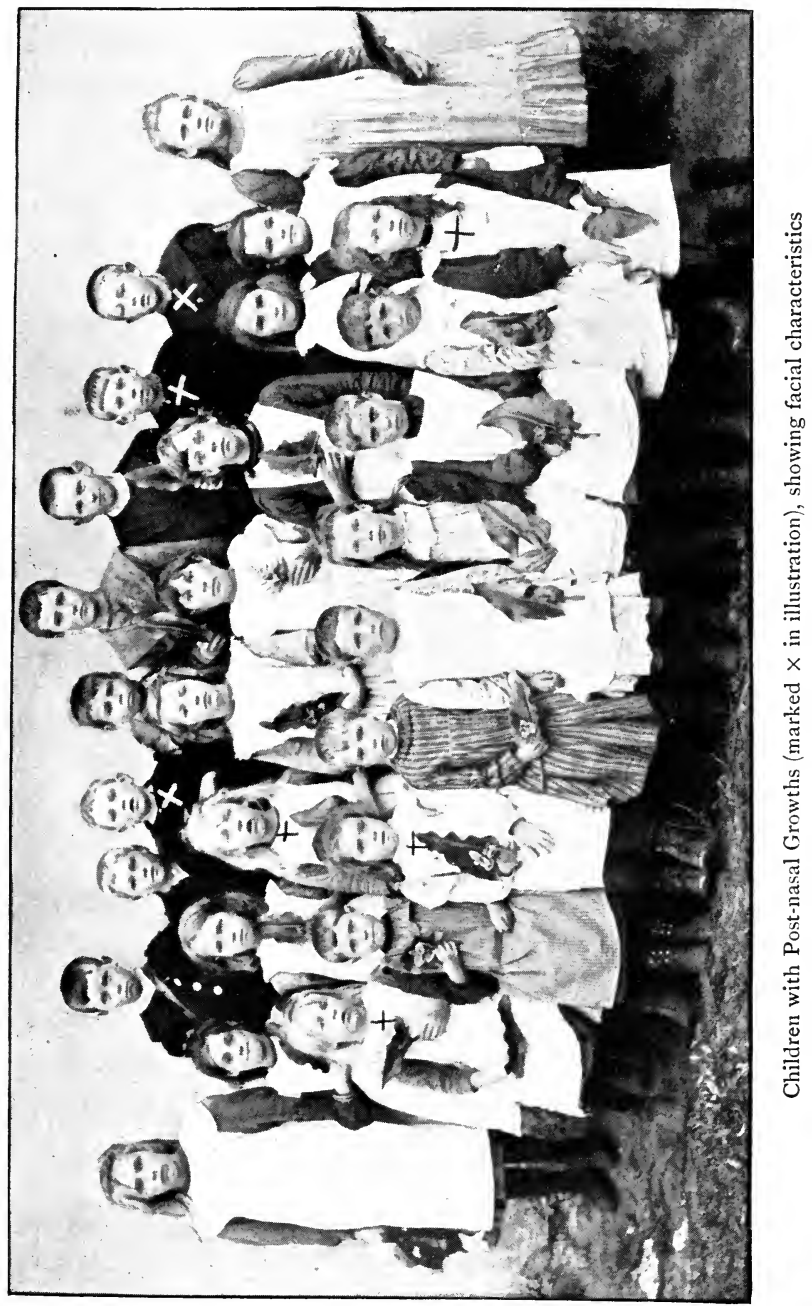



overgrowth of a small mass of tissue at the back of the throat, which under normal conditions forms a sort of third tonsil. When this overgrowth occurs it blocks up the openings from the back of the nose into the throat, obliging the child to breathe through its mouth. It blocks up the Eustachian tube and prevents the ear-drum from vibrating properly. As the overgrowth increases, a surface of absorptive tissue is present in the throat, upon which decomposable matter from the unfiltered mouthbreathed air and from the food collects, and from which it is absorbed. By these means, assisted probably by some obscure specific action on the brain, advanced post-nasal growths seriously hamper the reasoning and thinking powers of a child, and eventually produce a condition of real mental defectiveness.

In addition to thus interfering with the working powers, they predispose the victim to a number of serious consequences from other diseases. Measles or scarlet fever in a child with large post-nasal growths almost inevitably result in serious permanent injury to one or both ears. The mouth-breathing predisposes to colds, to diphtheria, to scarlet fever, to consumption, and to tonsillitis. The restriction in the entry of air to the lungs, and the natural plasticity of the ribs and breastbone, allow the chest to be squeezed out of shape by the air pressure. Pigeon breast and flat chest are frequent results of long-standing post-nasal growths. The defective air circulation in the lungs predisposes to lung troubles and interferes with growth and development. In addition to this formidable -but by no means exaggerated or fantastical-list of possible evil consequences from untreated post-nasal growths, the physical and mental deformity produced 
must react very seriously upon the child's happiness and prospects, both at school and in after-life.

The typical bad case of post-nasal growths is the typical "dunce" of less enlightened days-heavy, fatuous, and inexpressive of face, dull of hearing and of comprehension, thick with dull nasal voice, lack-lustre eyes, snuffling dirty nose, and slack open mouth with projecting teeth. Such a one goes through school life with the reputation of being "dull", "stupid", "incapable", "defective", or "weakminded", according to the teacher's way of phrasing it and the degree of the infirmity, to leave school branded as an incapable and an educational bad bargain. Many a poor wretch has been spoiled for life through unknown post-nasal growths, many a poor human soul has been shut up in a dull prison-house of unhealthy body and cramped mind when it might have enjoyed freedom and happiness.

All cases of post-nasal growths do not go so far as this, however, but when it is noticed that a child wears its mouth habitually ajar, that it has difficulty in breathing with the mouth closed, a tendency to snuffling and discharge from the nose, or to occasional spells of deafness, and a nasal "flat" voice, their existence may be suspected. A history of snoring when asleep is very suspicious. The condition is quite easily cured by a small operation in skilful hands, the diseased tissues being scraped away. The results are almost incredible in advanced cases, and parents should be advised to submit such children to a medical man for examination and operation if necessary, before worse consequences ensue.

Hearing can be easily tested as follows. A tape or 
piece of string marked in feet and inches is stretched along a wall, between a couple of tacks 2 feet from the ground, or a scale about 6 feet long is marked on the floor. The child stands at one end with the back to the teacher, closes its eyes, and holds a piece of folded cloth over one ear. A handkerchief is not thick enough for this purpose. The teacher holds a watch and approaches the child from behind, beginning at about 6 feet. The child is instructed to say when it catches and loses the sound, the watch being moved backwards and forwards to verify and check the limit of hearing. Five feet is a fair distance at which to hear the average watch. It is necessary to take into account noises from outside, and the fact that watches differ a good deal in sound. A stop-watch is best for this purpose.

Another method is for the teacher to whisper with expired breath various numbers, beginning at a distance of some 20 feet, and noting the distance at which the whispered number is distinguished. This method is less liable to disturbance by school noises. Eighteen feet is a fair distance. Whichever method is used, care must be taken to test each ear separately and to record the results. These are averaged, and a standard of normal distance obtained for those particular conditions. In subsequently using the standard care must be taken to repeat the conditions under which it was obtained.

Deaf children should be seated in proper positions for hearing, those with one defective ear being placed on the side of the teacher which brings the good nearest to him. Children with mattery discharges from the ears are liable to serious illness, as the condition is generally due ( B 775 ) 
to inflammation of the deep parts. Severe earache with redness and tenderness about the bony lump behind the ear (mastoid process) are dangerous signs necessitating immediate exclusion and treatment.

It should never be forgotten that in justice both to the child and to the educational system the hearing and eyesight of every allegedly "dull", "stupid", or "inattentive" child should be submitted to one or other of the tests above described. If a defect is found, an endeavour should be made by the teacher to get the parents to have it looked to by a medical man; and meanwhile the maimed sense should be assisted as far as possible by an intelligent utilization of the available facilities. Systematic testing of all children is very advisable, but systematic testing of all abnormal children is essential alike for the sake of effective pedagogy and of humanity. Without this safeguard teachers will run a serious risk of damaging the valuable property entrusted to their charge, and worse than that, of irreparably warping human souls.

\section{CHAPTER IX}

SOME ACCIDENTS AND INJURIES OF SCHOOL LIFE

A knowledge of what to do till the doctor comes, or "first aid" as it is generally called, will in emergency be found very useful by teachers and particularly by those in rural districts. In the larger centres ambulance classes are often available and the instruction so obtained is generally both interesting and useful. Where these 
classes are not accessible a good deal can be learned from one or other of the many good books on ambulance work and first aid; and the information so acquired may be made more serviceable by practice on some goodnatured friend or fellow-learner. It will soon become evident to the student of the subject that an important object of first aid is to teach folk what they should not do.

As a rule this is exactly what their natural impulses in the face of an emergency are apt to urge them to do. A street accident often provides a striking but frequently disastrous example of the need for more extended popular acquaintance with elementary first aid. A child, we may suppose, is knocked senseless in the street by a cart. The usual crowd collects at once, everybody offers advice and pushes in to have a look. Then some humanitarian picks up the sufferer and takes him into a shop, where he is supported on a chair by well-meaning hands. As many of the crowd follow as can manage to jam themselves into the place, and another humanitarian arrives with sixpennyworth of bad brandy, with which he proceeds to further asphyxiate the unconscious victim, already almost on the brink of being suffocated by the crowd of well-meaning sympathizers. When the doctor arrives and makes a few quite natural remarks as to the extraordinary number of fools in the world, people's feelings are hurt, and comments are made on the overbearing nature and lack of politeness of the medical profession nowadays. The discovery that the first humanitarian has-with the best intentions possibleconverted a simple fracture of the leg into a compound one by allowing the limb to dangle unsupported whilst 
picking up and carrying the victim, and that the second has half-poisoned the already feeble heart with neat brandy, does not tend to make the doctor withdraw his remarks. And yet, what is more natural at first glance than to remove an injured person, and to revive him with what is believed to be the best available means? The whole objection to the proceedings is the manner in which they are carried out, and herein a knowledge of first aid would have proved beneficial.

Once a person has really learned and can automatically recollect that a spirting artery cannot be stopped by covering it up with rags, that a fainting person is not to be stood up or sat up, that a person in a fit is not to be held down, that a broken limb is not to be allowed to dangle unsupported, and that spirits are not to be given to an injured person except on medical authority, there is a much improved outlook for any victim of an accident who may come under his hands. Any teacher may be suddenly brought face to face with a child who has a piece of food or other foreign body stuck in its throat, or with a furiously bleeding wound of a large artery from a fall on broken glass. There is then no time to turn up books or to wait helplessly for the doctor. Action is necessary, and it must be the right kind of action or life may be lost. Only an outline of the methods of treating the more important emergencies can here be given, but those who have not already received a training in first aid will do well to take the earliest opportunity of joining one of the classes of the St. John or other Ambulance Society for at any rate the first course.

Bleeding, or "Hæmorrhage" as it is more pedan- 
tically called (for both words mean the same thing), is of three kinds, according as the blood comes from an artery, from a vein, or from the tiny vessels which interweave all over the body and which are known as capillaries. It may be from an external part, or from some internal organ such as a lung.

A wounded Artery is a surprising and startling thing

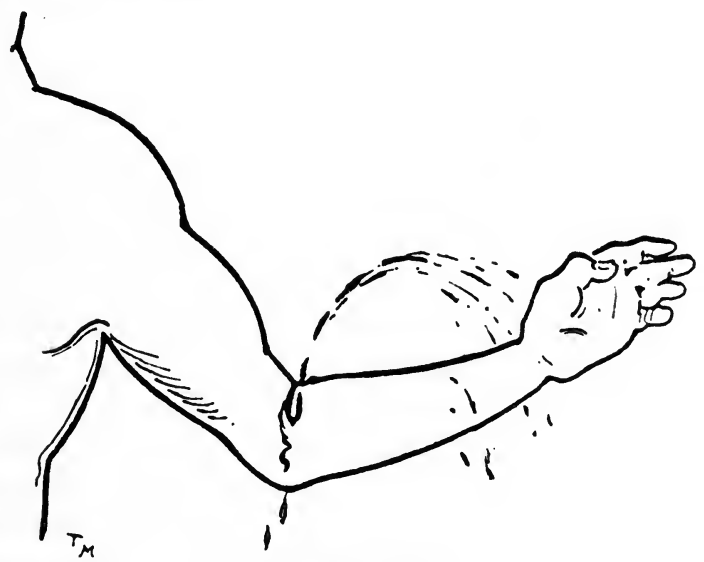

A Spirting Artery

when seen for the first time. If the wound is open, the end of the artery nearest to the heart spirts out bright red blood, perhaps to a considerable distance, one jet occurring each time the heart contracts, with a less vigorous stream in between the beats. Where there is a free connection with another artery or with large veins farther on, the other end may bleed strongly. There is no need to be afraid of a wounded artery so long as a finger can be pressed firmly down on to the cut end. 
There is no need to be afraid of the blood, but there is much need for recollecting that the loss of any considerable amount of it will be a serious matter for the injured person. Any fainting can just as well be done afterwards, and most people can hold off a faint if they try, under such conditions. A cut artery requires to be stopped at once, and the most convenient instrument for

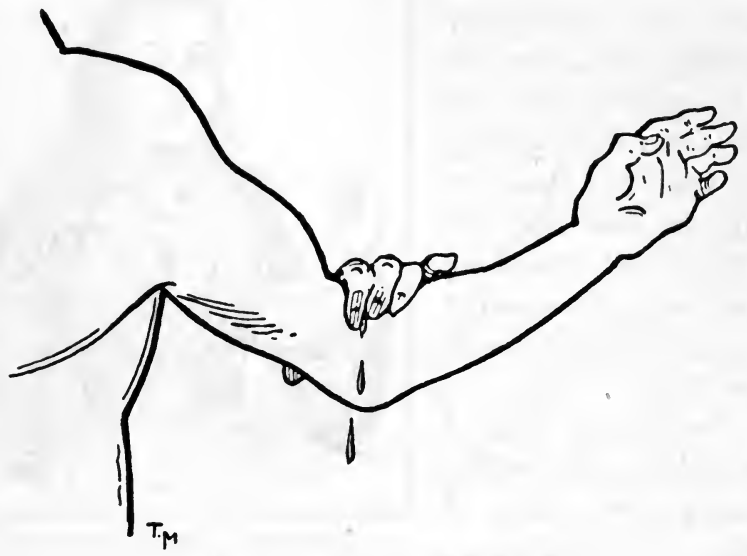

Bleeding Stopped by Finger-pressure

any such emergency is the finger or hand firmly applied. Very little pressure is sufficient if properly applied, and if possible the pressure should be so applied as to squeeze the vessel against a bone-an easy matter with a scalp wound, for instance. If no assistance is at once available, a large artery can be controlled in this way for hours. If the other end begins to bleed by communication with other vessels it can be stopped in the same way. 
In the limbs the main arteries can be felt in several places and can be compressed above the wound by a pad. For wounds of the arteries in the forearm and hand the elbow should be bent up hard in order to compress the main arteries-the marked effect of this can be judged by feeling one's own pulse with the arm straight, and then gradually bending the elbow till it is tightly flexed. In the same way bending the knee will lessen or stop the flow from cut arteries in the lower leg and foot. Elevation of a part will also diminish the flow.

The jetting from a wounded artery usually settles down after a while to a steady pour, if allowed to go on, but

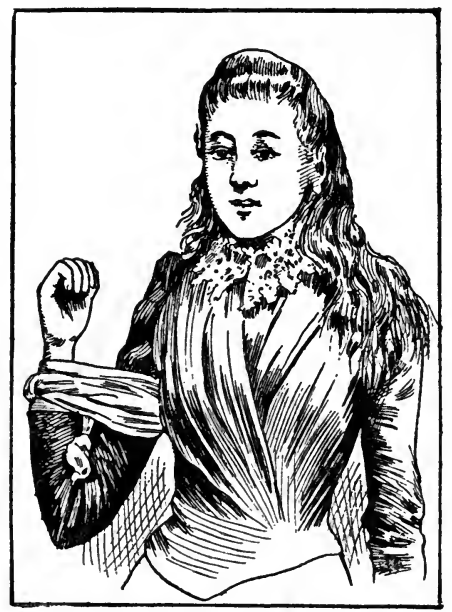

Treatment of a Wound between the Elbow and Wrist

this does not improve matters for the patient. The loss of blood must be checked.

Having checked furious bleeding, feel for the main artery if the wound is in a limb, and put a pad over its course above the wound. The pad may consist of a knotted handkerchief, a tight wad of paper, or any other suitable object at hand. Then encircle the limb loosely at the level of the pad with a handkerchief, or piece of cord, knotted together at the ends, insert a stick between 
the loop and the skin away from the pad, and twist it up tightly till the bleeding either stops altogether or diminishes to a mere trickle.

If the cut artery is not in a limb-it may, for instance, be in the neck or scalp-it is generally better to depend on preliminary pressure with the fingers followed by a firm pad. This will usually stop the bleeding, especially about the neck and face. A cut artery in the lip or cheek is easily controlled by gripping it between the finger and thumb, one inside the mouth the other outside.

A Cut Vein bleeds with a steady pour of dark blood, generally from the end farthest from the heart. Sometimes, in large veins, the bleeding may be from both ends. It can be stopped in the same way as an artery can by pressure with the finger on the end of the vessel. The pad should be applied over the main vein, but beloze the wound, because the flow in veins is towards the heart.

When no artery or considerable vein has been wounded the bleeding is not serious as a rule, except in certain peculiarly constituted persons who are known as "bleeders" because of their peculiar liability to severe losses of blood from very slight injuries. In ordinary folk it may be stopped by pressure with the fingers or a tightly-rolled handkerchief. The edges of the wound should be pressed together, after removing any dirt, in the manner to be described.

The First Treatment of Cuts is simple enough once the bleeding has been stopped or reduced to a slight oozing from the capillaries. All that is then necessary is to remove any dirt with a little boiled water and to cover 
up the wound from the air with a pad of clean linen. It should never be covered up, however, so long as any real bleeding goes on. It is advisable to use boiled water if possible, and if it is just hot enough to enable the hand to be kept in it, so much the better, as the heat will stop any capillary oozing. If antiseptics are at hand they may be used in the water. A heaped tea-spoonful of boracic acid in a pint of hot boiled water, or a tea-spoonful of carbolic acid in the same, form useful antiseptic solutions. Care should be taken not to use the antiseptic too strong. If hot water is not available, use the coldest obtainable, so long as it is clean.

Finally, do not give stimulants. Their only effect is to make the heart pump more energetically and to break down the plugs which Nature is striving to form in the wounded vessel.

Choking is another startling experience for a layman, and if serious requires very prompt attention. The time at your disposal in such cases is measured by seconds. Try to hook out the obstruction with the forefinger, getting it well to the back of the throat and "clawing". This will usually make the patient retch, which further assists in expelling it. A piece of wood or a cork may be put between the teeth to protect the finger from being bitten. If this fails after repeated attempts and breathing has stopped, catch the tongue between the finger and thumb with a handkerchief, pull it well forward, and try to push the obstruction downwards and backwards with the forefinger of the other hand, on the chance that it may clear the breathing passage. In any serious case of choking send for a medical man at once, as it may be necessary to open the throat. 
When sending make sure that the doctor will be told by the messenger what the trouble is, so that he may bring the necessary instruments. If the breathing has stopped before the obstruction is removed artificial respiration should be used in the same manner as for an apparently drowned person.

Fractured Bones are of course the same as broken bones, and the popular idea of a distinction between a "break" and a "fracture" has no foundation in fact. The softer bones of children render them liable to an injury known as "greenstick fracture", wherein the bone may be cracked and bent to a remarkable degree without being snapped across. No attempt should be made by the teacher to straighten it.

Fractures are generally divided into Simple and Compound, a simple fracture being a break pure and simple, and a compound fracture a break which communicates with the air by a wound. Compound fractures are very much more serious than simple ones, and they are usually caused by the sharp ends of the broken bone sticking through the skin, rather than by the violence which has produced the break in the first place. Hence every precaution should be taken to prevent a simple fracture from being made into a compound one by so supporting the bone that the sharp ends will not be able to cut their way to the surface.

The signs of a broken bone are as a rule fairly obvious, and in bones near to the surface, such as the shin-bone, can often be felt with the fingers, even if no bending or distortion of the part is to be seen. Swelling occurs rapidly, however, and soon obscures this sign.

A broken limb should be firmly supported through its 
whole length before any attempt is made to move the sufferer, and a rough splint for the purpose may be improvised from palings, or boards, - sheets of thick bark are useful-padded in the hollows with grass or rags, and
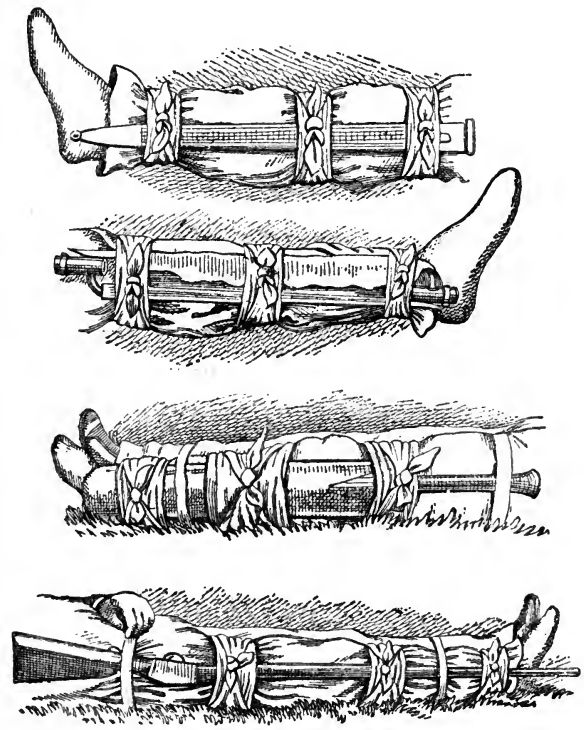

Temporary Splints applied for Fracture of Bones of the Leg

secured with handkerchiefs. A thick flexible copy-book may with advantage be used to support the actual site of fracture. For fractures of the forearm in children a copy-book bent round will serve as a good temporary splint. If possible it is better to make the sufferer from any serious fracture as comfortable as one can where he is until the doctor comes. The clothes should be removed from over the injured part by ripping them down the 
seam with a sharp penknife or small pair of scissors. If an external wound exists bleeding should be stopped as far as possible without moving the limb, and the wound cleaned with boiled water. It should then be covered

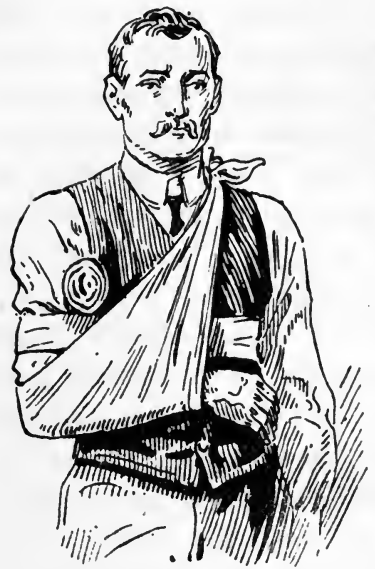

Temporary Treatment of fractured Collar-bone

(Shoulder loops not shown). up from the air as quickly as possible in order to exclude germs of inflammation.

\section{A Broken Collar-} bone should be treated by laying the sufferer flat on his back with a rolledup coat longitudinally along the spine in order to allow the shoulder on the damaged side to fall back. The forearm should be bent across the chest. This position should be maintained till the doctor comes. If the injury must be sent home for treatment, a handkerchief should be loosely knotted round each shoulder and through the arm-pit, and a third handkerchief or a duster inserted through the loops across the back. The shoulders should then be braced well back, a folded copy-book or other suitable pad put in the arm-pit, and another handkerchief tightened round the chest and arm till the collar-bone comes back into shape. The pad in the arm-pit acts as a fulcrum. The wrist should then be slung to the breast of the shirt, and the elbow allowed to hang. 
Burns and Scalds are best treated by carefully removing the clothing from the part without breaking the blisters. If it should stick it should be floated off with warm water. As soon as possible the air should be excluded by covering the burn with narrow strips of clean linen, soaked in olive-oil, or a mixture of olive-oil and lime-water, or by dusting it well over with flour. A thick layer of cotton-wool should be bandaged over this again. Small burns and scalds may be treated by a strong solution of baking soda applied on a rag. A solution of picric acid is an excellent application for scalds and burns. In no case should a blister be opened or broken.

If a dress catches fire the wearer should be at once thrown to the ground and rolled on the burning part in order to smother the flame. Fire tends to ascend, and this is the only way in which disastrous effects can be avoided, A coat or rug should be wrapped tightly round in order to further exclude air from the flame. The most dangerous of all materials in this connection is flannelette, which ignites with remarkable ease and blazes furiously. It should never be used for clothing purposes, particularly for children.

Dislocations are liable to be confused with fractures, especially in children. They are caused by the pulling apart and displacement of joint surfaces, and a fracture may exist together with a dislocation. The joint is fixed and distorted from its usual shape. There is generally a good deal of pain. Beyond a single steady straight pull no attempt should be made by an unskilled person to get the joint back into place, but the limb should be got into the easiest position and secured there by rough bandages. 
If the dislocation is in a finger or thumb, however, an attempt may be made to pull it back into place. It should return into its natural position with a snap. If it does not do so at once, it should be left for a medical man. Hot or cold water bandages or a hot poultice should be applied to ease the pain and swelling.

Sprains are really missed dislocations, where the force has only been sufficient to stretch and tear the ligaments of the joint without pulling the bone ends away from each other. There may be a good deal of pain and swelling with much discoloration afterwards. The best application for a recent sprain is hot water, as hot as it can be borne. A hot linseed poultice is an excellent thing for removing pain from a sprain, especially if a tea-spoonful of laudanum is sprinkled on it just before putting it on. The after effects of sprains are often serious, and a bad sprain should always be seen by a doctor.

Foreign Bodies in the Eye. The sufferer can usually tell whether the foreign body is under the upper or lower lid. If the lower, pull it down and pick off the intruder with the corner of a handkerchief or a clean camel-hair brush. If the upper, put a wooden match or thin pencil on the eyelid, take the eyelashes between the finger and thumb, pull them gently downwards and then turn them up, pressing downwards meanwhile with the match or pencil. The object can then be removed as above. If it is a sharp piece of metal or grit, and has stuck in the eyeball, it is better to put a few drops of oliveoil in the eye, tie a handkerchief over it, and send the sufferer to a doctor.

Foreign Bodies in the Ear are best left to the 
doctor, as interference by unskilled persons may lead to serious trouble.

Foreign Bodies in the Nose may often be got rid of by making the child blow vigorously through the affected nostril. If not, they too are best left for the doctor.

Nose-bleeding, if serious, is treated by making the sufferer sit or stand upright and lift the arms above the head. A handkerchief dipped in cold water and placed over the root of the nose or the back of the neck will further assist. The sufferer should not be allowed to lie down.

In Fainting Fits, the sufferer should be laid down flat in the open air or near a window, and the clothes loosened. A tendency to faint may often be overcome by seating the person in a chair and pressing the head well down to the knees. If children faint or complain of faintness in school careful attention should be paid to the ventilation.

Fits are generally attended with convulsive movements, but the sufferer should never be held down. A small pillow if at hand, or a folded coat, may be placed under the head to prevent injury to the scalp, and the clothes should be loosened. In epileptic fits care should be taken that the tongue does not get bitten-a cork or the corner of a book between the teeth may be required. By-standers should not be allowed to crowd round, and the sufferer should be got into the open air as soon as possible. Hysterical fits in girls are best treated by firmness and cold water. Sympathy will probably result in another fit. It must be remembered that hysteria is not mere deliberate simulation of disease, but that 
there is a disordered state of the physical or nervous organizations-or of both-at the bottom of it. An intense craving for sympathy is the most prominent feature, and it is not uncommon in boys and men of a certain type.

Snake Bite requires prompt treatment. If the bitemark consists of one or two punctures only, and swelling and pain occur about it, it is almost certainly that of a poisonous snake. It may be so if there are more than two punctures. In any case prompt measures should be taken wherever the slightest doubt exists as to the poisonous qualities of the reptile. If the bite is on a limb a piece of stout cord should be knotted round above the bite, and twisted up tightly with a stick. The object is to prevent the poison from being carried into the general circulation and distributed to the special parts upon which it exercises its effects-the nerve centres or blood, according as the poison is from a colubrine or viperine snake. If it can be prevented for twenty minutes or so from getting into the circulation, it will be neutralized by chemical combination with the tissues below the ligature. Immediately the ligature is on, the fang marks should be cut down upon with a sharp knife and the wound well sucked. If crystals of potassium permanganate are at hand they should be rubbed into the wound, as they will neutralize the poison if brought in contact with it. No attempt should be made to inject strychnine or ammonia. These and all other injections, except antivenene made from the poison of the particular species of snake which is causing the mischief, are worse than useless. Stimulants should on no account be given save under 


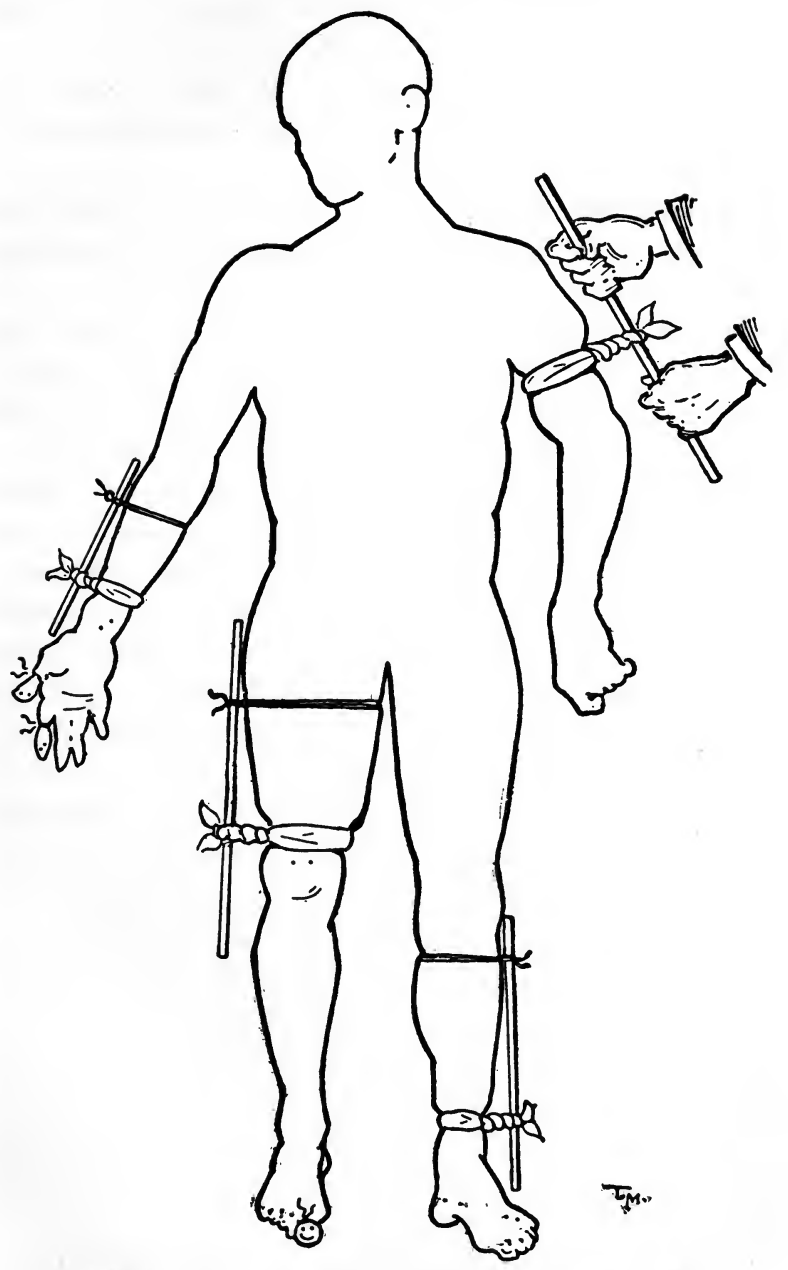

Method of applying ligatures for Snake Bite or Hæmorrhage (B 775) 
medical direction. Hot strong coffee or tea is far better.

The ligature if put on sufficiently tightly is apt to cause much pain. At the end of thirty minutes it should be slacked off, as by this time the poison will have combined with the tissues in its vicinity, and will

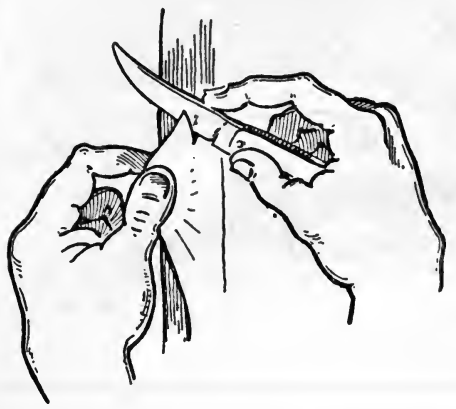

Cutting out bitten part thus have been rendered inert.

If the bite is on the neck or face, where a ligature is impossible, the piece should be pinched up in the fingers and cut out. Failing this, a number of small cuts should be made round and over the bite. In either case the wound should be well sucked and potassium permanganate crystals rubbed in.

Restoration of the Apparently Drowned.Excellent clirections for this work are given in the placards and literature of the Royal Humane Society.

The person should be got out of the water as quickly as possible, and the mouth and throat rapidly cleared of any mud or rubbish by means of the finger.

He should be at once turned face downwards for a second or two, and the tongue pulled well forward.

$\mathrm{He}$ is then turned on his back and stretched out full length with a rolled-up coat under the shoulders so as to allow the head to fall well back.

The operator kneels behind the victim's head, takes 


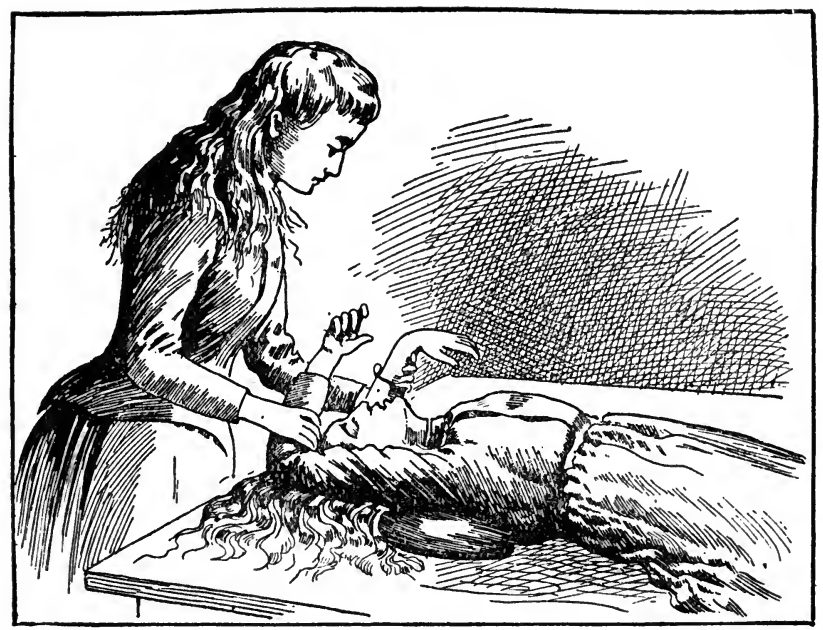

First Movement

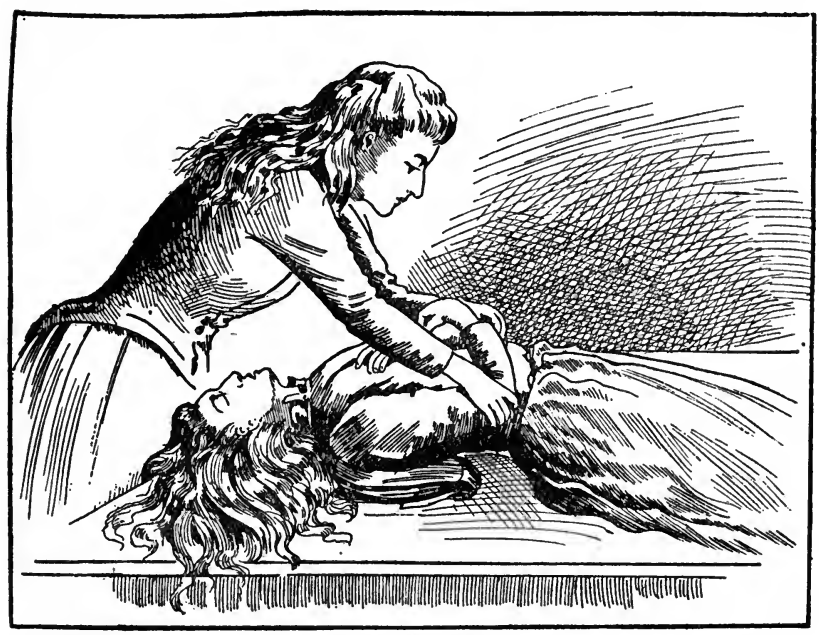

Second Movement

The Restoration of the Apparently Drowned.-Sylvester's Method 
hold of the arms just above the elbows, pulls them steadily upwards well above the head, counts "one", "two", slowly, and brings the arms smartly down to the sides of the chest, pressing them firmly against it. No excessive force should be used, particularly in children, or ribs may be fractured.

The operator then counts "one", "two", slowly, as before, elevates the arms, and repeats the process at intervals of about 15 times a minute. The object of counting is to avoid getting flurried and pumping away at 30 or 40 times a minute, instead of imitating the natural rate of deep breathing, which is about 15 times per minute.

The movements should be kept up as long as there is the least hope-for hours if necessary. The first sign of success is generally a deep sigh, and when this occurs care should be taken to assist the attempts at natural breathing by means of the movements, and not to interfere with them. Whilst the movements are being carried on, a couple of assistants should vigorously rub the legs and body in the direction of the heart, taking care not to bear on the chest. The wet clothing should be replaced by dry warm blankets.

As soon as breathing is re-established he should be put to bed, with hot bottles at his feet and under the arm-pits. A cup of hot coffee may with advantage be given, as soon as he can swallow, but alcoholic stimulants should be avoided.

Fire Drill.-In large schools, and particularly in those of more than one story, the children (particularly the youngest ones) should be systematically trained to march out rapidly and in order at the word of command. 
This really constitutes a fire-drill of a very useful kind in emergency.

The following articles (kept together in a box) will enable most school surgical emergencies to be temporarily met:-

Flexible Collodion

Cyllin, Kresol, or other good liquid antiseptic, with

$\begin{array}{lllllll}\text { directions for use } & \ldots & \ldots & \ldots & \ldots & \ldots & 8 \text { ounces. }\end{array}$

$\begin{array}{llllll}\text { Boracic Acid (antiseptic) } & \ldots & \ldots & \ldots & \ldots & \text { I ounce. }\end{array}$

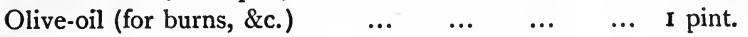

$\begin{array}{llllllll}\text { Cotton-wool } & \ldots & \ldots & \ldots & \ldots & \ldots & \ldots & \text { I l lb. }\end{array}$

Bandages, rolled calico, 2 inches wide, 4 or 5 yards long 3

These may be cut through with a knife, when rolled, to any narrower width required.

Calico, 2 feet square (fold diagonally for a triangular bandage).

Lint, or clean soft Rags.

$\begin{array}{llllllll}\text { Stout Cord } & \ldots & \ldots & \ldots & \ldots & \ldots & \ldots & 2 \text { yards. }\end{array}$

$\begin{array}{lllll}\text { Potassium Permanganate in crystals } & \ldots & \ldots & \ldots & \mathbf{1} \text { ounce. }\end{array}$

$\begin{array}{lllllll}\text { Safety Pins, large } & \ldots & \ldots & \ldots & \ldots & \ldots & \text { I dozen. }\end{array}$

$\begin{array}{lllll}\text { Lancet, or sharp clean Pocket-knife } & \ldots & \ldots & \ldots & \text { I }\end{array}$

First Aid in cases of Poisoning is dealt with in Appendix II, p. 183 .

\section{CHAPTER $\mathrm{X}$}

THE PERSONAL FACTOR, FATIGUe, RECREATION, SLEEP, AGE, SEX, AND ABNORMAL CHILDREN

There was a time when Mr. Grimwig's famous classification of all boys under the two great heads of "beeffaced boys" and "mealy boys" had its counterpart in the terminology of what then passed for Educational Science. One of the most striking evidences of the soundness and common sense of the so-called New 
Education is the disappearance of the "average child", the "dull child", and the "hopeless dunce" from wellmanaged schools. The "average child" survived for a long while-in fact, until it was relentlessly pointed out that he must of mathematical necessity be the rarest kind of child. With him there passed away that convenient young person the model child or Child-as-he-should-be, now happily extinct in all schools where a sound educational method is employed. The discovery of the Child-as-he-is has rendered it necessary for teachers to educate children in place of teaching subjects to classes, and this again has resulted in the discovery that the Child-as-he-is is the Individual Child.

Nowadays it is a truism that for the ordinary adult individual the spiritual side of life is largely subordinated to the physical side, and a trite poetic query as to the probability of the maintenance of philosophic calm under the physical stress of an aching tooth points a moral to the School Hygienist. Many notable and curious psychological phenomena in adults are now known to depend on simple physical causes, and the part played by the digestion in the psychology of everyday life has even been made the subject of a clever comedy. It is but logical to conclude that the plastic mental organization of a child, depending as it does almost wholly upon sensory and motor impressions for its development, must react still more profoundly to physical influences. The psychical crippling which is expressed by dulness, inattention, or even sullenness generally depends on some simple physical cause either in the teacher or the taught. There are possible psychical causes for such phenomena, but these can be safely set 
aside until the possible physical causes have been eliminated. The experienced teacher uses the signs of ill-health and fatigue in the individual as danger signals indicating pressing need for regulation of the working conditions of that individual or of the collection of individuals under his or her care. These signs are easy to read, and most teachers of any experience know them well enough in practice.

Fatigue is of two kinds, muscular and nervous. In either case certain waste products which have come into being as products of tissue-change are retained in the organization and exert a poisonous influence upon it. In either case also these poisonous bodies are naturally eliminated during rest, and any interference with the process of elimination produces that condition of poisoning which is termed fatigue and which interferes with the action of the muscular or nervous organization from which the poisonous bodies have come. It is not necessary to go into the minuter details of the two classes of fatigue, and for general purposes they may be taken as being largely dependent one upon the other.

The principal signs of fatigue are evident enough. The head drops forward, slightly at first, but more and more as fatigue increases. The face assumes a characteristic expression of general slackness of the muscles of expression-difficult to describe in detail, but recognizable enough as the "tired look". The reactions of the mind suffer coincidently and attention fails. The body muscles take part in the general relaxation, and the child lolls in its place. If ordered to sit up, the muscles soon relax again. The upper eyelids droop, and the child has a tendency to yawn. If the hands are held out at arm's- 
length in front of the body the fingers, and particularly the thumb, show a tendency to drop. Nervous excitable children if fatigued may stiffen the hands at first, but the thumb soon relaxes and the fingers curve down languidly. Corrugation of the forehead and grimacing are often seen in young children when fatigued. Sleeping in class is a very evident sign of fatigue, especially amongst the infants.

These signs have to be watched for in the individual, and when appearing in a number of individuals are indications that something is seriously wrong in the method of management. It is not easy in some cases to discriminate off-hand between mere idleness and the beginning of fatigue; in fact this can only be effectually done from the special knowledge of each individual child. Presuming this knowledge, the signs of fatigue will soon be noticed, and as it is mere waste ot time and energy to attempt to teach fatigued children, enquiry into the cause becomes necessary. The school conditions should be investigated first. Is the ventilation effective and intelligently utilized? Was the room perflated at the last change? What proportion of carbonic acid may be expected to exist? Is there any special or partial overcrowding? What is the effect of altering the blinds so as to give more light? What is the effect of improving the air-supply by opening the windows? Is the lighting adequate and intelligently utilized? How long is it since the last recreation or physical-exercise period? What have the children been doing since then? What has been the length of this lesson? What was the length and what the subject of the preceding lesson? Do the seats and desks fit the individual children? Is there any connection between badly-fitting seats and 
desks and early appearance of fatigue in particular instances?

Perhaps the school conditions can be exonerated, but certain children constantly show signs of fatigue at particular times. The enquirer then turns his attention to the individual circumstances of each case. Is he a nervous excitable being prone to early exhaustion? Is his rate of growth normal? Has he recently suffered from any acute illness? Does he appear to be sickening for any acute illness? What is known about his eyesight? Are there any obvious evidences of post-nasal growths? What are the home conditions? Does he get plenty of sleep? Are fresh air and cleanliness likely to be domestic virtues? Has he to walk far to school? Or to do much work before starting? In dairying localities this last question may produce startling results at times. And lastly, is he a lazy young scamp who is all go and vigour in the playground, but who assumes an air of exhaustion for the special benefit of a soft-hearted teacher? A little observation will generally settle this point; but it is not a conclusion to be jumped at without careful elimination of the other reasons for apparent exhaustion.

It is well known to most of us by experience that the onset of muscular and nervous fatigue bears no hard-and-fast relation to the amount of work done. Congeniality of work and the methods of its presentation have much to do with its effects qua fatigue. This brings us to another aspect of school fatigue-the teacher's ability to make his subject interesting and stimulating. We will have occasion later to consider the fatigue values of different subjects, but there is no doubt that young Britain aged ten at school has quite as keen an appreciation of a vivid 
and illuminating discourse upon some subject in which he may or may not take any particular private interest, as has grown-up Britain aged forty at a political meeting or public lecture. The points of view are certainly different, but it is the teacher's business to know where the light should be thrown on the mental landscape set out before him.

Now and then we hear a good deal about "overpressure" of school children under modern educational conditions, with all its concomitant effects of exhaustion of neurones and degeneration of the race. Well dished up, this appeals to the sentimentalist, but prosaically speaking, "overpressure" is generally due to neglect of common rules of hygiene. Given a well-constructed school providing plenty of fresh air and light, a sensiblydrawn syllabus, and a skilful and experienced teaching staff, overpressure need never be feared in school life. Failing these, however, we may look for overpressure, just as we may look for and find it and its results anongst underfed and overworked adult operatives in a manufacturing town. Books, pens, and black-boards are not necessary factors in overpressure; but foul air, badly-lit workplaces, improper food, and unhygienic habits may be depended upon to produce the feeling in anybody.

To a considerable extent the muscular and nervous activities are complementary. The principal time of rest for both is during sleep, but large tracts of the brain can be thrown out of gear and allowed to rest whilst physical exercise is being taken. As we have seen, the material waste products of brain action must be removed from the body or they will interfere with the action of the brain when work is again required from it. Physical movement 
undertaken under proper conditions of fresh air quickens the respiration and circulation and hence hastens this removal; if not carried too far it does not result in any appreciable replacement of the products of nerve waste by those of muscle waste. Nerve force is certainly used in these physical movements, but it is used in a different direction, a direction, moreover, for which the child organism is particularly adapted. The amount of nerve waste varies widely under different conditions, and we will have occasion later to go into the different fatigue values which have to be considered in the school curriculum.

It is obvious, on general principles, that we must look for the best educational results to short lessons, graduated with due regard to ages of pupils and difficulty of subjects, with frequent intervals of recreation and exercise for the removal of brain waste. Due precaution should be taken, however, against replacing the products of brain waste by the even more poisonous products of body waste. To this end, all recreation and organized physical exercise must be taken in the open air or in a specially wellventilated room, and not in the school-room. Change of attitude from sitting to standing is permissible here, but for the regular breaks between lesson periods, change of scene and air are required.

Sleep requires careful consideration from all who have to deal with children of school age, and the great variations in sleeping hours occurring at different ages have not received the attention they deserve. A child requires much more sleep than does an adult, and if deprived of it, its powers of reaction and recuperation suffer seriously. Children in dairying localities and in cities frequently do not get enough sleep. At five years 
of age a healthy child if given the chance will often sleep for an hour or two during the day, and for ten or eleven hours during the night. He needs every scrap of it, and although the mid-day sleep is given up as he grows older, the time spent in bed at night should be very gradually curtailed. Even at fourteen years of age a healthy child requires at least nine and a half hours' sleep, and the customary eight hours of our national proverb cannot be safely attained before twenty years.

The following table (British Medical Journal, vol. i, I905, p. 208) will show the manner in which a child's day should be spent at various ages:-

THE CHILD'S DAY

\begin{tabular}{|c|c|c|c|c|c|c|}
\hline \multirow{2}{*}{$\begin{array}{l}\text { Under } \\
\text { Age }\end{array}$} & \multirow{2}{*}{ Sleep } & \multirow{2}{*}{$\begin{array}{l}\text { Dressing, } \\
\text { \&c. }\end{array}$} & \multirow{2}{*}{$\begin{array}{c}\text { Meals } \\
\text { and } \\
\text { Rest }\end{array}$} & \multirow{2}{*}{$\begin{array}{l}\text { Free } \\
\text { Time }\end{array}$} & \multicolumn{2}{|c|}{ School } \\
\hline & & & & & Lessons & Play \\
\hline Years & Hours & Hours & Hours & Hours & Hours & Hours \\
\hline 4 & II I & I & 3 & $31 / 2$ & $23 / 4$ & $23 / 4$ \\
\hline 5 & I I & I & 3 & $31 / 2$ & $23 / 4$ & $23 / 4$ \\
\hline 6 & I I & I & 3 & $31 / 2$ & 3 & $21 / 2$ \\
\hline 7 & I I & I & 3 & $31 / 2$ & 3 & $21 / 2$ \\
\hline 8 & II & I & 3 & $31 / 2$ & $31 / 2$ & 2 \\
\hline 9 & I I & I & 3 & $31 / 2$ & $31 / 2$ & 2 \\
\hline IO & $101 / 2$ & I & 3 & $31 / 2$ & 4 & 2 \\
\hline I I & $101 / 2$ & I & 3 & $31 / 2$ & 4 & 2 \\
\hline I 2 & IO & I & 3 & 3 & 5 & 2 \\
\hline I3 & 10 & I & 3 & 3 & 5 & 2 \\
\hline 14 & $9^{1 / 2}$ & I & 3 & 2 & 6 & 2 \\
\hline
\end{tabular}

Some observers are disposed to increase the sleep and playtime at the expense of the lessons, but for our purpose these figures may be taken as the minima for safety. They cannot be averaged week by week, or year by year, but must be followed out day by day. Extra sleep will not compensate for extra brain work at the expense of rest and playtime. 
It will be noted that the basis of this classification by a profound authority upon all matters relating to the care of children, is Age. This question of age dominates all questions of sleep, recreation, and work throughout school life. A child of ten may weigh as much as another of twelve, but this does not form any excuse for curtailing the hours of sleep and play, or increasing the periods of work to the twelve-year-old limit. Physically that child is ten years old, and whether or not the teacher considers that he is mentally fitted for the work of a higher class than that which includes the majority of ten-year-olds, the physical facts cannot be safely neglected. Accordingly, if he is put up, his individual curriculum must at first be modified to suit his age and a sharp eye kept on his reaction to it.

On the other hand, in all questions of desking and seating age is neglected, and size governs the entire position. American children of six years vary in height some $6 \frac{1}{2}$ inches according to Professor Bowditch. At eleven years, according to the same authority, boys vary as much as 8.03 inches, whilst girls showed a difference of 8.63 inches. There is no reason to believe that these surprising variations are confined to America. The nonadjustable desk is hence impossible, and the specious lists of measurements put forward by certain manufacturers, to fit "all ages" of school children in three sizes of desk may be contributed without a pang to the waste-paper basket.

Sex requires consideration from several points of view, and it should first of all be clearly recognized that the growth of children of different sexes does not proceed in the same fashion throughout school life. Till about $12 \mathrm{~T} / 2$ 


\begin{tabular}{|c|c|c|}
\hline \multirow{2}{*}{ 至突 } & \multirow{2}{*}{$\frac{\dot{8}}{\dot{8}}$} & \multirow{2}{*}{ 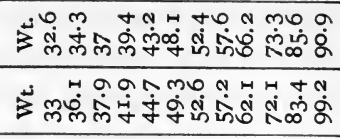 } \\
\hline & & \\
\hline \multirow{4}{*}{ 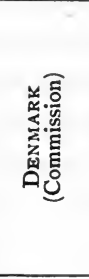 } & \multirow{2}{*}{ 总 } & | | | \\
\hline & & 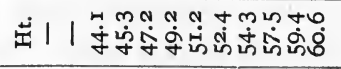 \\
\hline & \multirow{2}{*}{ 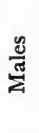 } & | | | \\
\hline & & 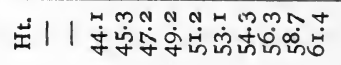 \\
\hline \multirow{4}{*}{ 总忿 } & \multirow{2}{*}{ 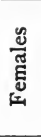 } & 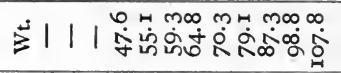 \\
\hline & & 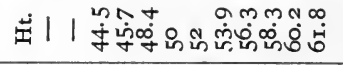 \\
\hline & \multirow{2}{*}{ 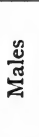 } & 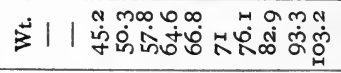 \\
\hline & & 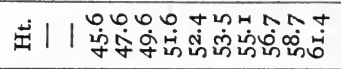 \\
\hline \multirow{4}{*}{ 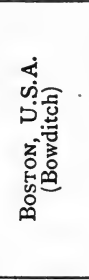 } & \multirow{2}{*}{ 苞 } & | \\
\hline & & 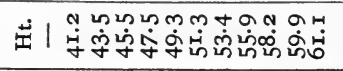 \\
\hline & \multirow{2}{*}{$\sum_{\bar{z}}^{\frac{\mathscr{s}}{\pi}}$} & 岁| \\
\hline & & 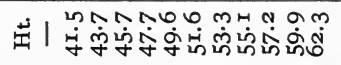 \\
\hline \multirow{4}{*}{ 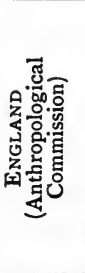 } & \multirow{2}{*}{ 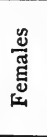 } & 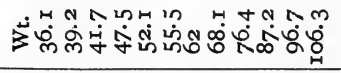 \\
\hline & & 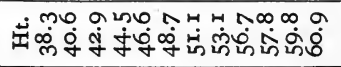 \\
\hline & \multirow{2}{*}{$\frac{\mathscr{y}}{\frac{3}{2}}$} & 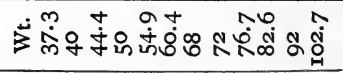 \\
\hline & & 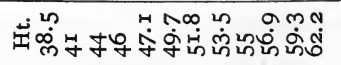 \\
\hline 본 & & త్ర \\
\hline
\end{tabular}


years of age the two sexes keep on fairly equal terms as regards growth, boys averaging an inch or two taller than girls. At about $121 / 2$ years, however, girls begin to grow rapidly, not only catching up the boys, but passing them, so that during the fourteenth year they are, on the average, almost an inch taller and considerably heavier than boys of the same age. The ratio of weight in both sexes is of great importance during school life, and any marked departure from it is of serious import. Any undue increase in height relatively to weight, or any sudden stoppage of growth, especially if accompanied by decreasing weight, should receive careful attention from the teacher and should be notified to the parent. A rapid increase in height is generally accompanied by great diminution of the powers of mental application and of physical work. The table on p. 142, adapted from the American Journal of Psychology, will serve to show the average height and weight observed in a large number of children of different ages in different cities and countries. The yearly average increments can be readily deduced.

A weighing machine and measuring standard should form a part of the equipment of every large school, and should be regularly used. In less extensive establishments arrangements can generally be made for ascertaining the weight of any children who appear to diverge from the usual physical standard.

The profound growth changes occurring in girls between I 2 and 14 years of age should receive careful recognition in school life. The onset of puberty produces notable psychical changes which must also be taken into account. The height and weight ratios should be carefully watched for stoppage or increase, and as Dr. Newsholme points 
out, an increase of height at this stage in a girl who has ceased to become heavier may be an early indication of threatened consumption. Great attention should be paid to securing fresh air, moderate regular exercise, and suitable food through this important period of life. Excitement and strain, physical or mental, should as far as possible be avoided, but steady well-chosen mental work does not do the least harm if the ordinary rules of hygiene are observed. Bad hygienic conditions, on the other hand-lack of fresh air, improper food, lack of exercise and recreation, together with forced mental work - may produce the most disastrous results, as indeed they may do at any period of school life in either sex. The advisability or otherwise of girls working for examinations is largely a question of individuality, but generally speaking, school girls are quite as capable of undertaking strenuous mental work without injury as are boys of the same age, provided that proper hygienic conditions prevail in their daily life. Defective mental or physical stability should, however, form a complete bar to examination work.

There will be found in almost every school of any size, certain children to whom the term abnormal may be applied without doing violence to the teachings of modern Educational science. In former days these were the miserable pariahs of school life, who welcomed the dismissal bell as affording a change from the hunted existence of the school-room to the comparative seclusion of the outside world, where they might be despised by their fellows but were seldom subjected to active torture. Nowadays, however, the pendulum has swung a little too far to the other side, and young educationists 
of a psychological turn of mind are apt to recognize abnormality where none exists. We are here concerned only with the less pronounced forms of abnormality, wherein the difficulty is, however, greatest. The completely deaf, the deaf-mute, the blind, the idiot, and the imbecile groups of abnormal children do not come within the scope of this book, although their care and treatment is a subject of great interest which may reasonably be taken as a highly specialized branch of scientific educational work. Morally degenerate children of both sexes also have to be reckoned with amongst the abnormal, and to the conscientious teacher they are a very heavy responsibility.

Excluding all these, there are certain children who cannot be regarded as possessing the necessary mental capacity to enable them to react to the stimuli supplied by ordinary school work. These will soon be detected by a skilful teacher, and require individual investigation. Again the physical causes should be excluded before the psychical are approached. Is there anything in the school conditions likely to affect that particular child? Can anything of the kind be ascertained regarding the home conditions? I have known a case where an extraordinary series of physical and mental phenomena in a child of $\mathrm{I} 2$ was traced to an escape of gas from a leaky pipe in her bedroom, but teachers cannot, of course, be expected to carry out investigations of this kind. If defective school conditions can be excluded with certainty as a possible cause, and home conditions do not appear to throw any light on the difficulty, personal defects require close consideration. The skilful teacher will have considered the possibility of artificial stupidity 
long before this stage is reached, and will have detected any obvious eye and ear defects. It is advisable if possible to get the parents to obtain a medical opinion before these can be completely excluded. Having got rid of post-nasal growths, perforation of the ear drum, or other deep-seated ear mischief, short-sight, long-sight, astigmatism, habit spasm, or other eye defects, and fatigue from any special cause, such as recent acute disease, the investigator has merely cleared the ground for the consideration of psychical phenomena.

Here is required a great deal of very special knowledge indeed, if the abnormality is not a marked one. The feeble-minded child can generally be picked out as the condition shades into absolute imbecility in marked cases, and the child with retarded intelligence usually bears evidence of retarded physical growth which assists in the diagnosis. The uncertain remainder are really subjects for the Specialist in Psychological Medicine; but a teacher's own sense may generally be relied upon to guide him, if he has proceeded on regular lines thus far in the investigation of an abnormal child. Such children should always receive special care and attention both inside and out of school. The finer degrees of mental and physical defects may cause great suffering in an otherwise sensitively organized child, by producing in the school a sense of inferiority, and of loneliness in the playground. The moral results may be disastrous if such a morbid condition is allowed to continue unchecked. 


\section{CHAPTER XI}

\section{THE CURRICULUM AND ITS HYGIENIC ARRANGEMENT}

The arrangement of the curriculum may at first appear, even to the experienced teacher, wholly a matter of pedagogic method. When looked at from a physiological stand-point, however, it will be seen that the school hygienist possesses an excellent right of entry to this apparently alien ground. The very raison d'être of the curriculum is to obtain the maximum of useful educational result, and it has already been made clear that the health of the children must not be imperilled or injured by the methods pursued. But another excellent reason, quite apart from any economic, altruistic, or humane ideals, is to be found for the exercise of special knowledge in the arrangement of the school curriculum. It is an indubitable fact that the best educational results cannot be attained by haphazard methods, and that any attempt to fit the curriculum to anything but the widely varying physical and mental needs and capacities of the child himself is predoomed to failure. Before this can be done it is obviously necessary to have a clear idea as to what these needs and capacities are, and how and why they vary so greatly. Teachers nowadays cannot afford to proceed on a trial-and-error system, because although the trial part may be interesting, the errors mean waste of time and waste of money. More than this, they often mean impairment of somebody's chances of usefulness and happiness in after-life.

The cultivation of child life at school ages is a highly 
artificial process for which Nature has made no special provision, and which in fact must, even under the best conditions, be carried on to some extent in actual defiance of her intentions as expressed in the physical and psychical construction of children. Fatigue we have already considered in its more evident aspects, but far short of the point at which physical expressions of fatigue can be noted by the most experienced observer, we may meet with overstrain which is capable of serious interference with the acuteness of the mental reaction. The brain does not turn the whole strength of its grey matter on to any subject at once, and for all practical purposes teachers are working with a series of little brain-plots in each individual, from each of which by assiduous planting, manuring, and watering they desire to get a maximum crop of a separate plant. To pursue the agricultural metaphor, the seed, the soil, the season, and the climate vary in each of these plots, and vary again to some extent in each individual. Teachers are growing exotic plants most of the time, and growing them too in trust land whose proprietor may some day require a strict account of their stewardship.

Without hunting an unfortunate metaphor to death I hope to have made it clear that there are very good reasons why the school hygienist may with propriety have something to say about the curriculum. The attainment of the best results depends upon the conformity of the curriculum with elementary physiological and psychological facts ascertained and proved by experience. It may seem rather a dry sort of subject, and even an unpractical one for the everyday work of teaching. Nevertheless, experiments have been made 
in order to ascertain the best working limits of the child brain under very variable conditions, and they have incontestably proved that if mental application is carried beyond a certain point in any one direction under any one set of conditions, more is lost than is gained. Moreover, if this condition of overstrain is rendered continuous-and it will be remembered that overstrain in this sense is quite a different thing from fatiguepermanent damage results to the powers of mental reaction and real harm is done. The brain can protect itself from overstrain for a long while, but it does so at the expense of the immediate educational results.

It is scarcely necessary to remind teachers that they are tied down irrevocably to the natural capacities of their pupils. There is no royal road to learning either for the teacher or the taught, and hence it is impossible to expect much from a curriculum which is arranged from any other stand-point than that of the minds and bodies which are to be submitted to the education process. Convenience of particular teachers, conveniences of school management, such as the rotation of classes in special subjects, and subjects of supposedly special value, must be all subordinated to the dominant natural laws of supply and demand. If the child brain does not want arithmetic, for instance, at a particular time it will not accept arithmetic, and if it has had enough arithmetic at one dose it will not have any more just then. The nominal proprietor of the brain may be quite anxious to acquire arithmetic, perhaps under stress of those mental and physical stimulants to the pursuit of knowledge which teachers know how to apply, but he is powerless in the matter. Neither he, nor the teacher, 
nor anybody else can get a crop of arithmetic off that exhausted brain-plot until the existing one, such as it is, has been garnered into the bulk stock of arithmetic which he keeps in his mental storehouse, and the ground has had time to be freshened up for the next sowing. Persistence only means waste of good arithmetic and further exhaustion of the arithmetical brain-plot.

Before a working syllabus can be constructed, therefore, a number of apparently extraneous matters have to be taken into account. Age is of course highly important, but later on we will have occasion to go into its importance with some degree of detail. Subjects are important from our present stand-point, in relation to the ages at which they are imparted, to their fatigue values, and to the working conditions which they demand. The structural conditions of the room used by each class at each lesson may well receive attention, since the most mentally fatiguing lessons should, for reasons which will be easily understood from what was said about fatigue, be carried on under the best available hygienic conditions in order to avoid superadding bodily strain to mental stress. The time of day is of much importance, and it is a recognized axiom in many educational systems that the real acquisitive work should be all carried out in the morning, the afternoon being devoted to subjects requiring comparatively little application. The time of day hence requires close coaptation to subjects, particularly in schools where defective hygienic conditions prevail, as these may produce a steady deterioration of powers of reaction throughout the school day. The day of the week, and the period of the term, also have their effects on receptiveness; length of lessons, and their 
punctuation by intervals of physical occupation, require to be considered in relation to the attitudes required and the amount of eye-strain and brain-strain resulting from them. The hygienic conditions of a room may also impose limits in this direction.

Finally, the home conditions may often be taken into account with advantage as they are found to exist at various seasons and in various localities. In agricultural and dairying districts children often reach school in an actual state of exhaustion at certain seasons of the year, owing to the amount of work they have been called upon to perform at home, and the limited hours of sleep. These, and possibly other considerations which may be of importance under special conditions, all require attention from the thoroughly skilful teacher, who is bent on getting the best results out of his material, and they have a very practical bearing upon inspectorial results when the time comes to take stock of the mental storehouses of the pupils. We may now proceed to discuss some of the matters in rather more detailed fashion.

Age is perhaps the dominant factor in school life, so far as the curriculum is concerned. At the great Teacher's Conference held in London during January, I 905, one of the speakers made a strikingly wise assertion, that whereas we generally account a University Professor the most important of our teachers, infinitely more important is the nursery governess or the teacher of the Kindergarten class. With this I wholly concur, and the reasons will be sufficiently obvious when we realize that it is in the infant rooms that the material is most delicate and most plastic, and that it is above all at the age of habit formation. The actual basic knowledge of life 
is gained here, and contrary to frequent usage it is the last place in the school where the inexperienced teacher should be found. We recognize this in the training of animals, and no good horse trainer allows his yearlings to be spoiled by beginners. Those who have had much to do with horses know well that vice is generally a matter of bad breaking in, and similarly the gun-shy or roving dog is the product of loose handling in puppyhood. When we have these and a score more of good analogies from other divisions of the animal creation, when we have Froebel's historical warning that it is not the child that is playing but primitive man that is trying to educate himself, and when we have the expressed experience of great educationists all pointing to the same conclusion and based on incontrovertible physical facts, we are forced to recognize the fact, if we have not done so already, that the Kindergarten and infant teacher ultimately dominate the result of the whole school and of the whole educational organization.

The brain attains almost its full weight by the end of the seventh year, and although mental capacity is not to be estimated by mere weight of brain, the child is throughout this time recapitulating ancestral stages of development. All the while, the physical and mental reactions are gradually specializing from the coarser to the finer. "The child of five or six is undergoing a strenuous education by virtue of mere living; he pursues knowledge through his waking hours, looking, touching, talking, asking, listening, for the myriad stimuli that are awakening him into fuller life." If a teacher can assist him to find these she is helping him on towards a useful life: if she hinders him she is doing him an irreparable injury. 
There are children who sit still motionless or asleep all day, seeking no stimuli, but these children are idiots. The normal infant is continually at work exercising and developing his motor and sensory brain cells. The brain does not develop all at once in its various areas, but separate patches of it are continually bursting into spring, and each of these springtimes once over will never recur. Of course one cannot make out a calendar of the cerebral seasons according to age; individualization is even more important in teaching infants than it is in later school life, and the springtimes have to be watched for. But on general principles it is safe to rely on appeals to the senses and to gradual training of the motor powers by constant experiment and habit formation. To take a single example: Mr. Horsfall, an accepted English authority in this subject, has laid it down that "there are not half a dozen children in every thousand who cannot gain the power of singing correctly and of enjoying music if they are well taught in childhood while the nervous system can easily form habits, and have not yet formed the habit of not noting differences of sound".

Another quotation will serve to illustrate my meaning -it, too, is from a skilled educationist speaking at the I905 Conference on School Hygiene in London:- "We forget that many die to beauty very early in life, even though nearly all had once power to grow in the love and appreciation of it". Once past seven, and these habits of not noting sensory impressions are often fixed for ever, but vast oceans of real character-forming knowledge can be imparted before that age by a skilful and sympathetic teacher.

The infant school is the school of large movements 
and not of fine ones, because the basal motor reactions develop in that order. The shoulder and elbow must be thoroughly trained before we can attempt to specialize on the hands and fingers. Watch the sweeping free actions and continual movement of a five-year-old child directly he gets outside the school door, and ask yourself whether it is natural for such a one to be kept sitting upright at a desk for an hour on end doing fine work. This can be taught as a habit just as almost anything else can be taught as a habit at this age, but it is a useless unpractical habit. For merely disciplinary purposes a dozen other habits would serve as well. Correct attitude when sitting or standing, to avoid undue compression or strain of organs or muscles, is a profoundly important habit to form here, but it must not be continued too long at first or it will produce strain and fatigue.

The eternal battle for correct working attitude, with the body straight and the eyes at least I 2 inches from the work, must be commenced on the day the infant begins school, and relentlessly carried on. The six-yearold, with his left ear on the desk strenuously rendering himself myopic by a steady glare at a pen-point wobbling in response to the physiological clumsiness of his feeblycontrollable hand-muscles, will then be no longer a common object of the school-room.

The habit of proper breathing (that is, breathing through the nose, with good inflation of the upper part of the chest) should receive close attention from the infant teacher. Whilst this is being imparted post-nasal growths can often be detected and efforts made to procure the removal of these serious impediments to educational results. The cultivation of the faculty of attention in 
infant pupils is one of the most delicate and really scientific branches of the teaching art, and one which possesses in high degree that sporting element which appeals to most human beings. Beyond alluding to its importance-for upon its degree of development depends to a considerable extent the character formation of the child-I need not emphasize this to experienced teachers.

The habit of appreciating and distinguishing colours and sounds must be formed almost wholly in the infant school if it is to be real and lasting. "The Goth and the Artist sit side by side in the child brain, and if we do not cultivate the Artist the Goth will rule, as he rules to-day despite the vast sums of money spent on picture-galleries and libraries." A better system of infant teaching will some day, perhaps, enable these to be appreciated by the multitude.

The habit of discipline is formed here, and all play must be disciplined, albeit gently. The debated question of corporal punishment hinges principally upon the training in the infant school. With good infant training any frequent necessity for the cane in later school life points at once to defective hygienic conditions from whose effects pupil or teacher or both are suffering. It is needless to say that real corporal punishment in the infant school is wholly unnecessary and inadmissible. If babies are to be beaten it should be done by their parents, and that teacher who cannot develop in the normal small child the habit of not deserving a beating, should work elsewhere than in the infant room.

Books are rarely required for these bases of character formation, and pens, ink, fine pencils, needles and thread, and anything else which demands fine work from the 
physiologically uncontrollable finer muscles and the physiologically long-sighted eye, should be banished from the infant rooms. These things do not teach life, and it is life that is being learned. Every object of attention requires to be large, simple, distinct, and well lit. Fine needlework, fine print, and writing between lines are hygienic crimes if committed upon children under seven years of age, for they demand fine movements and fine sighting. Both are impossible of attainment except at grave risks, and in any case such matters could be properly learned in a quarter of the time during any later year. These things waste time, money, and chances in life, and interfere seriously with the work of the higher classes.

After seven years the teacher must accept to a great degree the results of the kindergarten. If it has been a child garden in reality the work of drafting a hygienic curriculum is comparatively easy, but if on the other hand it has been a manufactory for artificial flowers the difficulties will be enormous if the best educational results are to be expected. The finer movements are now becoming well developed, the eye is losing the physiological long-sightedness of infancy, and the reasoning powers are awakening. The child is losing to a great extent its powers of forming new habits, and is beginning to think.

So much, then, for the great factor of age, so far as it can be now alluded to. A great deal of valuable experimental work has been done in connection with the varying Fatigue Values of Subjects, and some curious results have been obtained. Of mental subjects mathematical studies are stated to be the most fatiguing, 
and hence require to be taken first in the school day. Foreign languages come next, and should be correspondingly treated. Religious instruction comes next in order. History, natural history, and nature study are least fatiguing. Singing and drawing vary widely in their fatigue value in different subjects. These results are worthy of study, but an American observer (Thorndike) has raised certain objections to their value. These objections, however, point rather in the direction of crediting the methods of teaching with a large influence for or against the production of fatigue from any given subject.

It is scarcely necessary to emphasize the importance of the Time of School Day on the receptiveness of children, beyond referring to its practical appreciation in several leading educational systems, where all subjects requiring real application are dealt with in the morning. "The most taxing work", as Professor Shaw points out, "should come in the first hour of the day". The marked influence of holidays in stimulating receptiveness is well known to experienced teachers, and the best and most enduring work is to be expected on physiological principles early in the day, early in the week, and as early in the term as possible after the settling down and readjustment of life have been completed.

The punctuation of mental work by proper intervals of physical occupation and recreation is of the greatest importance in securing the best mental reactions. There are few attentive students who have not realized by experience the difficulty of keeping even a trained adult intelligence fixed upon any one subject-particularly a dry one-for more than a certain length of time, but 
in the case of children this period of attention capacity is usually very short at first for any subject and of very gradual growth. At six years of age most children cannot fix the attention for more than fifteen minutes on any one subject, and this slowly increases until at twelve years of age thirty minutes of close attention can often be obtained. Here again the personality of the teacher is a powerful factor, but it is a safe rule to prescribe short intensive periods followed by activity of a different kind. Hence frequent interludes of physical occupation or play, sandwiched between short varied lessons, not more than two of which separate any two physical interludes, really save educational time instead of wasting it.

Amongst modern educationists it is accepted almost as a truism, that excessive Home-work is an expression of inferiority in teaching skill, the teacher thereby proving that he regards his work not as teaching but as hearing and setting lessons and examining home-work. From the school hygienist's point of view home-work is quite inadmissible before twelve years of age, and should never exceed one hour daily at ages from twelve to fourteen. In any case it should never break new ground, but should merely recapitulate work done during the day. Serious doubts are being cast on the value of, or necessity for, home-work at any age, even for examination purposes, where an afternoon session exists. Some good reasons for this statement will, no doubt, suggest themselves from what has been said concerning fatigue and overstrain. A further objection to home-work lies in the frequently defective home conditions as regards lighting and working atmosphere generally, physical and mental alike. If parents demand home-work, either as a proof that they 
are getting what they consider to be value for their money, or with a view to establishing habits of industry and keeping the child out of mischief, some constructive work of a manual character may be prescribed with advantage. This is of far greater value to the real mental development of the child than any book-work can ever be, for it is concrete and engages his interest.

It may seem a bold undertaking to introduce a brief allusion to Punctuality into this chapter, but physical life is largely a matter of punctuality on the part of the various organs and cells which go to make up our bodies. There are good hygienic reasons for punctual observance of lesson periods both at their commencement and their termination, and there are further excellent educational reasons. If any part of school life is to suffer by unpunctuality, however, it should not be the rest or play periods. These should never be encroached upon save possibly for disciplinary purposes at the end of the school day. Even then, real acquisitive work should be excluded, and the period of detention utilized in physical and not mental exercise. In the chapter on school cleaning a suggestion was made as to a practically useful method of employing punishment detention, but this is only one of many methods which will readily suggest themselves. 


\section{CHAPTER XII}

THE TEACHING OF HYGIENE TO CHILDREN

In Chapter I (p. 15) certain reasons are briefly set forth to show the necessity for systematic instruction of children in the elementary laws of health preservation and health protection as an essential portion of their training in citizenship. The proofs of such necessity are forthcoming on all sides. They are evident in the slouching corner groups of town streets; they spring out on us in every room of well-nigh every workman's home; their results fill our hospitals and empty our tax-paying purses. Setting aside the sceptic who "don't believe in these 'ere germs", the Christian Scientist who allows children to choke to death of diphtheria, the wretched victims of the quack and the cure-all vendor, and all such freaks of ignorance and foolishness, we have still to pay a vast bill for our past neglect. The stress of civilization presses ever more heavily, and Nature resents to-day any infraction of her immutable laws as remorselessly as she did in the long-past days when our savage ancestors wrung a scanty living from a stubborn environment. Failing instruction in the Art of Life we must ever be exposed to more and more risk. In ancient days the penalty for ignorance came in the shape of vast and horrifying epidemics, which left the few survivors shuddering in their loneliness to repeat their sanitary crimes and to receive fresh correction after long intervals. Now it comes in less wholesale but none the less deadly fashion, for the increased stress renders wounded and maimed bodies well-nigh as helpless 
as does death itself. The school teacher will not be the sanitary administrator of the future; but it is only through his-and particularly her-work and intelligent co-operation that any nation can ever hope to attain to that natural physical morality wherein preventible disease shall appear in its true light as somebody's crime, and the preservation and protection of health shall be accepted as a sacred duty. Prevention is proverbially better than cure, but its results are less evident. It is only at school ages that the national common sense can be so developed as to include the habits of health, the intelligent inclusion of health protection amongst the great life-purposes, and the appreciation of the physical side of the life environment as an all-controlling influence upon the spiritual side.

Withal there is no need to weigh down a school curriculum with heavy masses of hygienic or scientific teaching. As Professor Kenwood has pointed out, the bare, basic laws of healthy living might be written on a half-sheet of note-paper, and committed to memory in a single lesson by any normal child. Yet this will not serve; mere dogmatic teaching never can serve to influence the really useful independent after-mind. Habit, mind-pictures, attention, and reasoning must form the steps in hygienic teaching as in any other basic subject of child instruction. With it can be interwoven other teaching-of profound individual and national importance. Elementary hygiene, domestic economy, and elementary civics may be so taught as to form one subject of profound interest, and to create an increasing purpose towards the healthy happy life of the Eugenist. Above all, the teaching must be practical. In every school the material is ready, the necessity is ever present; the results to be obtained are 
the very things which will increase mental reaction and assist the development of mental powers. From a pedagogic stand-point elementary hygiene provides the teaching tripod of seeing, reasoning, and remembering; from a national and personal stand-point its effects are to lessen taxation for preventible disease, to increase educational efficiency, and to develop the national and individual common sense. Let us review some of the methods which may be employed for these most desirable ends.

The infant (grouping under this generic term all school ages up to and including eight years) is wholly a creature of habit. We have already seen the necessity for forming here the habits of proper working, attitude, of proper breathing. To cause young children to intuitively keep their eyes a foot or so from their work, whilst adopting an attitude which does not cramp their chests or tire their backs, and to practise them at frequent intervals in the art of filling and emptying their lungs to their full extent in the open air are simple matters. Yet they are of immense importance. Upon the latter accomplishment can be gently grafted the habit of noticing and avoiding stuffiness and foul air, for in after-life more err through ignorance and thoughtlessness in such matters, than sin deliberately. The habits of personal cleanliness and tidiness may be instilledhowever old and ragged are the clothes, the normal child body can always be made a wholesome shrine for the soul within. A daily hand and head drill should especially include the youngest children. The habit of seeing dirt is all-important, for on its non-development depend many of the abominations of the domestic 
environment of so many lives. The habit of disliking and removing dirt forms a natural corollary. In the formation of these habits the school-room should be made to assist as an ever-present example of cleanliness and tidiness. The habit of not-spitting, if taught in early years, may save many lives, and no child is too young to learn the disgrace and danger attendant upon this consumption-spreading and unnecessary accomplishment. The habit of clean feeding and the habit of drinking clean water may well be added to the list. No books, no models, no particular expenditure of time, are required for this teaching. A few pictures may occasionally be of service, but are not essential. Yet the results are astonishing in the hands of an interested and skilful teacher.

So we may follow the child into the nine to twelve year attention-plus-mind-picture stage. The habits have been formed, and if well implanted are ineradicable. The habit of proper working attitude requires close attention from the teacher, however, as the working materials become smaller and contain finer detail. Elementary information as to the necessity for care of the eyes both in school and at home may be imparted. A working sanitary organization may be formed with great advantage in each class, one child being selected at fortnightly intervals by the teacher as sanitary officer. To this functionary may be deputed the executive responsibility for attending to the ventilation during school time, and particularly of throwing open the windows to perflate the room when recess or dismissal arrives. Before the class assembles in morning or afternoon heor she-should be required to see that the room has 
been thoroughly aired and is sweet and wholesome. The general cleanliness of the class-room or class-space should also form a portion of the official responsibilities. If instituted as a reward for merit such a position will be eagerly sought after, the semblance of authority so conferred being much prized by children. The duties and responsibilities should be systematized by the teacher, and the record of each successive occupant checked. A small prize at the end of the year will tend to stimulate interest, and a simple badge should form one of the honours of office.

In addition to this, no opportunity should be neglected of impressing upon the children's minds the necessity and reasons for personal cleanliness and tidiness. At the morning assembly the examination of hands and heads before the children are marched in should never be omitted. This can be rapidly carried out with the children in open ranks, the teacher passing along in front of and behind each rank. The information so obtained is of great use. It enables certain cases of communicable disease to be detected and excluded before entering the school-room, it checks the return of contacts before quarantine periods are up (see Chapter VII), and it exercises a powerful effect upon personal cleanliness and tidiness. It further familiarizes the teacher with the physical characteristics of the children to a degree which is impossible under school-room conditions only.

Regular instruction in the methods and benefits of personal and domestic hygiene may now be systematically commenced and carried on. The advantages of health and the simpler principles of health-protective precautions can easily be rendered attractive at such ages. The 
necessity for care of the teeth-with an explanation of the practical uses of the tooth-brush, the necessity for clean bodies and clean underclothing, the advantages of open bedroom windows, and the disgrace and danger of promiscuous spitting, are excellent subjects for instruction. The communicable nature of certain diseases (which should be named and briefly described-see Chapter VII - where prevalent in the country or locality) may be alluded to, and the Golden Rule used as an exemplification of the necessity for care in protecting others from them. Where the local sanitary organization issues printed information concerning any of these diseases, or habitually carries out disinfecting measures, the objects of such procedure should be simply explained and its benefits pointed out.

Here also some practical instruction may well be given in actual methods of cleaning the school-room and its surroundings. School cleaning does not differ greatly from ordinary house cleaning, and in most rural localities the school must almost inevitably be more or less dirty unless the teacher enlists the services of the children. The instruction so imparted is not only of extreme value from an educational point of view, but has, for reasons already given, an important influence upon the health and welfare of the children both during and after school life. The principles of mutual organization and effort for the common good cannot be better exemplified than by the formation of school-cleaning gangs from the children themselves, preferably by competitive selection. Few parents will be found to object once the question is put before them in a proper light, and with tactful management the children themselves can soon be made the 
strongest supporters of such an organization. The authority of the class sanitary officers should be preserved by giving them a sort of non-commissioned rank. The work should be controlled by the teacher through a sani-: tary monitor.

In the higher classes, from twelve years onwards, very little difficulty should be found in carrying the instruction on to a more specialized degree. The appointment of a sanitary officer for each class or class group should be continued, but the appointments should be made for a fixed period by ballot of the class or class group interested, and the duties extended on definite lines. This will form a peg on which to hang useful information concerning the methods of civic, municipal, or even political election. Elementary Hygiene should form a regular subject of instruction, sufficient Physiology being taught with it to explain the principles involved. Communicable and preventible diseases, together with domestic methods of disinfection and isolation, should be clearly explained, and the requirements of local law concerning such diseases indicated, together with their moral aspects. A friendly officer of health or other medical man can perhaps be induced to give an occasional demonstration and explanation of such matters. Such questions as those of proper food, exercise, the dangers of an impure watersupply, the abuse of alcohol and tobacco, refuse disposal domestic and civic, ventilation, and the general outlines of healthy living, should receive some detailed attention. The choice of a text-book or reader merits careful attention, and mere dry collections of hard facts should be avoided. Due attention should be paid to local requirements and local examples-it is, for instance, 
of little use to describe the details of a modern system of sewerage to a child living and likely to continue living in a back-blocks township. The broad general principles of physical self-respect, and avoidance of avoidable disease, will supply enough material to enable the children in any locality to be thoroughly taught, without going beyond their own schools and their own homes for concrete examples of what to do and what to avoid.

Especially should the alcohol question be sensibly dealt with at these ages amongst boys and girls alike. Mere strings of appalling facts-facts though they beare of little use in this connection, as compared to the physical self-respect argument, when boys are to be instructed and warned. The line of reasoning in the boy-mind subjected to the usual temperance fireworks is only too often: "Father gets drunk sometimes-he never murders anybody, or gets into jail-teacher's talking nonsense". He probably uses a shorter and terser word. If a teacher can rather suggest examples of the athlete in training who must not drink, of the helplessness of the drunken person if called on to help others or to save life by some heroic feat, of the manner in which drink interferes with strength-development in young men, he is far more likely to catch the boy-mind. It is the period between boyhood and twenty-five years which produces drunkards and alcohol-degenerates. Hence one can advise a boy with perfect truth and wisdom, that he needn't look forward to always remaining a total abstainer, but that on his twenty-fifth birthday he will be old enough to decide what he will do about it-not before, save at the risk of his strength and vigour. Girls can be taken on the cost and home-comfort side - a 
deftly woven calculation of the annual cost of six pints of beer per week, and a bottle on Sundays, converted into clothes and holiday trips, will often strike deeper than the most lurid tales of wife beating and child desertion. Total abstinence to twentyfive is also an advisable lesson, and particularly should the specifically poisonous effects of alcohol on babies be insisted upon. Finally, it should be carefully ascertained that the children do not leave school with a dim idea that "alcohol" is some weird poison sold by chemists, and consumed only by blotchy-faced drunkards.

There is no possible doubt as to the profound necessity for instructing girl-pupils in the elements of domestic economy and domestic management. It is not possible for all schools to run cooking or housekeeping classes, but it is possible for very many schools to give a certain amount of instruction in such matters. Not the least useful kind is an occasional demonstration by a friendly nurse to the elder girls upon the proper methods of clothing, washing, and generally caring for a baby. With a little tact a real baby can generally be obtained for demonstration purposes-its mother being, of course, asked to attend-and young mothers (often themselves the school-girls of a very few years before) may be invited. Preparation of baby food for artificially-fed infants forms a useful part of the demonstration; but it must be always explained that artificial feeding is artificial feeding, and that the natural food should always be given wherever possible. The following pamphlet on the feeding and care of babies is distributed to Tasmanian schools, as well as to parents and others registering the births of children. 


\section{THE FEEDING AND CARE OF BABIES}

\section{1.-WRONG FEEDING IS DANGEROUS}

Every year many babies in Tasmania die through wrong feeding. A great many more are made very ill from the same cause. Wrong feeding is also very likely to make children grow up unhealthy and weak when they ought to be healthy and strong.

Young babies are delicate and tender little things. A very little will upset them, and they cannot stand starvation or exhaustion. Wrong feeding causes both these.

\section{2.-BREAST FEEDING IS BEST WHEREVER POSSIBLE}

There is only one natural way to feed a baby-that is, from the breast. Every mother who ean do so should nurse her baby till it is at least seven months old, or better still, nine months. If she can nurse (provided that the milk agrees with the child) and does not, she is selfishly risking the child's health. She is also risking her own health to some extent, because breast-nursing is very helpful in her recovery.

\section{3.-HOW NURSING MOTHERS SHOULD LIVE}

When nursing, the mother should be careful of her health, and should take no alcoholic drinks. Some people think that a nursing mother must take stout or ale to keep her strength up. This is quite wrong. It does her no good, and often does the child harm.

A nursing mother should take plenty of plain nourishing food, and regular gentle exercise, and should have plenty of fresh air for herself and the baby. She should also try to live as quietly as possible, avoiding excitement and late hours. There is no reason for a healthy nursing mother to think herself an invalid merely because she is nursing, or to altogether neglect her housework after she has quite recovered from her lying-in. 


\section{4.-ONLY FEED ARTIFICIALLY IF NURSING IS IMPOSSIBLE}

If the mother cannot nurse her baby-that is, if she is too ill or weak from any cause, or if the milk does not come, or if (after trying) it is found that the child does not thrive properly on the breast-artificial feeding ("hand-feeding") becomes necessary.

Sometimes a mother can give only a few meals a day from the breast, but not enough for the child to thrive on alone, although what there is of the breast-milk is good. Then both artificial and breast-feeding can be used. Whatever good breast-milk she has should be given, even if it is only one meal a day, so long as it does not upset the child.

\section{5.-THINGS TO RECOLLECT FOR BABY'S SAKE}

I. Never give a young baby Arrow-root or "Arpowroot Biscuits". These are absolute poison to it, whatever the advertisements tell you. Never give bread, or sago, or potatoes, or tea, or cheese, or any solid food. Never give it "a bit of anything that's going ".

2. Never give a baby Teething Powders, or Soothing Syrups, or "Baby Quieteners" of any kind. These usually contain opium, and are very dangerous. They may be the means of "quietening" the baby for ever. It does not matter what the advertisements say; they are written to sell the preparation, not to help your child.

3. Keep the baby warm in cold or cool weather, especially its feet and legs, but don't muffle it up; babies want fresh air. Keep it cool and dress it lightly in warm weather.

4. If the baby is hand-fed everything the food touches must be as clean as you can get it. Have two proper feedingbottles (one in use, one being cleaned), a special enamelled saucepan, and a jug for making and keeping the food in. Clean the feeding-bottle out after every meal (see below for directions).

5. The food must always be Preshly made. Stale food is poison to babies. Make it twice every day-morning and evening. 
6. Flies and dust must be carefully kept away from the food. You don't want to put filth into your baby's food, so remember some of the places where flies are fond of sticking their feet and crawling about in. Dust is often dried gutter-dirt, or worse.

7. Feed the baby at regular times. Do not forget to feed it at these times, and do not feed it in between them.

8. Get the best and purest and freshest milk you can, even if you have to pay more for it. It is cheaper in the end.

9. Do not wean the child in hot weather if it can be avoided.

\section{6.-HOW TO BRING BABIES UP BY HAND}

Until the child is at least seven months old nothing but milk and cream properly diluted can be digested. "Infant foods" should not be given to any baby under seven months except by a doctor's special direction.

I. Until it is six weeks old, a baby should be fed every two hours between 4 o'clock in the morning and ro o'clock at night, and once in the night between these times.

How to make the food.-Mix a quarter of a pint of fresh pure cow's milk (one part) with half a pint of freshly boiled water (two parts), in a clean enamelled sauce-pan, which is kept for baby's use alone. Bring the mixture just up to the boil and take it off the fire. Then stir in with a clean spoon a small tea-spoonful of good brown sugar. Put it into a clean scalded jug or mug, cover it with a clean cloth or a metal cover, and keep in a clean cool place.

This supply is enough for half a day at first (see below, "Simple rule for feeding"). It should be made twice every day. Any remains from the old food should be thrown away, and the jug rinsed and scalded when the new supply is ready.

How to elean the bottle. - The best feeding-bottles are shaped like a boat, with an opening at each end. On one end is a short rubber teat which can be easily turned inside out for cleaning. Take off the teat, turn it inside out, wash it thoroughly inside and out in clean tepid water till it is quite clean and sweet. Then 
wash the bottle out with tepid water and a small bottle-brush to get rid of any food left in it. Then put the bottle in boiling water for a minute. Take it out and stand it on end in a clean place to let the water drain out. Cover it with a cloth to keep dust off while it drains. Rinse the brush in tepid water and then dip it into boiling water.

Have two bottles, so that one is always ready for use whilst the other is being cleansed and is draining. After feeding wipe the baby's mouth out gently with a little piece of soft flannel dipped in. boiled water.

How to give the food.-Every two hours, from 4 in the morning till ro at night, and once in the night measure out (with a clean spoon) three table-spoonfuls of the food (at first) in the clean bottle and put on the clean teat. Put the bottle of food into warm water until it is just about as warm as your hand. Never give the food cold. When warm enough put the teat in the child's mouth, and it will generally do the rest. When the bottle is finished, or the child has had enough, rinse it out. After the first week, begin to give two or three table-spoonfuls extra every week in each day's feeding (not in each meal). At three weeks the child will want a little over four table-spoonfuls at a meal, at five weeks about six table-spoonfuls. As more food is taken more will require to be made at one time. Gradually increase the milk after the first month by about a tea-spoonful every two days to each quarter-pint used.

2. When the baby is six weeks old you should begin to give more milk and some cream.

Instead of using one part of milk and two of water, you now use equal parts of milk and water boiled and sweetened as before. Do not change it suddenly, however, but get the child used to it. Mix about two tea-spoonfuls of fresh cream in every meal. The sugar is at the rate of a small tea-spoonful to each pint of food.

Eight table-spoonfuls of this should be given at each meal every two hours up to seven weeks, watching the motions to see that curds are not being passed. If they are, give rather less food at a meal.

From the seventh week gradually lengthen the times between feeding (ten minutes or so every few days), and at the same time 
increase the amount at each meal a little to make up. When the baby is eleven weeks old it should be getting about ten table-spoonfuls at a meal every two and a half hours between 4 in the morning and ro at night. Gradually increase the milk when making the food, so as not to upset the baby's stomach when the next change is made.

3. When the baby is three months, and until it is seven months old, you again add more milk, and still keep to the cream.

Use two parts of cow's milk to one part of water (that is at the rate of one pint of milk to each half-pint of water), boiled and sweetened.

Gradually increase the amount of food till about twelve tablespoonfuls at each meal are being taken. Increase the cream till it is three or four tea-spoonfuls with each meal. Watch to see that the motions do not contain curds.

Lengthen the time between feedings gradually till when it is seven months old the baby is being fed every three hours from 4 in the morning till Io at night. Increase the arnount of each meal as the time is lengthened. The meal in the night between ro and 4 need not be given now unless the child happens to wake.

Simple rule for feeding up to seven months.-Begin with about thirty-two table-spoonfuls a day as above (I). Increase this at the rate of about two to four table-spoonfuls a week up to the end of the seventh month.

4. When the baby is seven months old it is usually beginning to cut teeth. Some may cut them earlier, some later.

Now use less and less water when making the food until the baby is soon getting ten or twelve table-spoonfuls of good pure cow's milk with four table-spoonfuls of cream in it at each meal every three hours between 6 or 7 in the morning and 9 or ro at night.

The beginning of teething is a sign that the baby can take a little other food than milk. Therefore, to three of the meals stir in, after boiling well, about a tea-spoonful of baked flour or some good infant-food. Do not give this for more than one meal at first, and watch the baby carefully to see if the new food agrees with it. At 
the same time let it have something hard to bite on. A fresh wellpicked chop-bone with a little salt on it, or a hard, leathery piece of crust, will do well for this. See that they do not fall on the floor, or if they do, that they are not used again. These hard articles are not for food, but as exercisers for the jaws, and to help the development of sound teeth. Never use a "baby comforter".

5. From twelve to eighteen months give from twenty to twenty-four table-spoonfuls of pure cow's milk every three hours between early morning and night. Porridge, bread and milk, bread and gravy, bread and butter, or a lightly boiled egg, may gradually be given in place of some of the milk as the child grows during this time.

\section{7.-CONDENSED MILK}

This is never so good for babies as fresh milk. If it must be used, make the milk up with not more than two parts of added water (that is at the rate of one table-spoonful of the condensed milk to every two table-spoonfuls of water), and use it in place of the cow's milk in the food described above. If the condensed milk is that known as "sweetened", the brown sugar may not be necessary.

Never give a baby condensed milk from a tin which has the word "skimmed" or "separated" on the label. Most of the good has been taken out of these kinds of condensed milk and the child will be starved.

\section{8.-BABY'S HEALTH}

I. If the baby, although growing well, becomes fretful and peevish, or if he suffers from indigestion and vomiting or diarrhoea, look at his motions. If whitish lumps of curded milk are passed, reduce the food or add more water, and be especially careful about regular feeding.

2. If the baby loses flesh or (especially in hot weather) gets diarrhœa, with slimy or green motions, take it to the doctor. Then do just as he tells you, for he knows a deal more about babies: insides than you or your neighbours do. 
3. Never give too much food at one meal. A new-born baby's stomach will only make use of, or even hold, three or four tablespoonfuls at a time, so that it is useless and harmful to allow it to gorge itself from a full feeding-bottle.

4. Don't think the baby wants feeding every time it cries till nursed or fed. Often it is thirsty (babies get thirsty, just like their elders), and a little water is what it really needs; or it may have a pain, and the food will make this worse afterwards. Babies can be easily trained to regular hours for feeding.

5. Watch the baby's growth and condition carefully. Some children can digest more food and some less than others. Big babies of course require more food than little ones of the same age. The amounts given above are good average quantities, but may perhaps be rather too much for some or rather too little for others.

6. Don't put binders on a baby. Don't let its feet get cold. Don't neglect to change and wash its napkins regularly. Don't let it chafe under the napkin. Don't dress it in flannelette shirts if you possibly can get woollen or gauze flannel.

$$
\begin{aligned}
& \text { J. S. C. ELKINGTON, M.D., D.P.H., } \\
& \text { Chief Health Officer of Tasmania. }
\end{aligned}
$$

Department of Public Health, Tasmania, 1906. 


\section{APPENDIX I}

THE HEATING OF SCHOOL-ROOMS, AND HOW IT MAY BE MADE TO ASSIST IN VENTILATION

Heat is conveyed in three ways: namely, Radiation, Conduction, and Convection. Radiation is the principal channel for heat-supply from an open fire. The heat rays pass out in straight lines and fall only on those sides of objects which are towards the source of heat. They do not warm the air through which they pass. Their intensity decreases in inverse proportion to the square of the distance, so that if two surfaces of equal area are placed respectively I and ro feet from an open fire, that at $\mathrm{I} 0$ feet will receive only one-hundredth part of the heat received by that at $\mathrm{I}$ foot. When we know, in addition, that some nine-tenths of the heat produced in an ordinary open fireplace goes up the chimney, it will be readily seen that radiant heat from an open fire is uneconomic and unsatisfactory.

Where open fireplaces are used as the sole source of heat in schools, the fire should be lit at least an hour before the children assemble, in order that the walls and furniture may be warmed up sufficiently to prevent them from robbing the children's bodies of heat. Open fires are certainly cheerful, and where hot-water or steam heaters are installed a fireplace should also be provided in each room. They assist in some degree in ventilation, but are frequently so placed that the air extracted by them is not drawn from the inhabited parts of the room but from cracks in the door and window fittings and 
from under the floor. The practical result of open fireplaces in cold weather is that the children are warm on one side and cold on the other, and their feet and legs are often exposed to cold draughts. These remarks do not of course apply to properly placed "radiators" in a heating system.

Conduction is effected by the passage of heat from one particle of matter to others in contact with it. Air is a very poor conductor of heat.

Convection depends on the transference from place to place of masses or currents of warmed air. If this is pure air the possible utilization of convection in the ventilation of schools will be obvious. The physical principle involved is illustrated by the hot "draught" from a chimney-top (where, however, the conveyed heat goes to waste), or by the rising and falling currents seen when a glass vessel of slightly sedimented water is heated. Properly applied the convection of heat can be readily utilized for school-heating purposes, with much economy in fuel consumption, and great assistance to ventilation.

The ordinary unlined cast-iron stove is a dangerous and undesirable appurtenance for school-rooms. It is particularly apt to get red-hot, in which case poisonous gases are liable to permeate the metal and to affect the occupants of the room. Particles of organic matter in the air settle on the hot metal and are burned, a fusty unpleasant odour resulting. These stoves also reduce the proportion of air moisture (relative humidity), and cause irritation of the throat and lungs, with liability to "cold", when the inmates emerge into the moister and colder air outside. Finally, they do not assist in ventilation to any appreciable extent, and are wasteful of fuel. 
The various forms of ventilating stove or ventilating fireplace afford practically the only solution of the ventilation-warming difficulty for country schools, and for those town schools where radiators or mechanical ventilation with warming of the air are not provided. These devices vary in form and also in efficiency, but all depend largely on the convection of heat by air. They use the fuelheat to warm the pure air obtained from outside, and hence yield far more economic results than can be expected from radiation alone, however well applied.

One of the earliest and best patterns for use with fires is that of Galton, whose well-known ventilating grate is widely used. It should, however, be put in when the chimney is built, and is expensive to fit to an existing fireplace. The Hygiastic and Manchester stoves are other good patterns for school use.

George's Calorigen, and Bond's Euthermic ventilating stoves are useful and effective. They are fitted for use with gas rather than with ordinary fuel. Where gas is available and a proper "humidifier" is employed they yield excellent results with proper management. Care must be taken to prevent the heating agent from playing directly on the inlet air-tube.

A useful device for employment with any kind of fuel is found in the jacketed ventilating stove. This practically consists of a long air duct reaching from outside to 5 or 6 feet above the floor, in which is placed a slowcombustion stove lined with fire-clay and so constructed as to prevent its becoming red-hot. The smoke and gases from the fire are led to the outside by means of a pipe or flue. The humidity of the warmed air is restored by a water tank or humidifier. 
The fresh-air duct should be made of galvanized iron, and should be at least 6 inches by 12 inches in its narrowest sectional area. Its outer end is protected by a hood and a cover of half-inch mesh galvanized wirenetting. It is led in under the floor, and the inner end opens under the stove, which may be of any good slowcombustion pattern. Round the stove is placed a sheetiron cylinder, 5 or 6 feet in height and large enough to leave an annular space of at least 8 inches in all parts. It should fit close to the floor. A water tank is fitted either on the jacket or on top of the stove, with a small baffle-plate to direct the air over its surface. It should contain at least 2 gallons. This tank should have a gauge and filling opening. If it fails to provide sufficient moisture, strands of lamp-wick or pieces of flannel may be hung from wires over the tank so as to dip into the water and to increase the humidifying surface. The cylinder is provided with a small close-fitting door to enable the fire to be replenished and the stove to be cleaned. Dampers can be fixed in the inlet pipe and stove pipe to regulate the flow of air and the flue draught respectively.

In all systems of heating by the admission of warmed air to a room, two things must never be forgotten. These are:-

I. That adequate outlets must be provided, or the air will not continue to flow into the room. 2. That sufficient moisture must be added to the warmed air to keep the relative humidity at about 70 per cent.

The first of these requirements will have been already made clear from the chapter on Ventilation. The second depends on the fact that the amount of moisture which 
air is capable of taking up varies with the temperature of the air, and increases rapidly as the temperature is raised. Thus, a cubic foot of air at $32^{\circ} \mathrm{F}$. can only take up $2 \cdot 13$ grains of water, whereas at $100^{\circ} \mathrm{F}$. it can take up over I 9 grains. The relative proportion of moisture in the air has a powerful influence on health and comfort-most people are aware, for instance, of the marked difference between "dry heat" and "moist heat" even when the actual thermometric reading is the same in each case. It is found by experience that the most comfortable and healthy proportion of moisture at about $60^{\circ} \mathrm{F}$. is somewhere about 75 per cent of the total capacity for moisture of the air at that temperature. With this proportion the natural evaporation from the body will not be increased to an uncomfortable extent, nor will it be checked with consequent heavy sweating or chill. Average air in temperate climates contains somewhere about this proportion of moisture, although in certain places, or under certain conditions, it may be above or below this. When such air is brought, at a temperature of say $40^{\circ} \mathrm{F}$., into a room at $65^{\circ} \mathrm{F}$., it is obvious that the relative humidity will be greatly lowered, and that for health and comfort it will be necessary to replace the missing moisture. This is also necessary for economy in fuel, as dry air does not carry heat nearly so well as does moist air. The "relative humidity" can be readily calculated by the use of tables from observations on wet- and dry-bulb thermometers. The requisite moisture can be readily added by allowing the warmed air to flow over a sufficient surface of water, and, as already stated, lamp-wicks or pieces of flannel may be used to increase the exposed water-surface.

A useful addition to the George or Bond pattern of 
stove is known as a "humidifier". This consists of a box open at the bottom and also at two of its sides. A small water tank is placed under the side openings, and strands of lamp-wick are hung about an inch apart from wires so as to dip into the water tank. It is placed over the air duct on the top of the stove. The warmed air enters at the bottom and flows out of the side openings through the moist wicks.

The heating of buildings by hot water or steam from a central boiler and furnace cannot be dealt with here, and the reader is referred to one or other of the standard works on the subject. Hot-water heating has been brought to a high degree of efficiency and economy, especially in America, and now forms a special branch of engineering. In cold climates an installation of this nature for schools of any size possesses great economic advantages both as regards fuel-consumption and comfort.

The relative proportion of expenditure on heating apparatus in new buildings is very striking when a comparison is made between England and America. In installing any such system, however, due regard must be given to the maintenance of proper relative humidity, and to the assistance and maintenance of ventilation by means of the available heating surfaces. A small fireplace should always be provided in a mechanically-heated school-room.

A thermometer should form an essential piece of apparatus in every school-room, and its uses should be explained to the children. Amongst English people a temperature of about $60^{\circ}$ or $65^{\circ} \mathrm{F}$. is found the most suitable for schools in cold weather. In America $70^{\circ} \mathrm{F}$. 
is aimed at, and in several of the States teachers are directed to dismiss the class if the temperature falls below $60^{\circ} \mathrm{F}$. The difference probably depends on the greater dryness of the air arising from the radiators which are so generally used in America. As has been already pointed out, the maintenance of a proper degree of relative humidity improves the warming power of the air and thus economizes fuel.

\section{APPENDIX II}

\section{POISONING}

Very special knowledge is required for the treatment of cases of poisoning, and a medical man should be sent for at once. The following directions are given in order to enable urgent symptoms to be relieved to some extent pending his arrival, or for use in cases where no medical help is available.

\section{General Principles}

The main general objects of treatment are: r. To get rid of as much as possible of the poison from the body as quickly as possible where this can be done with safety. 2. To counteract what remains. With some poisons (arsenic, antimony, \&c.) vomiting occurs naturally; with others (carbolic acid, strychnine, opium, \&c.) it does not, and has to be produced; with others again (acids and strong alkalies) it must not on any account be artificially 
produced, owing to the danger of perforating the corroded stomach. The poison must then be neutralized in the stomach. In poisoning by gases, and in certain internal poisons, such as opium, carbolic acid, and prussic acid, artificial respiration may be necessary.

It is always advisable to preserve some of the vomited material for examination by the doctor.

\section{To INDUCE Vomiting}

I. Give half a pint of warm water with a table-spoonful of mustard stirred into it; or,

2. Give a pint of tepid water at a time, and tickle the throat entrance with the finger or with a feather. Repeat till vomiting occurs.

\section{To CHECK EXCESSIVE VOMITING}

I. Let the patient lie down.

2. Give sips of cold water (or better still, small pieces of ice to suck).

In cases of poisoning, especially by strong acids or alkalies, great shock and prostration may occur. The patient should then be kept warm, hot bottles or warm bricks wrapped in flannel being packed about the body and applied to the legs, and the body covered with warm blankets. 


Porsons

\section{ACIDS.}

Sulphuric Acid (Oil of Vitriol).

Hydrochloric Acid or Muriatic (Spirits of Salt). Nitric Acid.

Carbost Acid.
Hydrocyanic Acid.

Prussic Acid. Cyanide.

\section{Trentment and Antidotes}

Do not cause vomiting, but endeavour to neutralize the acid by giving one of the following in plenty of water:-

I. (a) Whiting, (b) powdered chalk, (c) wall plaster, (d) washing soda. Soap and water may be given freely if none of these is at hand.

2. Next give one of the following: $(a)$ olive-oil $1 / 4$ pint in I pint of water, $(b)$ milk or milk and egg, $(c)$ thick gruel.

3. Mitigate shock by keeping the sufferer warm with blankets and hot-water bottles or warm bricks applied to the sides, legs, and arm-pits.

I. First give half an ounce of Epsom salts in a pint of warm water.

2. In a few minutes induce vomiting (if this is done at once the acid will not have had time to be neutralized, and may cause more danger).

3. Then give large draughts of milk, or olive-oil, in water, as under $2(a)$ above; or white of egg in water in large draughts.

Keep the sufferer lying down, and use artificial respiration if the breathing fails.

I. Place the sufferer in the open air.

2. Induce vomiting immediately.

3. Dash cold water on head and along spine, and at once

4. Use artificial respiration.

5. Hold smelling salts to nose at short intervals.

6. Give tea-spoonfuls of a mixture of equal parts of spirits and water.

The greatest promptness is required, as these poisons act with exceeding rapidity. 


\begin{tabular}{l}
\hline \multicolumn{1}{c|}{ Porsons } \\
\hline Oxalic Acid. \\
Salts of Lemon. \\
Salts of Sorrel. \\
\hline II. ALKALIES. \\
Caustic Soda. \\
Caustic Potash. \\
Soap Lye. \\
Ammonia.
\end{tabular}
POISONS.

\section{Antimony.}

Tartar Emetic.
III. METALLIC

\section{Treatment and Antidotes}

I. Do not cause vomiting, but give freely of $(a)$ whiting, (b) powdered chalk, (c) powdered wall plaster, $(d)$ or lime-water.

2. Large draughts of milk.

I. Do not cause vomiting. Try to neutralize the alkali by giving freely of $(a)$ vinegar in plenty of water, $(b)$ lemon juice or lime juice in water.

2. Afterwards give plenty of milk, or of white of egg and water, or olive-oil, $1 / 4$ pint in water.

3. Mitigate shock as under Acids.

I. Encourage the vomiting by giving tepid water in large draughts. If vomiting has not occurred, induce it.

2. If vomiting becomes excessive, give plenty of strong tea. Repeat as vomiting recurs.

3. When vomiting subsides give freely of milk or white of egg in water.

4. Treat shock as described.

Arsenic.
1. Induce free vomiting at once.

2. The best antidote is made by mixing an ounce and a half of tincture of perchloride of iron with a wine-glassful of water, and adding to it half an ounce of washing soda dissolved in half a tumbler of water. Give half of the mixture when the vomiting subsides, and the other half in ten minutes. Repeat as necessary.

Or, dialysed iron, a tea-spoonful at a time up to ten tea-spoonfuls, each followed by a little common salt dissolved in water.

3. Afterwards give freely of milk and white of egg, or olive-oil in water, or barley-water.

4. Treat shock as described, and thirst by sips of cold water. 


\begin{tabular}{l}
\hline \multicolumn{1}{c|}{ Porsons } \\
\hline Copper. \\
Blue Vitriol. \\
Verdigris. \\
\hline Mercury. \\
Corrosive Subli- \\
mate. \\
White Precipitate, \\
Cinnabar, \&c. \\
Calomel. \\
\hline
\end{tabular}

\section{Phosphorus} Match-heads. Rat-paste.
Silver Nitrate.

Lunar Caustic.

Zinc Salts.

White Vitriol. Burnett's Fluid.

\section{Treatment and Antidotes}

I. Give at once plenty of milk and white of egg, or flour and milk, or flour and water.

2. Then induce free vomiting.

I. Give at once plenty of milk and white of egg, nixed; or of water and white of egg. If these are not at hand, flour and water will do some good.

2. Then induce free vomiting.

I. Induce free vomiting at once.

2. Three grains of copper sulphate dissolved in 4 ounces of water given every five minutes till vomiting is again produced, and then every fifteen or twenty minutes, is useful as an antidote as well as an emetic.

3. The best antidote is old (French) turpentine, 40 minims in I ounce of water every quarter of an hour, for one hour. American, German, or any other turpentine than Old or French turpentine, should on no account be given.

4. Milk and eggs freely. On no account give oil or fat of any kind.

I. Give at once two table-spoonfuls of common salt in a tumblerful of water. Repeat if vomited.

2. Then induce vomiting.

3. Then give large quantities of white of egg in water.

Do not induce vomiting but give-

I. Plenty of white of egg and milk.

2. Plenty of washing soda dissolved in warm water.

3. Plenty of strong tea. 


\begin{tabular}{l}
\hline \multicolumn{1}{c}{ Poisons } \\
\hline IV. ORGANIC \\
POISONS. \\
Alcohol alcoholic \\
(Acute aisoning). \\
pois
\end{tabular}

Chloral.

Poisonous Fungi (mushrooms).

Meat, Fish, \&c.

Opium.

Laudanum.

Chlorodyne.

Paregoric.

Morphine, \&c.

Strychnine.

Nux Vomica.

\section{Treatment AND Antidotes}

I. Induce vomiting.

2. After vomiting has occurred freely give I ounce of Epsom salts in a tumbler of water.

3. Cold water to face. Hot coffee when roused.

4. Artificial respiration may be required, and the patient should be kept warm whilst it is being applied.

I. Induce vomiting.

2. Keep patient warm. Rub limbs and body in direction of heart.

3. Hot coffee when able to swallow.

4. Artificial respiration may be necessary.

I. Induce vomiting if it has not occurred freely.

2. Unless bowels are already loose give I ounce of castor-oil.

3. Keep warm. Give sips of hot coffee.

I. Induce vomiting.

2. Give plenty of hot strong coffee.

3. Give eight grains of potassium permanganate crystals dissolved in half a tumbler of water.

4. Cold water dashed on face and neck.

5. Keep patient warm. Apply artificial respiration if necessary, as for cases of drowning.

I. Give at once 30 drops of tincture of iodine in half a tumbler of water.

2. Then induce vomiting.

3. Then give plenty of strong tea. 


$\begin{array}{r}\text { Poisons } \\ \hline \text { Turpentine. }\end{array}$

V. POISONOUS GASES.

\section{Coal Gas.}

\section{Pit Gas.}

Sewer Gas.

Acetylene Gas.

Hydrocyanic Acid Gas.

Fruit Fumigation.

\section{Treatment and ANtidotes}

I. Induce vomiting.

2. One ounce of Epsom salts in a tumbler of water.

3. Milk and white of egg freely.

I. Get the patient into the fresh air.

2. Dash cold water over face and neck, but do not wet clothing through.

3. Artificial respiration.

4. Warmth.

5. Smelling salts to nostrils, sips of strong coffee, or spoonfuls of spirits and water.

Proceed as under Hydrocyanic Acid, with exception of inducing vomiting. 


\section{APPENDIX III}

\section{CARD SCHEME FOR PHYSICAL DETAILS OF SCHOOL-CHILDREN}

(Front)

Icbool

Name

Date of Birth

Place of Birth

Father's Name

Father's Occupation Mother's Occupation (if any)

Address

Admitted (date)

Class allotted

Physical defects or personal peculiarities on admission

Disease History on admission

Height, ins. Weight, lbs. $\mid$ Eye Test (Card) $\mid$ Hearing Test 


\section{(Back)}

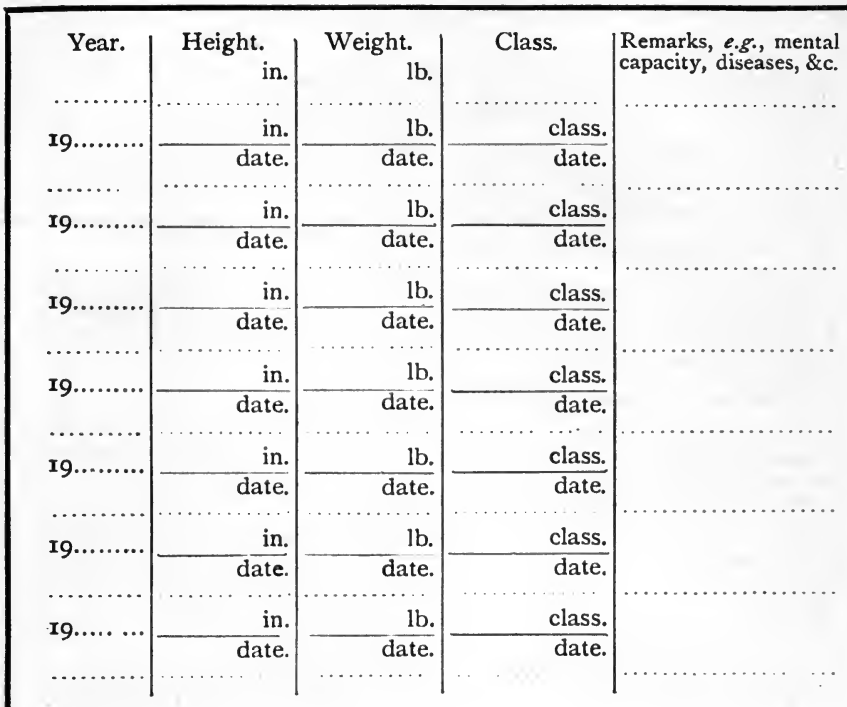

Date of, and reason for leaving

Remarks (e.g., after-career, \&c.) 


\section{N D E X}

Accidents, 114 .

Age, in reference to sleep, recreation, work, $14 x$.

Air-amount needed, 17; contamination of, 17 ; effects of contaminated, 17; fatal effects of highly contaminated, 18; educational need for fresh, 28.

Air, sewage, indications of presence of, 18, 19.

Alcohol, its abuse, 116; teaching regarding, 167 .

Ambulance training, advantages of, Ir 6 .

Artery, spirting, how it cannot be stopped, I16.

Astigmatism, ror ; disease of students, 104 .

Attention, cultivation of faculty of, 154 ; duration of, 158 .

Attitude, forward-sitting, 45; backward-sitting, 47; correct working, 154 .

Black-boards, 52.

Bleeding, $1 \mathrm{r} 6$.

Blight, 93 .

Blinds, 44.

Brain, growth of, 152.

Breathing, 16 ; habit of proper, 154 .

Building, purposes of, 40 .

Burns, 125.

Carbolic acid, 59.

Carbonic acid, effects on mental reaction, 17.

Card system, 189.

Ceilings, height of, 43 .

Cesspools, 72 .

Chicken-pox, 89.

Children, abnormal, 144 .

Chlorinated lime, 59.

Choking, 12r.

Chorea, or St. Vitus Dance, 95.

Cleansing - necessity for, 40, 53 ; educational value of, 40,53 ; influence on disease, 79 ; methods of, 55 ; structural assistance in, $4 \mathrm{r}$.

Closets, 68; dry-earth pan, 69.

Collar-bone, broken, 124 .

Coloration of walls, 42 .

Communicable diseases - spread of, 78; detection of, 164 ; dirt and sequels of, 79 ; incubation periods, 82 ; mild cases of, 83 ; readmission after, 83 .

Conduction, 176 .
Consumption, 94 .

Convection, 176 .

Corrosive sublimate, 60.

Cubic space per child, practical limits of height of ceiling in reckoning, 23 .

Curriculum and hygienic arrangement, I47.

Cuts, first treatment of, 120.

Cyllin, 6r.

Desks and seats, 45 ; dual, 49 ; evils of ill-fitting, 45 ; need for adjustable, 51; rearrangement in lighting, 36 ; requirements for good, 48 : Sheffield, 50.

Diphtheria, 83 .

Dirty heads, 9 I.

Disinfectants-chemical, 59 ; methods of using, 62 ; misleading advertisements of, 58 ; physical, 58 .

Disinfection, 58; school-room, 62.

Dislocations, 125.

Domestic economy, need for teaching girls, 168.

Drains-flushing, 74; absence of, 67 . filtration gutter for, 75 .

Draughts, 20, 26.

Drinking-cups, 66.

Drowning, 130.

Dust, danger of, 18, 40; methods of removing, 54 ; structural avoidance of, $4 \mathrm{r}$.

Ear defects, I to; foreign bodies in, 126.

Enteric fever, 88.

Eugenists, happy life of, $16 \mathrm{r}$.

Eye-astigmatism, ror, ro4; foreign bodies in, 126; habit spasm, 104; long sight, ror; short sight, ro2.

Eyesight-dullness due to defective, Ir 4 ; educational importance of, 96 ; methods of testing, 105, 106; results of defective, 97 .

Eye-testing, ro6.

Fainting, 127.

Fatigue, kinds of, and signs of, $x_{35}$.

Filter, 65.

Filtration gutter, 75 .

Fire-drill, I32. $_{32}$

Fits, 127 .

Floors, 44 .

Formalin, 6o.

Fractures, 122.

Fumigation, uselessness of, $6 r$.

Furniture, 44. 
German measles, 87.

Growth of children, 142.

Growths, adenoid, x10; post-nasal, 1 ro.

Habit, formation, 153; spasm, ro4.

Hæmorrhage, 116 .

Hearing, rog; testing of, I12 ; postnasal growths and, 1 ro.

Heat as a disinfectant, $5^{8}$.

Heating, 176.

Height-average, 142; necessity for observing ratio of, 143 ; variation in, at equal ages, 51 .

Homework, 151, 158.

Humidifier, 178 .

Hygiene-educational value of, 123; arrangement of curriculum to suit, 147 ; teaching of, to children, 160.

Hypermetropia, 104.

Incubation periods, 82 .

Infant-care of, 169; training of, 124, I51; teacher, 152.

Injuries of school life, 114.

Interiors-materials, 39 .

Itch, 93 .

Izal, 6r.

Kerol, 6r.

Kindergarten teacher, influence of, 152.

Kit, emergency for schools, 133 .

Kitchen waste, 77.

Lavatory waste, 74 .

Lessons, rotation of, 149 .

Lice, $9 x$.

Lighting-amount of, 32 ; artificial, $3^{8}$; direction of, 32 ; effects of wrong direction, 36 ; effects on air of artificial, 17: methods of improving, 37 ; results of defective, 30 ; teachers responsibility for, 30,31 ; tests for amount of, 32.

Long sight, ror.

Malaria, 96 .

Measles, 86.

Medical inspection, 13.

Mumps, 88.

Myopia, ror, ro3.

Nightsoil, 71.

Nits, gr.

Nose, foreign bodies in, 127 .

Nose bleeding, 127.

Ophthalmia, 93.

Overpressure, 138.

Oxygen, 16.

Pediculosis, 9r.

Perception, 108.

Perchloride of mercury, 60.

Perflation, 24, 28.

Poisoning, 182.

Privy vaults, 72 .

Punctuality, 159 .
Quarantine periods, 82.

Radiation, 176.

Recreation 159.

Refraction, errors of, rox.

Refuse house, 77.

Relative humidity, 177 .

Respiration, artificial, 130.

Rest, 139.

Ringworm, 92.

St. Vitus Dance, or Chorea, 95.

Sanitary accommodation-amount required, 68; construction of, 69 ; earth closets, 69; management of, 71 ; cesspools, 72.

Sanitary officer, 28.

Scabies, 93.

Scalds, 125.

Scarlet fever, 85 .

School Hygiene-meaning of, 7 ; scope of, $\mathrm{II}$; lavatories, 74 .

School-room, length of time it may be continuously occupied with safety, 28.

Seats-See Desks.

Sex, 14 I.

Short-sight, ror.

Slates, evils of, use of, 52.

Sleep, 139.

Small-pox, 89

Snake bite, 128.

Snellens' types, ro8.

Spitting, tubercular diseases and, 94 .

Splints, 123.

Sprains, 126.

Stoves, 177 ; ventilating, 178.

Subjects, fatigue value of, 156 .

Syllabus, construction of, 150.

Thermometer, $\mathbf{r} 8 \mathbf{r}$.

Tuberculosis, 94 .

Typhoid fever, 88.

Urinals, 73.

Vaccination, 89 .

Ventilation-by windows, 24,28 ; heating and, 26,176 ; importance of, 16 ; mechanical, 26 ; natural defects of, 26 ; principles involved in, 22 ; purposes of, 16: ventilators, examination of, $2 \mathrm{x}$; ventilating stoves, 178 .

Vision, tests of, 96-110.

Walls, 42.

Water-contaminated, 63 ; methods of purifying, 65 ; filtering or boiling, 65 ; storage of, 66 .

Weight, average, of children at different ages, 142 .

Whitlows, 95 .

Whooping cough, 87 . 


\section{BRIEF - GENERAL - LIST - OF}

\section{MATHEMATICAL • SCIENTIFIC \\ AND - TECHNICAL - WORKS}

PUBLISHED • BY • BLACKIE · AND · SON • LIMITED

\section{Arithmetic}

A Complete Short Course of Arithmetic. By A. E. Layng, M.A. A new highly practical text-book, covering the whole ground of the ordinary school course, and provided, in addition, with separate sections on mental and other short and approximate methods of calculation. With Answers, Is. 6d. Without Answers, Is.

Layng's Arithmetic. By A. E. Layng, M.A., Editor of "Layng's Euclid". With or without Answers, $4 s .6 d$. In two Parts, with or without Answers, 2s. 6d. each. Part I: To Decimals and the Unitary Method. Part II: Unitary Method to Scales of Notation.

Layng's Exercises in Arithmetic. (The Exercises of the above, published separately.) Crown 8vo, cloth, 2s. $6 \mathrm{~d}$.; with Answers, 3s. Part I (5000 Exercises), Is.; with Answers, Is. 6d. Part II (3500 Exercises), Is. $6 d$.; with Answers, $2 s$.

A Complete Arithmetic. With Answers, 234 pages, Is. $6 d$. Exercises only, 192 pages, $1 s$. Answers only, limp, $6 d$. net.

Higher Arithmetic and Mensuration. By Edward Murray, Mathematical Master at the Civil Service Institute, Dublin. With Answers, 3s. $6 d$.
Higher Rules. For Commercial Classes, Civil Service and other Examinations. $6 d$. With Answers, $8 d$.

Mercantile Arithmetic. For Commercial and other Classes. By E. T. Pickering. Cloth, Is. $6 d$.

Short Cuts and By-Ways in Arithmetic. By Cecil Burch. A labour - saving Arithmetic. With full explanations, many examples, numerous exercises, and a chapter on Magic Squares, \&c. $2 s$.

Blackie's Supplementary Arithmetics.

Decimals and the Metric System. 2d.; cloth, $3 d$.

Common Weights and Measures. $3 d$.; cloth, $4 d$.

Higher Rules. Cloth, $6 d$. With Answers, cloth, $8 d$.

Answers, separately, $3 d$. net each.

The Teacher's Black-Board Arithmetic. By “Tact". In two Parts, Is. 6d. each.

Mental Arithmetic. Consisting mainly of Problems specially designed to give the power of ready solution. $6 d$.

Examination Arithmetic. I200 Arithmetical Problems and Exercises with Answers, selected from Examination Papers, \&c. Classified by T. S. Harvey. 2s. Key, 4s. 6d. net. 
Typical Mental Problems. In Six Numbers, each, paper, $2 d$. ; cloth, $3^{d}$.

TEACHER's Fidion of Typical Mental Problems. Numbers I to VI. With Answers, 6d. each.

Typical Government Problems. Numbers I to VI, each $40 \mathrm{pp}$., paper, 2d.; cloth, $3 d$. ; Answers to Numbers I, II, V, VI, $2 d$. net each. Answers to Numbers III and IV (one vol.), $3 d$. net.

Practical Problems in Arithmetic. Mental and Written. Numbers I to VII, each, paper, $2 d$.; cloth, $3 d$. Answers to Numbers I to VII (one vol.), cloth, $3^{d}$. net.

\section{Blackie's Arithmetics for Course} "B". Crown 8vo, large type, many examples.

Nos. I, II, \& III, each, No. VI, $3^{d}$. $2 d$.

Nos.IV \& V, each, $21 / 2 d$. No. VII, $3^{\mathrm{I} / 2 d}$. Cloth covers, $x d$. extra.

Answers to Nos. I and II, one vol., $3 d$. net; to Nos. III-VIII, $3 d$. each net.

Arithmetical Tests for Scheme "B". Numbers I to VII. Paper, Id. each. Answers to the Seven Numbers (one vol.), cloth, $3 d$. net.

\section{Blackie's Concentric Arith-} metics. The treatment is concentric: formal rules are avoided : practical exercises: measuring work provided : newer methods of subtraction and multiplication explained : printed in script figuring.

Book I. .......3d. | Book III.....4d .

Book II......... 3d. Book IV......6 Answers, Books I-II (one vol.), $3 d$. Book III, $3 d$.; Book IV $3 d$. net.

\section{Blackie's Model Arithmetics for} Scheme "B". Concrete sums. Three-Term. In Script Figuring.

Book I......1 I $1 / 2 d$. Book IV....21 $1 / 2 d$. Book II ......2d. Book III ...2d. Book V......3 d. Book VI..... 4 d.

Cloth covers, I $d$. extra.

ANSWERS I-III (one vol.), $3 d$. net , IV-VI , " $3 d$. net

Blackie's Three Division Arith metic. A New Series based on
Scheme B, for use in schools adopting the tripartite classification recommended by the Board of Education. No. I, 2d.; No. II, $4 d$.; No. III, 4d. Answers (complete), cloth, $6 d$. net.

Blackie's Script-Figure Arithmetics. In Bold Written figures, specially designed for the series. Nos. I and II, I $d$. each. Nos. III and IV, $2 d$. each. Nos. V, 3d., VI, $4 d$. Cloth, I $d$. extra each. Answers I-II, $3 d$. net; III-IV, $3 d$. net; V-VI, $3 d$. net.

\section{Blackie's New Scottish Arith- metics.}

A First Course in Arithmetic (Junior Division). $4 d$. Cloth, 5 d. Answers.

A Second Course in Arithmetic (Senior Division). Cloth, 6d. With Answers, $8 d$. ANSwERS, separately, $3 d$. net.

Merit Certificate Arithmetic. Covering the whole work of the Standards. Cloth, 8d. With Answers, cloth, rod. ANSWERS, separately, cloth, $3 d$. net.

\section{Blackie's Arithmetical Tables. Price I $d$.}

\section{ARITHMETICAL SHEETS}

\section{Typical Government Problem} Sheets. Printed on strong manilla paper. Size $30 \times 40$ inches, and mounted on rollers. Sets for Standards III and IV, price $6 s$. each.

The Vivid Mental Calculator and Table Tester. Printed in Colours, cloth backed, size $44 \times 36$ inches. On rollers, $6 s$.

The Vivid Concrete and $\mathrm{Ab}$ stract Arithmetic Sheets for Number-Laying. 4 large Sheets printed in Colours. With cover, ros. per set. Coloured Tablets, to accompany the sheets, in box, $4 d$. In packets of $400,1 s .6 d$.

Hand-and-Eye Arithmetic. A Teacher's Handbook. Is. $6 d$.

The Class-Teacher's Arithmetic (Course "B"). For Standards I and II, Is. $6 d$. 


\section{Geometry, Algebra, \&c.}

Elementary Mathematics-A1gebra and Geometry. By A. Leighton, M.A., B.Sc. $2 s$.

A First Course of Algebra. By A. E. Layng, M.A. Embodying Graphic and other solutions and applications to Arithmetic and Geometry. Part I, up to and including easy quadratic Equations. 2s. $6 d$.

An Introduction to Algebra. By R. C. Bridgett, M.A., B.Sc., F.C.S. Is.

A New Geometry for Beginners. Theoretical and Practical. By Rawdon Roberts, B.Sc. Is. $6 d$.

Elementary Geometry of the Straight Line, Circle, and Plane Rectilineal Figures. By Cecil Hawkins, M.A. On the lines of the new Cambridge University Syllabus. $3 s .6 d$. Also in two Parts, 2s. each. Key, 5s. net.

Exercises in Theoretical and Practical Geometry. By R. B. Morgan. Cloth, Is.

Constructive Geometry. Arranged for the First Year's Course in Science. By John G. Kerr, LL.D. Is. $6 d$.

Euclid's Elements of Geometry. Edited by A. E. Layng, M.A. With Exercises, Appendix, and Examination Papers. Books I to VI, and XI, 3s. 6d. Book I, Is.; II, $6 d$.; III, Is.; IV, 6d.; $\mathrm{V}$ and $\mathrm{VI}$ together, Is.; XI, Is. $6 d$. Books I-II, Is. 3d.; IIII, 2s.; I-IV, 2s. 6d. Key to Book I, 2s. $6 d$. net; complete, 5s. net.

A New Sequel to Euclid. By Professor W. J. Dilworth, M.A. 2s. 6d. Part I, Is. Part II, 2s.

Easy Mathematical Problem Papers. By Charles Davison, Sc.D. Containing numerous problems in Algebra to the $\mathrm{Bi}$ nomial Theorem, Euclid, Books I-VI and XI, and Trigonometry to the Solution of Triangles and Geometrical Applications. 2s. With Answers and Hints for Solution. $2 s$. $6 d$.

Preliminary Geometry.

Rawdon Roberts, B.Sc. Cl., Is. Elementary Plane Geometry. By V. M. Turnbull. Cloth, $2 s$. Test-Papers in Mathematics. By John Dougall, M.A. With Answers, Is.

Blackie's Euclid and Mensuration for Beginners. $6 d$. Euclid, Book I. Paper, 2d. Elementary Mensuration.

Lines, Surfaces, and Solids. By J. Martin. Iod.

Descriptive Geometry. Including chapters on Plane Geometry and Graphic Arithmetic. By Alex. B. Dobbie, B.Sc. $2 s$.

Mathematical Facts and Formulæ. By A. E. Lyster, M.A. Cloth limp, 9d.; cloth boards, is.

Elementary Text-Book of Trigonometry. By R. H. Pinkerton, B.A.(Oxon.). New Edition. Cloth, $2 s$.

Introductory Mathematics. By R. B. Morgan, B. Litt., L.C.P. 2s. Answers, 6d. net.

Elementary Graphs. By R. B. Morgan. Is. 6d. Answers, 4d. net.

Graphs for Beginners. By Walter Jamieson, A.M.I.E.E. Is. $6 d$.

A Handy Book of Logarithms. With Practical Geometrical Appendix. $2 s$.

Blackie's Algebra for Beginners. From Notation to Simple Equations and Square Root. With Answers, 6d.

Elementary Algebra. From Notation to Easy Quadratic Equations. Is. 6d. With Answers, cloth, 2s. Also in three Parts, 3d.; cloth, 4d. each. Answers, $3 d$. net each; complete, $9 d$. net. 
Exercises in Elementary Algebra. By A. E. Layng, M.A. With or without Answers. Is.

Algebra. Up to and including Progressions and Scales of Notation. By J. G. Kerr, LL.D. 2s. With Answers, 2s. $6 d$.

An Introduction to the Differential and Integral Calculus. With examples of applications to Mechanical Problems.
W. J. Millar, C.E. Is. $6 d$.

Mathematical Wrinkles for Matriculation and other Exams. Six Sets of London Matriculation Papers, with full Solutions. By Dr. W. T. Knight. 2s. $6 d$.

Algebraic Factors. How to Find them and how to Use them. By
Dr. W. T. Knight. 2s. Key, 3s. $6 d$. net.

First Mathematical Course. Containing Arithmetic, Algebra (to Simple Equations), and the First Book of Euclid. Reduced price, Is., with or without Answers. Answers, $6 d$. net.

Blackie's Mathematics, First, Second, and Third Stages.

First Stage. Euclid and Algebra. Paper, 6d., cloth, $7 d$.

Second Stage. Euclid and Algebra. Paper, 10d., cloth, Is.

ThIRD STAGE. Algebra. Cloth limp, $6 d$. Layng's Euclid, Books I-III, $2 s$.

Answers to each Stage, 3d. net.

K'ey to Stage I, cloth, Is. net.

\section{Science}

\section{PHYSICS AND CHEMISTRY}

Deschanel's Natural Philosophy. An Elementary Treatise. By Prof. A. Privat Deschanel, of Paris. Edited by Professor J. D. Everett, D.C.L., F.R.S. Medium 8vo, cloth, I8s.; also in Parts, limp cloth, 4 s. $6 d$. each.

PART I.-Mechanics, Hydrostatics, \&c. PART II.-Heat.

PART III.-Electricity and Magnetism. PART IV.--Sound and Light.

Electricity. (Being an expansion of Part III of Deschanel on the lines of modern electrical theory.) Edited by Professor J. D. Everett, M.A., D.C.L., F.R.S. 4s. 6d.

A Text-Book of Heat. By Charles H. Draper, B.A., D.Sc.(Lond.). $4 s .6 d$.

Light, Heat, and Sound. By Charles H. Draper, B.A., D.Sc.(Lond.), Head-master of the Technical School, Brighton. $2 s$.

Elementary Ophthalmic Optics. By Freeland Fergus, M.D., F.R.S.E., Surgeon to the Glasgow Eye Infirmary. $3 s .6 d$. net.

Elementary Text-Book of Physics. By Professor Everett, D.C.L., F.R.S. 3 s. $6 d$.
Elementary Experimental Science. An Introduction to the study of Scientific Method. By W. Mayhowe Heller, B.Sc., and E. G. Ingold. 2s. 6 d. net.

Elementary Physics. Practical and Theoretical. First Year's Course. By John G. Kerr, M.A., LL.D. Illustrated. Is. $6 d$.

Elementary Physics. Practical and Theoretical. Second Year's Course. By John G. Kerr, M.A., LL.D., and John N. Brown, A.R.C.S. Illustrated. $2 s$.

Elementary Physics. Practical and Theoretical. By John N. Brown, A.R.C.S. Third Year's Course. Illustrated. $2 s$.

Elementary Chemistry. Practical and Theoretical. FIRST YeAR's Course. By T. A. Cheetham, F.C.S. Is. $6 \%$.

Elementary Chemistry. Practical and Theoretical. SECOND Year's Course. By T. A. Cheetham, F.C.S. $2 s$.

Chemistry for All. Or, Elementary Alternative Chemistry. By W. Jerome Harrison, F.G.S., and R. J. Bailey. Is. $6 d$. 
Elementary Inorganic Chemistry. Theoretical and Practical. By Professor A. Humboldt Sexton, F.I.C., F.C.S. $2 s .6 d$.

Systematic Inorganic Chemistry. FROM THE STAND-POINT OF THE PERIODIC LAW. A Text-Book for Advanced Students. By R. M. Caven, D.Sc. (London), and G. D. Lander, D.Sc.(St. Andrews and London). $6 s$. net.

Junior Chemistry and Physics. By W. Jerome Harrison, F.G.S. With numerous Illustrations and Diagrams. Is. $6 d$.

The Arithmetic of Elementary Physics and Chemistry. By H. M. Timpany, M.Sc. Is.

Chemistry for Beginners. By W. Jerome Harrison. Is. Also in three Parts, paper, $4 d$.; cloth, $5 d$. each.

A Text-Book of Organic Chemistry. English Translation from the German of A. Bernthsen, Ph.D. Edited by J. J. Sudborough, Ph.D., D.Sc., F.I.C. $7 s .6 d$. net.

Chemistry Lecture Notes. By G. E. Welsh, B.Sc. Adapted for Third and Fourth Years in Secondary and Grammar Schools under the Board of Education. Interleaved with blank pages for additional notes. Is. $6 d$.

Progressive Lessons in Science. Practical Experiments with Foodstuffs, Soils, and Manures. By A. Abbott, M.A., and Arthur Key, M.A. 3 s. $6 d$.

Laboratory Exercise Book. For Chemical Students. Tables for analysis; Sheets for results. By E. Francis, F.C.S. $6 d$.

Chemistry Demonstration Sheets. By E. Francis. Eight Sheets, $37^{\prime \prime} \times 28^{\prime \prime}, 3 s$. $6 d$. each.

An Introduction to Analytical Chemistry. By Prof. G. G. Henderson, D.Sc., M.A., and M. A. Parker, B.Sc. $5 s$.
MAGNETISM AND ELEC. TRICITY

Electricity and Magnetism. (Pt. III of Deschanel's Natural Philosophy.) Edited and enlarged by Prof. J. D. Everett, D.C.L., F.R.S. 4 s. $6 d$.

Magnetism and Electricity for Beginners. By W. G. Baker, M.A. Is. In three Parts, paper, $3 d$.; cloth, 4d. each.

The Arithmetic of Magnetism and Electricity. By R. Gunn. $2 s .6 d$.

Elementary Electrical Engineering. By John H. Shaxby, B.Sc. 3s. net.

Electrical Engineering Measuring Instruments. For Commercial and Laboratory Purposes. By G. D. Aspinall Parr, M.I.E.E., A.M.I.Mech.E. 9s. net.

DYNAMICS, MECHANICS, \&C. Elementary Text-Book of Dynamics and Hydrostatics. By R. H. Pinkerton, B.A. 3s. $6 d$.

Hydrostatics and Pneumatics. By R. H. Pinkerton. $4 s .6 d$.

Mechanics, Hydrostatics, and Pneumatics. (Part I of Deschanel's Natural Philosophy.) Edited by Prof. J. D. Everett, D.C.L., F.R.S. $4 s .6 d$.

Mechanics for Beginners. By David Clark. Is. 6 $d$. Part I, 4d.; cloth, 5d. Parts II and III, 5d.; cloth, $6 d$. each.

Theoretical Mechanics. (Solids and Liquids.) By R. H. Pinkerton, B.A.(Oxon.). $2 s$.

An Elementary Text-Book of Applied Mechanics. By David Allan Low (Whitworth Scholar), M.Inst. M.E. $2 s$.

The Geometry of the Screw Propeller. By William J. Goudie, B.Sc. Is. $6 d$. net.

PHYSIOLOGY, HYGIENE, \&c. Simple Lessons on Health and Habits. With Elementary Lessons in First Aid. 8d. 
The Laws of Health. By Carstairs C. Douglas, M.D., D.Sc., F.R.S.E. $3^{s}$. net.

Health in the School. By J. S. C. Elkington, M.D., D.P.H. 2s. net.

Animal Physiology for $\mathrm{Be}-$ ginners. By Vincent T. Murché. Cloth, Is. $6 d$. Part I, paper, 4d.; cloth, 5d. Parts II and III, paper, $5 d$.; cloth, $6 d$. each.

Elementary Physiology。 Prof. Ainsworth Davis. With Appendix for Agricultural Students. $2 s$.

Elementary Physiology. By Vincent T. Murché. An enlarged edition of Murché's Animal Physiology for Beginners. $2 s$.

An Elementary Text-Book of Physiology (Elementary and Advanced). By J. M'Gregor Robertson. $4 s$.

An Elementary Text-Book of Anatomy. By Henry Edward Clark. Illustrated. 5 s.

Elementary Hygiene and Physiology. By H. R. Wakefield. 2s. $6 d$.

Elementary Hygiene. By $\mathrm{H}$. Rowland Wakefield. 2s.

Food and its Functions.

Text-Book for Students of Cookery. By James Knight, M.A., B.Sc., D.Sc. Illustrated. $2 s .6 d$.

Progressive Lessons in Science. Practical experiments with foodstuffs, soils, manures, \&c., bearing on the science of daily life. By A. Abbott, M.A., and A. Key, M.A. 3 s. $6 d$.

BOTANY, AGRICULTURE, \&C.

First Lessons in Botany. An Introduction to Nature Study. By Miss C. A. Cooper, L. L.A. 6d.

Botany for Beginners. By Vincent T. Murché. I 44 pp., cloth, Is. Also in three Parts, paper, 3d.; cloth, 4d. each.

Elementary Botany. By Joseph W. Oliver.

$2 s$.
A First Course in Practical Botany. By G. F. Scott Elliot, M.A., B.Sc., F.L.S., F.R.G.S. With over I 50 Illustrations. $3 s .6 d$. The Student's Introductory Text-Book of Systematic Botany. By J. W. Oliver. 4s. $6 d$. Seasonal Botany. A Supplementary Text-Book, including an outline of General Botany and a detailed course of Physiological Botany. By M. O'Brien Harris, D.Sc. Interleaved. $8 d$.

The Natural History of Plants: Their forms, growth, reproduction, and distribution. From the German of the late Anton Kerner von Marilaun, by F. W. Oliver, M.A., D.Sc., with the assistance of Lady Busk, B.Sc., and Mrs. M. F. Macdonald, B.Sc. 2000 Illustrations. In two volumes, 30s. net.

Nature Studies. (Plant Life.) By G. F. Scott Elliot, M.A., B.Sc., F.L.S. Fully Illustrated. $3 s .6 d$. Nature-Study Exhibition Official Report, Ig02. 2s. 6d. net.

Agriculture for Beginners. By R. P. Wright, Professor of Agriculture, Glasgow Technical College. I44 pp., cloth, Is. In three Parts, paper, $3 d$.; cloth, $4 d$. each.

Elementary Agriculture. By R. P. Wright. An enlarged edition of Agriculture for Beginners. Is. $6 d$.

The Principles of Horticulture. A Series of Practical Scientific Lessons. By Wilfred Mark Webb, F.L.S. 2s. net.

The School Garden. A Handbook of Practical Horticulture for Schools. By J. E. Hennesey. Is.

GEOLOGY, ASTRONOMY, \&c.

Practical Experiments in Elementary Science, or, First Steps in Earth-Knowledge. Being an Introduction to Physiography. By J. Ansted Harrison, B.Sc.(Lond.), and W. Jerome Harrison, F.G.S. Illustrated. 2s. $6 d$. 
Earth-Knowledge. A Text-Book of Advanced Physiography. By W. Jerome Harrison, F.G.S., and H. Rowland Wakefield. 2s. $6 d$.

A Text-Book of Geology. An Introduction to the study of the Rocks and their Contents. By W. Jerome Harrison, F.G.S. 3s. $6 d$.

\section{METALLURGY, COAL- MINING, \&C.}

Elements of Metallurgy. By W. Jerome Harrison, F.G.S., and William J. Harrison. Illustrated. 2s. 6d.

Elementary Text - Book of CoalMining. By Robert Peel, Mining Engineer. With many Illustrations and a Coloured Map of the Coal Fields. 2s. $6 d$.

Fuel and Refractory Materials. By Professor A. Humboldt Sexton, F.I.C., F.C.S. $5^{s}$.

\section{ARCHITECTURE, BUILDING, $\& \mathrm{C}$.}

Elementary Building Construction and Drawing for Scottish Students. By Charles
Gourlay. With 24 plates and full descriptive letterpress. $6 s$. net. Plates of the above, with introduction, done up in portfolio. $3 s$. $6 d$. net.

\section{MISCELLANEOUS}

Blackie's Circular Protractor. For Practical Mathematics and Elementary Science. Diameter, 6 inches. Price $3 d$.

Blackie's Circle Series of Ruled Exercise Books.

No. r. Ruled in squares one-tenth of an inch, with page for notes. 40 pages, Id. 80 pages, cloth, $3 d$.

No. 2. Ruled in centimetre squares. 40 pages. $\mathrm{r} d$.

No. 3. Ruled in quarter-inch squares. 40 pages. I $d$.

No. 4. Ruled in millimetre squares. 32 pages. $3 d$.

No. 5. Ruled in one-eighth-inch squares. Id.

No. 6. Fire Insurance Surveyors' NoteBook. Ruled in one-eighth-inch squares, for working on 40 -feet scale. $2 d$.

No. 7. Fire Insurance Surveyors' NoteBook. Ruled in one-tenth-inch squares, for working on 30 -feet scale. $2 d$.

Portfolio to hold any one of the above exercise books. Handsomely bound in full leather, limp, is. $6 d$. net.

\section{Cookery, Domestic Economy}

A Handbook of Cookery for School and Home. By Ada T. Pearson. $6 d$.

Cookery for School Girls. Ten Elementary Lessons. By Mary R. Macdonald. Paper, $3 d$.; cloth, $4 d$.

Cookery and Laundry-Work. With simple lectures on Hygiene and Housewifery. By L. C. Andrews. 8d.

Food and its Functions. A text-book for students of Cookery. By James Knight, D.Sc. Illustrated. 2s. $6 d$.

Domestic Economy. By E. Rice. Is. $6 d$. In three Parts, paper, $3^{d}$. ; cloth, $4 d$. each.
A Manual of the Science of Laundry-Work. For Students and Teachers. By Margaret Cuthbert Rankin. Is. $6 d$.

The Art and Practice of Laundry-Work. For Students and Teachers. By Margaret Cuthbert Rankin. 2s. $6 d$.

Blackie's Domestic Economy Readers. The lessons provide a complete course of practical in. struction in all the branches of housekeeping. In 8 numbers. Fully Illustrated.

[List on Application.

The Care of the Baby. By Mrs. Crighton Davies. $3 d$. 


\section{Perspective, Sciography}

Elementary Perspective. By Lewes R. Crosskey. $3 s .6 d$. Advanced Perspective. Lewes R. Crosskey. 4s. $6 d$.

A Text-Book of Sciography.
Arranged to suit the requirements of those preparing for the examinations of the Board of Education, South Kensington. By J. H. A. M'Intyre. 3s. $6 d$.

\section{Drawing, Painting, Writing, dec.}

Vere Foster's Drawing CopyBooks. In 72 numbers, price 2d. each. Complete Edition, in Eighteen Parts at 9d. (Each part complete.)

Vere Foster's Complete Course of Drawing. In Eighteen Parts, price $9 d$. each.

Vere Foster's Water-Colour Drawing-Books. With coloured facsimiles of original water-colour drawings, hints and directions. List on application.

Poynter's South Kensington Drawing-Books. Issued under the direct superintendence of Sir E. J. Poynter, P.R.A.

A Selection from Turner's Liber Studiorum. In Four Parts, I2s. $6 d$. each; in portfolio, $£ 2,12 s .6 \%$.

A Complete Course of FreeArm and Industrial Drawing. By J. W. Topham Vinall, A.R.C.A.(Lond.). 52 charts, I $23 /$ " $^{\prime \prime} \times 83$ /" $^{\prime \prime}$. In portfolio, price I2s. $6 d$. net.

Brush-Drawing. By J. W. Nicol. $7 s .6 d$. net.

Blackie's Brush-Drawing Sheets. By J. W. Nicol. 3 Sets of 15 Sheets each. I $2 s .6 d$. per set.

Blackie's Brush-Drawing Cards. By J. W. Nicol. 3 Sets of 20 Cards each. I $s .6 d$. per set.
Blackie's Nature-Drawing Charts. Correlating NatureStudy, Drawing, and Design. I5 Charts in portfolio. $12 s .6 d$. net.

Graded Drawing for Infants and Junior Classes. By Anue E. Roberts. With Drawing Subjects and Hints for Procedure. Printed in black and colour. 2s. $6 d$.

Classic Ornament. Forty-eight Photographic Reproductions of South Kensington Casts. In Four Books. Price is. $6 d$. each.

Black-Board and Free-Arm Drawing. By H. P. Stephens, A.C.P. $4 s .6 d$. net.

Vere Foster's Writing CopyBooks.

Original Series, in 22 Nos., $2 d$. each. Palmerston Series, in $x$ I Nos.. on fine paper ruled in blue and red, $3 d$. each.

Bold Writing, or Civil Service Series, in 27 Nos., price $2 d$. each.

Upright Series, in 12 Nos., $2 d$. each.

Medium Series, in 12 Nos., and Nine Supplementary Books. 2d. each.

Reversible Series, being the Medium Series with the zuriting page always on the right-hand side. $2 d$. each.

Blackie's Commercial Course of Writing and Bookkeeping. A Series of Copy-Books. 6 Numbers. 2d. each.

Blackie's Civil Service and Commercial Copy-Book. By J. Logan. $6 d$.

\section{Complete Educational Catalogue on application}

\section{LONDON}

BLACKIE \& SON, Limited, 50 OLD BAILEY, E.C. 


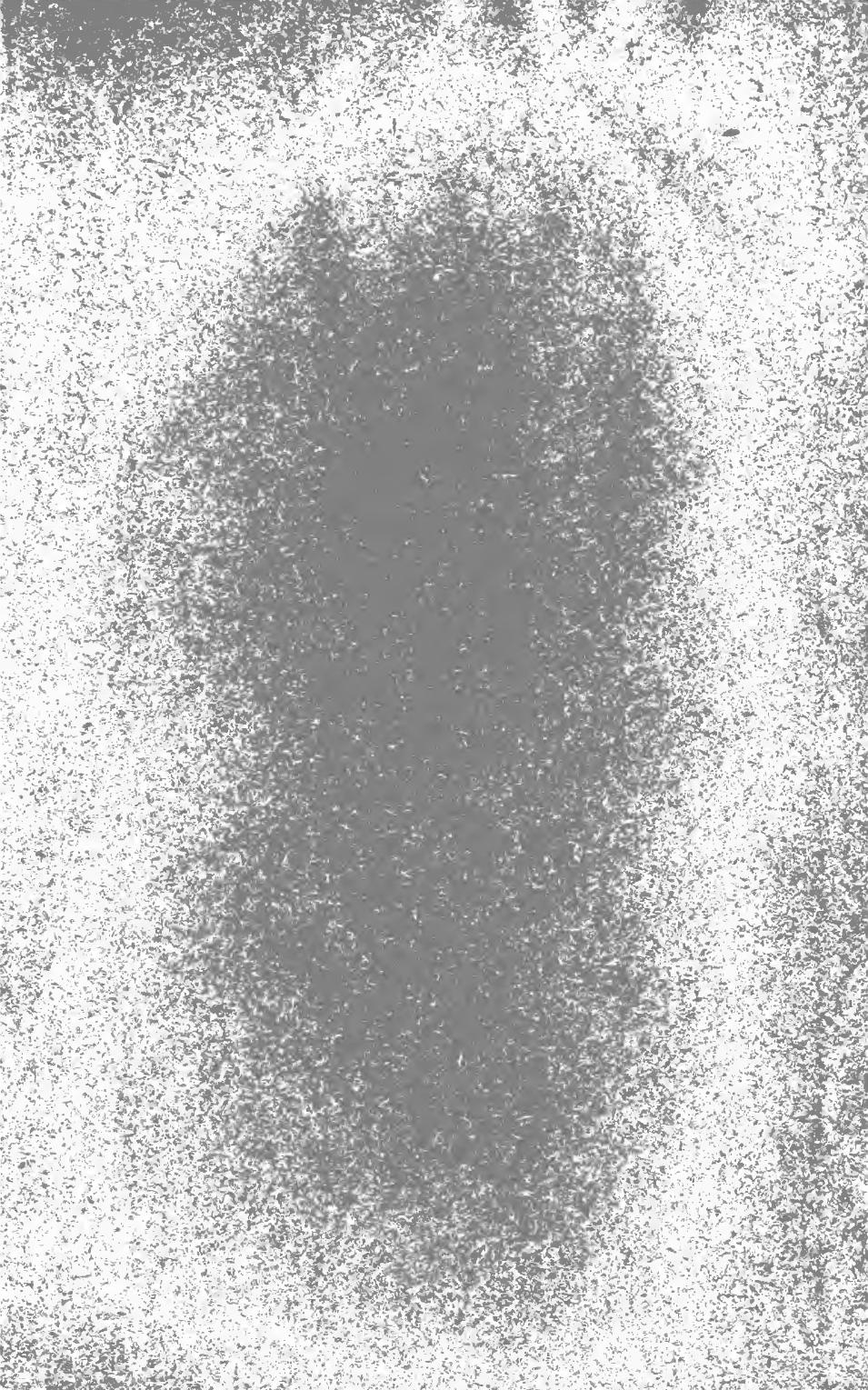

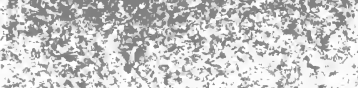

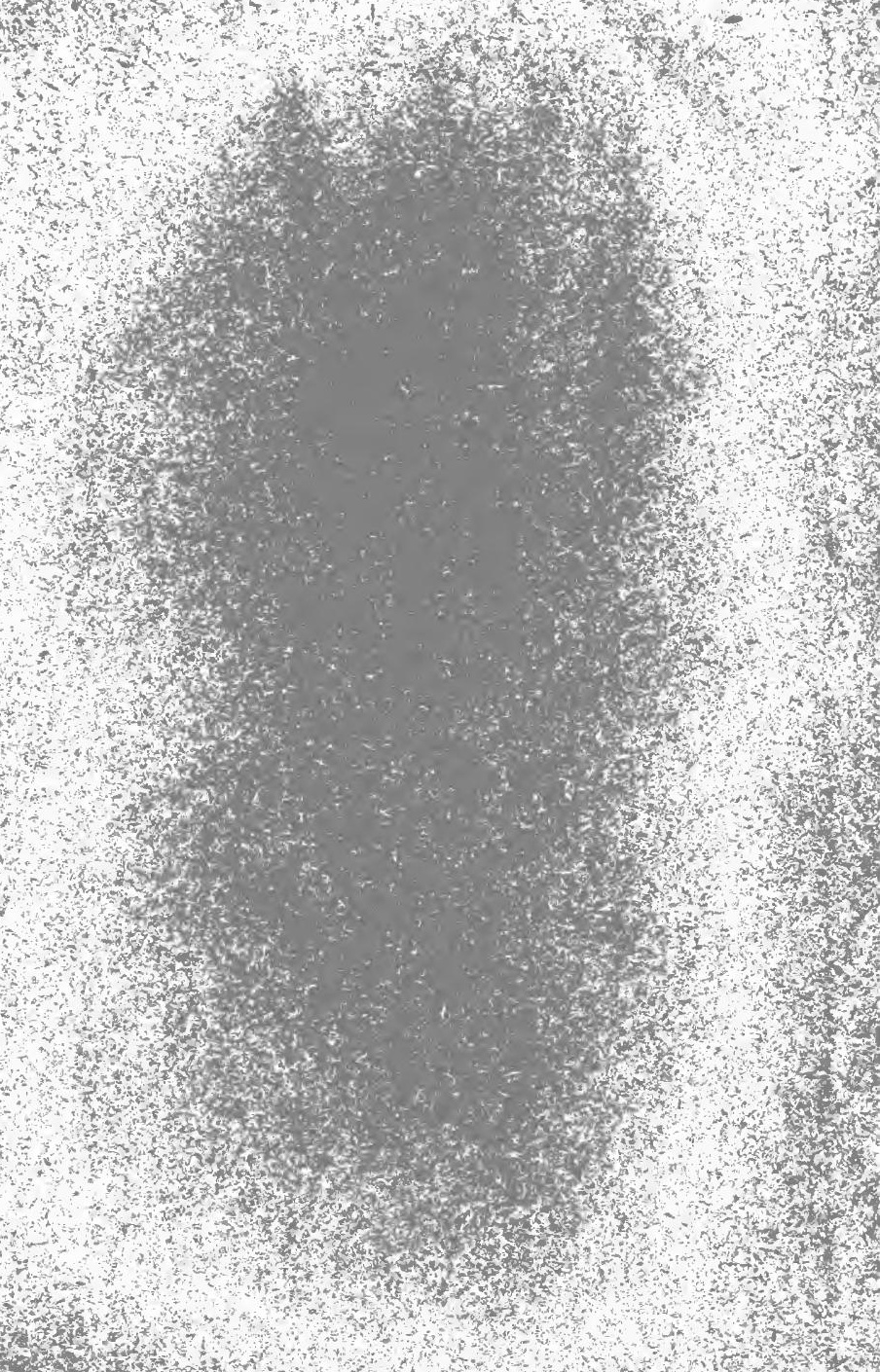
$m_{1}$ 
THIS BOOK IS DUE ON THE LAST DATE STAMPED BELOW

AN INITIAL FINE OF 25 CENTS WILL BE ASSESSED FOR FAILURE TO RETURN THIS BOOK ON THE DATE DUE. THE PENALTY WILL INCREASE TO 50 CENTS ON THE FOURTH DAY AND TO $\$ 1.00$ ON THE SEVENTH DAY OVERDUE.

\begin{tabular}{ll|l}
\hline JUN 101940 & \\
\hline SEP 69845 & & \\
\hline & & \\
\hline & & \\
\hline & & \\
\hline
\end{tabular}



